\title{
Reference
}

\section{A II01 7B521}

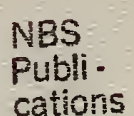

NATL INST OF STANDARDS \& TECH R.I.C.

Publi -

cations

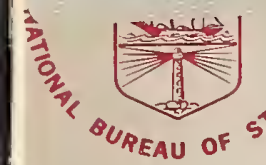

A11101785213
Risley, A. STh The National Measurement sy

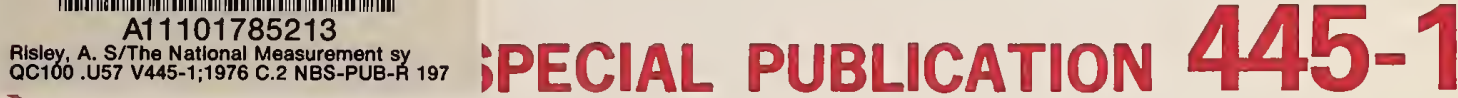
8

\section{U.S. DEPARTMENT OF COMMERCE / National Bureau of Standards}

\section{The National Measurement System for Time and Frequency}

QC

100

U57

No. 445-1

1976 
The National Bureau of Standards ${ }^{1}$ was established by an act of Congress March 3, 1901. The Bureau's overall goal is to strengthen and advance the Nation's science and technology and facilitate their effective application for public benefit. To this end, the Bureau conducts research and provides: (1) a basis for the Nation's physical measurement system, (2) scientific and technological services for industry and government, (3) a technical basis for equity in trade, and (4) technical services to promote public safety. The Bureau consists of the Institute for Basic Standards, the Institute for Materials Research, the Institute for Applied Technology, the Institute for Computer Sciences and Technology, and the Office for Information Programs.

THE INSTITUTE FOR BASIC STANDARDS provides the central basis within the United States of a complete and consistent system of physical measurement; coordinates that system with measurement systems of other nations; and furnishes essential services leading to accurate and uniform physical measurements throughout the Nation's scientific community, industry, and commerce. The Institute consists of the Office of Measurement Services, the Office of Radiation Measurement and the following Center and divisions:

Applied Mathematics - Electricity - Mechanics - Heat - Optical Physics - Center for Radiation Research: Nuclear Sciences; Applied Radiation - Laboratory Astrophysics ${ }^{2}$ - Cryogenics $^{2}$ - Electromagnetics ${ }^{2}$ - Time and Frequency ${ }^{2}$.

THE INSTITUTE FOR MATERIALS RESEARCH conducts materials research leading to improved methods of measurement, standards, and data on the properties of well-characterized materials needed by industry, commerce, educational institutions, and Government; provides advisory and research services to other Government agencies; and develops, produces, and distributes standard reference materials. The Institute consists of the Office of Standard Reference Materials, the Office of Air and Water Measurement, and the following divisions:

Analytical Chemistry - Polymers - Metallurgy - Inorganic Materials - Reactor Radiation - Physical Chemistry.

THE INSTITUTE FOR APPLIED TECHNOLOGY provides technical services to promote the use of available technology and to facilitate technological innovation in industry and Government; cooperates with public and private organizations leading to the development of technological standards (including mandatory safety standards), codes and methods of test; and provides technical advice and services to Government agencies upon request. The Institute consists of the following divisions and Centers:

Standards Application and Analysis - Electronic Technology - Center for Consumer Product Technology: Product Systems Analysis; Product Engineering - Center for Building Technology: Structures, Materials, and Life Safety; Building Environment; Technical Evaluation and Application - Center for Fire Research: Fire Science; Fire Safety Engineering.

THE INSTITUTE FOR COMPUTER SCIENCES AND TECHNOLOGY conducts research and provides technical services designed to aid Government agencies in improving cost effectiveness in the conduct of their programs through the selection, acquisition, and effective utilization of automatic data processing equipment; and serves as the principal focus within the executive branch for the development of Federal standards for automatic data processing equipment, techniques, and computer languages. The Institute consists of the following divisions:

Computer Services - Systems and Software - Computer Systems Engineering - Information Technology.

THE OFFICE FOR INFORMATION PROGRAMS promotes optimum dissemination and accessibility of scientific information generated within NBS and other agencies of the Federal Government; promotes the development of the National Standard Reference Data System and a system of information analysis centers dealing with the broader aspects of the National Measurement System; provides appropriate services to ensure that the NBS staff has optimum accessibility to the scientific information of the world. The Office consists of the following organizational units:

Office of Standard Reference Data - Office of Information Activities - Office of Technical Publications - Library - Office of International Relations - Office of International Standards.

1 Headquarters and Laboratories at Gaithersburg, Maryland, unless otherwise noted; mailing address Washington, D.C. 20234.

2 Located at Boulder, Colorado 80302. 


\title{
The National Measurement System for Time and Frequency
}

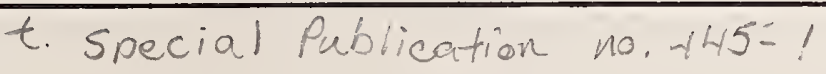

\begin{abstract}
Allan S. Risley
Time and Frequency Division Institute for Basic Standards National Bureau of Standards Boulder, Colorado 80302
\end{abstract}

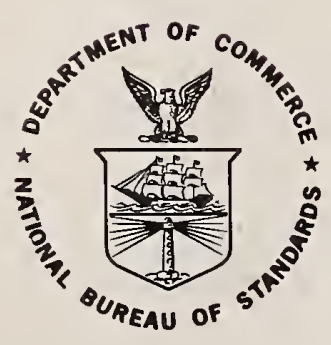

U.S. DEPARTMENT OF COMMERCE, Elliot L. Richardson, Secretary

Dr. Betsy Ancker-Johnson, Assistant Secretary for Science and Technology us NATIONAL BUREAU OF STANDARDS, Ernest Ambler, Acting Director Issued June 1976 


\section{Library of Congress Catalog Card Number: 76-608114}

\section{National Bureau of Standards Special Publication 445-1}

Nat. Bur. Stand. (U.S.), Spec. Publ. 445-1, 72 pages (June 1976)

CODEN: XNBSAV 
This is one of the reports from the 1972-75 NBS Study of the National Measurement system. It deals specifically with the current structure, status, and trends of the system used in this country for the measurement of time and frequency and closely related quantities, such as position (navigation).

The "Concept of a National Measurement System" has been discussed by NBS authors and spokesmen for a number of years, since the publication by Dr. R. D. Huntoon of an article by that title in the October 6, 1967 issue of Science (Vol. 158, No. 3797, pages 67-71). Dr. Huntoon began his article with the following paragraph:

"Concurrently with the growth and industrialization of this nation, there has developed within it a vast, complex system of measurement which has made possible the very growth that brought the system into being. This National Measurement System (NMS) stands today as one of the key elements in a worldwide measurement system that 1 inks a 11 major nations together in a consistent, compatible network for communication and trade."

The U. S. National Measurement System is defined as comprising all of the activities and mechanisms--intellectual and operational, technical and institutional--used by this country to produce the physical measurement data needed to create the objective, quantifiable knowledge required by our society. This knowledge is used to describe, predict, communicate, control, and react, in many aspects of our personal and social lives, science, and technology.

Dr. Huntoon continued his discussion in 1967:

"Our National Measurement System is one of a number of mutually interacting systems within our technologically based society that form the environment in which the individual citizen must live and function. Familiar examples are the communication, transportation, educational, medical and legal systems, all of which may be included under the general heading of social systems."

"In view of the demonstrated value of the systems approach for the understanding and improvement of hardware such as computers and weapons, some of these social systems are being subjected to the same type of analysis. The National Measurement System, which evolved in this country with little formal recognition as a system, is now being examined in this way at the National Bureau of Standards (NBS) which undertook the study of the National Measurement System partly because of the al1-pervasive nature and great economic importance of the nation's measurement activities, and partly because of the challenge to NBS in putting its splendid new facilities to optimum use for the benefit of the nation. Such optimum use can be approached only when the National Measurement System, of which NBS is a central element, and the services it requires for effective operation are sufficiently well understood."

Over the years both before and since 1967, NBS has taken a number of approaches to the study of our national system for physical measurements. The current series of studies was initiated in 1972 by Dr. Ernest Ambler, then Dr. Huntoon's successor as Director of the NBS Institute for Basic Standards, now Acting Director of the Bureau. The reports of these studies are being presented to the public at large for the purpose of increasing national understanding, and the operational effectiveness, of our National Measurement System. They are presented as an intial or interim, not final, word on the subject. NBS welcomes contributions from all sectors of the System which can aid it in increasing its understanding of and effectiveness in supporting that System. 
NOTICE

A diligent effort has been made to make this report comprehensive and accurate as of March 1975. Since that time no important changes or additions have been made. There have, however, been a few significant changes in the National Measurement System for Time and Frequency. The interested reader may wish to contact the author for his opinions on these changes.

iv 
EXECUTIVE SUMMARY

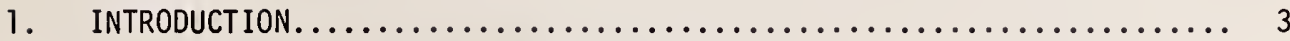

2. STRUCTURE OF THE MEASUREMENT SYSTEM..................... 3

2.1 Conceptual System............................... 3

2.2 Basic Technical Infrastructure.............................. 4

2.2.1 Documentary Specification System............... 4

2.2.2 Instrumentation System....................... 4

2.2.3 Reference Data................................... 7

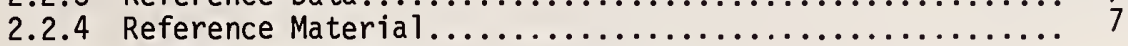

2.2 .5 Science and People...................................... 7

2.3 Realized Measurement Capabilities....................... 8

2.4 Dissemination and Enforcement Network.................... 13

2.4.1 Central Standards Authorities.................. 13

2.4.2 State and Local Offices of Weights and Measures......... 13

2.4.3 Standards and Testing Laboratories and Services.......... 14

2.4 .4 Regulatory Agencies........................... 14

2.5 Direct Measurement Transactions Matrix ............... 14

2.5.1 Analysis of Suppliers and Users............... 15

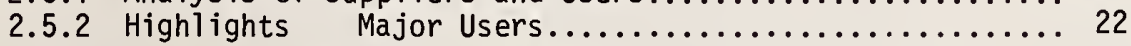

3. IMPACT, STATUS AND TRENDS OF MEASUREMENT SYSTEM............. 27

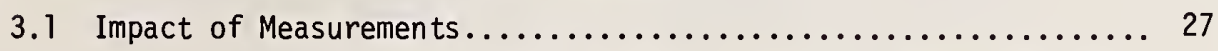

3.1.1 Functional, Technological and Scientific Applications.. 27

3.1.2 Economic Impacts - Costs and Benefits.............. 28

3.1.3 Social, Human, Man-on-the-Street Impacts.................. 30

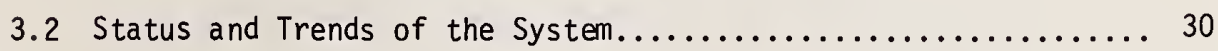

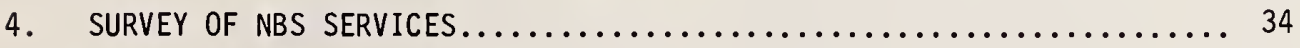

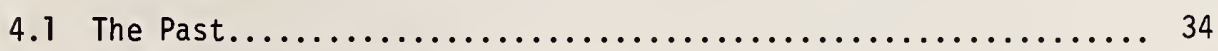

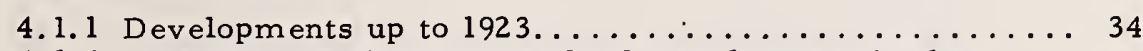

4.1.2 Frequency and Time Standard Development in the

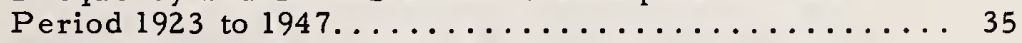

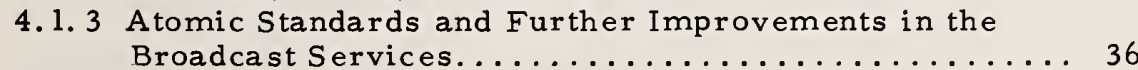

4.2 The Present - Scope of NBS Services................. 38

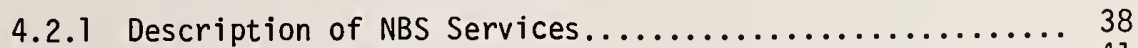

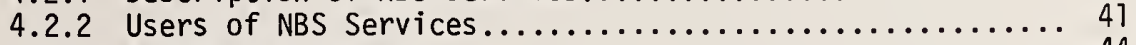

4.2 .3 Alternate Sources......................... 44

4.2 .4 Funding Sources for NBS Services...................... 46

4.2.5 Mechanism for Supplying Services................. 46

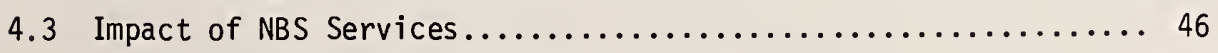

4.3.1 Economic Impact of Major User Classes............. 46

4.3.2 Technological Impact of Services................. 46

4.3.3 Pay-off from Changes in NBS Services.............. 46 


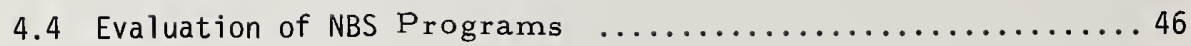

4.5 The Future........................... 46

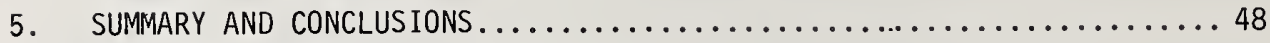

APPENDIX A. METHODOLOGY OF THE STUDY....................... $50-62$

REFERENCES...................................... $63-65$

\section{LIST OF FIGURES}

Figure 1. Historical Development of Time Keeping Accuracy.......... 5

Figure 2. General Time-Domain Behavior of 0scillators............. 10

Figure 3. Time-Domain Behavior Typical of Several Types of 0scillators. 10

Figure 4. Development of Frequency Accuracy in the FDM System of the

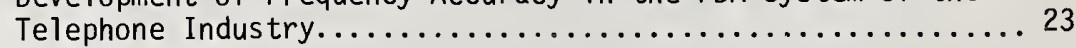

Figure 5. Responses to Set 1 of the Delphi Questionnaire.......... 32

Figure 6. Time-Doma in Behavior of NBS Sources and Measurement System... 40

Figure 7. Frequency-Domain Behavior of NBS Sources and Measurement System.................................. 40

Figure 8. Calling Rate for NBS Time-of-Day Service (303-499-7111) .... 44 LIST OF TABLES

Table 1. Instrumentation Hierarchy for Coordination of Frequency..... 6

Table 2. Instrumentation Hierarchy for Coordination of Time........ 7

Table 3. Characteristics of the Major T\&F Dissemination Systems...... 12

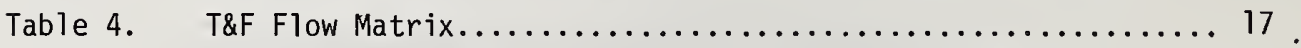

Table 5. Relative Use of WWV/VH Services $(12,000$ Respondees $) \ldots . \ldots .42$

Table 6. Adequacy of WWV/VH Services to Various Users............ 43

Table 7. Distribution of Respondents by Principal Use........... 43 
The results of a study of the National Measurement System for Time and Frequency are given. The system is viewed from three vantage points: (1) The Instrumentation that provides sources of time and frequency (T\&F). (2) The Suppliers and Users of T\&F. (3) The Calibration hierarchies for T\&F sources. An attempt is made to determine the technological, scientific, economic, and social effects of the system. Predictions are made about possible important changes in the system. The past, present, and possible future positions of NBS in the system is described in detail.

Key words: Atomic frequency standards; aviation industry; electric power industry; national measur ement system, position location. shipping and boating industries; standards laboratories; telephone industry and specialized carriers; time and frequency; time scales; users of NBS radio broadcasts. 

THE NATIONAL MEASUREMENT SYSTEM

FOR TIME AND FREQUENCY

Allan S. Risley

Time and Frequency Division

Institute for Basic Standards

\section{EXECUTIVE SUMMARY}

The major purpose in studying the National Measurement System for Time and Frequency was to determine who uses time and frequency, how they use them, and what their use means to society.

The system is viewed from three vantage points:

1. The instrumentation that provides sources of time and frequency (T\&F).

2. The suppliers and users of T\&F.

3. The calibration hierarchies for T\&F sources.

Most of the work of this study went into determining the present status of the system. Historical information was, however, helpful in forecasts of the future and in putting NBS T\&F activities into perspective.

Instrumentation. The major types of instrumentation which have served as sources of time and/or frequency over the last 75 years are pendulums, tuning forks, quartz oscillators, and atomic oscillators. Quartz and atomic oscillators are the sources of primary importance today.

The characteristics of precision quartz oscillators, superconducting cavity oscillators, and the major atomic oscillators are given, and some of their areas of application are described. For example, atomic oscillators are shown to be an increasingly important part of the telephone industry and basic science. The National Bureau of Standards has been a central element in the research and development of atomic T\&F standards throughout the some 25-year history of these standards. The Bureau has also made some basic contributions to the development of precision quartz oscillators.

Suppliers and Users. A compact description of fourteen basic supplier-user categories is given in matrix form. The relationship between a given supplier and user is specified by two descriptors. One descriptor gives the volume of use of a specified time or frequency output. The other gives the importance (to an organization's internal operations) of that output.

The majority of the effort devoted to this study of the National Measurement System for
Time and Frequency went into extensive studies of eight major areas. They are:

- Standards Laboratories

- Users of NBS Radio Broadcasts

- Telephone Industry and Specialized Carriers

- Military

- Position Location

- Aviation Industry

- Electric Power Industry

- Shipping and Boating Industries

Information gathered in these studies was vital in completing major portions of the T\&F flow matrix. The communication and position location industries emerge as two of the most important and sophisticated users of T\&F. The matrix indicates the great importance of the NBS standard T\&F broadcasts. A current study is increasing our understanding of the users of stations WWV and WWVH. The study confirms that the applications of communications, navigation, and standards laboratories are very important. The three most heavily used aspects of our broadcast services are voice announcements of time-ofday, one-second "ticks", and standard frequencies.

Calibration Hierarchies. The various sources of time and frequency must be compatible with one another to within some specified tolerance. The stringency of this requirement depends on the sources involved and the uses to which they are to be put. The necessary compatibility is often achieved by means of a calibration hierarchy.

There is no legal, technical, or economic force to create a unified calibration hierarchy, and none exists. This is one reason why it is difficult to comprehend the National Measurement System for Time and Frequency. Multiple hierarchies do exist, however, and they are basic to the system. Some of these hierarchies have the force of law and apply across organizational boundaries. Others are voluntary or are only binding within one organization. Those not having the force of law usually have the greatest requirements for quality of T\&F. To understand why these several hierarchies exist, it is essential to consider cost and ease-of-use as well as quality. 
Four major calibration hierarchies are those of the standards laboratories (industrial, governmental, etc.), telephone timeof-day, the military, and the telephone industry. The National Bureau of Standards has been a part of these four hierarchies. It is presently a fundamental part of the standards laboratory hierarchy and telephone time-of-day. It is also an important part of the military T\&F calibration system. The National Bureau of Standards' importance to the telephone industry is much less than it was in the past (since the telephone industry is now basing its synchronization on atomic oscillators), but is potentially still important.

The Future. The system appears to be changing in three major ways:

1.) By 1980-85 there will probably be a widespread, low-cost network of clocks that are synchronized in the range of 1 to $10 \mu \mathrm{s}$, Today, widespread synchronization, at a cost of a few hundred dollars per site, can only be done to about 1 ms.

2.) By 1980-85 the market for frequency equalization in the range $1 \times 10^{-9}$ to $1 \times 10^{-}$will probably be quite important. The cost per site will need to be less than about $\$ 2000$ (in 1975 dollars), and the equipment must be easy to use.

3.) The use of quartz watches and clocks, with digital readouts and the capability of being set to the precise second, will probably be extensive. This may necessitate a widespread calibration network for time-of-day that is accurate to about 0.1 seconds.

The Time and Frequency Division of NBS currently has two programs - T\&F dissemination via satellite, and frequency calibration via TV - that address the first two areas of probable change. A third program directed to these frequency equalization requirements, a low-cost, medium-accuracy oscillator, will likely begin soon.
The third area of probable change, if it occurs, will be more of an economic than a technical problem. As such, it would not likely increase the demand for NBS resources with regard to time-of-day.

Conclusions. This study of the National Measurement System for Time and Frequency clearly demonstrates that NBS has an important and unique role in the system. The question is not whether there are desirable alternative sources for the services presently rendered, or whether these services are in fact needed. It is instead whether NBS can perform its function more economically and effectively. Experimental broadcasts of standard T\&F via satellite and other developments indicate that it can do both.

The NBS T\&F services have been, and are, and should be, in the nature of what economists call a "collective good". This is a "good" (product) which is clearly of social value but one for which a fair market price is difficult to determine. It is interesting to note however, that there is now a minimum of one million dollars worth of specialpurpose receiving equipment in the field. This equipment was specifically designed to receive the broadcasts of WWV and WWVH or WWVB. Also, if $\$ 0.05$ per call were received for the NBS telephone time-of-day service this wouTd generate a revenue of $\$ 50,000$ per year.

One of the most general things that emerges from the entire study is that time and its ever-present companion, frequency are the great coordinators, the great organizers. Almost any activity today that requires precision control and organization rests on time and frequency technology.

(A diligent effort has been made to make this report comprehensive and accurate as of March, 1975. Since that time no important changes or additions have been, made. There have, however, been a few significant changes in the National Measurement System for Time and Frequency. The interested reader may wish to contact the author for his opinions on these changes.) 
"One generation passeth away, and another cometh; but the earth abideth forever.

The sun also ariseth, and the sun goeth down, and hasteth to the place where he arose."

Ecclesiastes $1: 4,5$

\section{INTRODUCTION}

Time is the great organizer. It organizes the activities of people and those of machines. People get up by it and go to work by it. It is the analog of work and a measure of value. For machines, time scales permit the time ordering of a sequence of events and facilitate the simultaneity of events. Good frequency control, which is a fundamental aspect of time keeping, is essential to almost all communications.

Time interval, or its reciprocal, frequency, can be produced more precisely and measured more accurately than any other physical quantity. It can be measured about four orders of magnitude more accurately than length, the next most accurately meas urable physical quantity.

Time and Frequency (T\&F) are unique among the physical quantities in that they can be transmitted by electromagnetic (EM) radiation. Frequency is an intrinsic property of every EM wave. Thus, if a transmitter is controlled in its frequency by a frequency standard, the frequency of that standard can be transferred widely as an EM wave. If the transmitter is controlled by a time standard (i.e. in phase as well as frequency) then the time of that standard can also be trans ferred as an EM wave.

Another property of T\&F that may be unique is that for almost all users, sources are commercially available which are as good or better than needed. This does not mean however, that it is always economic to use what is technically desirable.

This report is based on a study whose purpose was to gain a broad understanding of the National Measurement System for Time and Frequency. It describes the concepts and the instrumentation upon which the system is based, and the flows of T\&F equipment and services between those institutions which are the suppliers of T\&F and those that are the users. General conclusions are drawn about who the major users are and what the primary functions are that T\&F performs for them.

The report discusses significant changes in the National Measurement System for Time and Frequency which appear to be occurring, and an attempt is made to give a "feeling" for the economic dimensions of T\&F in U.S. society. Finally, the position of the Time and Frequency Division of NBS in the total system is examined, with present NBS services and possible non-NBS alternatives described.

\section{STRUCTURE UF THE MEASUREMENT SYSTEM}

\subsection{Conceptual System}

Time interval is one of the seven base units of the present International System of Units of Measurement (SI). The SI unit of time interval is the second. Frequency, which is dimensionally the reciprocal of time interval, is a derived unit in the SI system. The unit of frequency is the hertz. The frequency of a sinusoidal signal whose period is one second is one hertz.

It is important to understand the relationship between date and time interval. Date is an accumulation of time intervals beginning at a specific, and arbitrary origin. Historically, these intervals were based on the motion of the earth with respect to other celestial bodies. Prior to 1956, the second was defined as the fraction $1 /(86,400)$ of a mean solar day; from 1956 to 1967, it was the ephemeris second defined as the fraction $1 /(31,556,925.9747)$ of the tropical year at 00h00m00s 31 December 1899, and since 1967, in terms of a resonance of the cesium atom. The present definition of the second states, "The second is the duration of $9,192,631,770$ periods of the radiation corresponding to the transition between the two hyperfine levels of the ground state of the cesium-133 atom." [13th CGPM (1967), Resolution 1]

A very important change occurred when, in 1967, the second was defined in terms of an atomic transition. A very much more uniform time scale is generated by a cesium time standard than by the motion of the earth. Thus, the time interval between two events may not be accurately given by the difference between two dates [1]. Nevertheless, there is a practical reason for maintaining two types of time scales. Some people, such as navigators, must have a scale based on the earth's motion, whereas there are important technological and scientific applications based on the uniformity of an atomic scale.

It is useful to take a very general look 
at the functions that T\&F standards can perform. Because a time standard always contains a frequency standard as an integral part of its mechanism, I will only use the term "time standard" in discussing these functions. Examined from a general basis of its inherent capability, there seem to be three basic functions a time standard can perform:

1. Set a Pace. This is the constant frequency (rate) feature. It applies to those who need only frequency and not phase. A basic application of this function would be in dividing up "frequency space" for Frequency Division Multiplexing in telecommunications.

2. Uniform Time Scale. A time standard provides a uniform time scale. It is useful to divide this category into three sub-categories:

a. Labeling. The scale can be used to label events so that their order of occurence in time can be recorded. If desired, this recording can yield the time interval between any two events. From a practical point of view, the labeling function employs a time scale that runs uninterrupted for long periods of time. Date is a good example.

b. Start-Stop. This feature of a time scale, when the scale is available at more than one geographical location, allows events to be begun or concluded simultaneously. One basic application is in dividing up "time space" for Time Division Multiplexing in tel ecommunications.

c. Time Interval. In principle, the measurement of all time intervals falls under the sub-category of labeling. There are, however, a great many needs for the accurate measurement of short time intervals. These needs are usually met by time scales that run for only short periods of time. Thus, the user tends to obtain item (a) by different means than item (c) and it is useful to distinguish between the two.

3. Distance vs. Speed. A uniform time scale can be used in conjunction with the constancy of the speed of light to determine the distance between points that are spatially separated.
It is a basic technique in position location.

\subsection{Basic Technical Infrastructure}

The word "system" in the phrase National Measurement System, might be taken to mean a very high degree of organization. For example, an extent of organization which transcends individual institutions, permeates the entire structure and, perhaps, has the force of law. The National Measurement System for Time and Frequency does not possess this degree of organization, and this is one reason that the system is difficult to understand, or even to describe.

In the National Measurement System for Time and Frequency, there are some regulations which have the force of law but they impose tolerances which are very lax compared to the state-of-the-art. The fractional accuracies imposed on time, and fre-quency $1 \mathrm{ie}$ in the range $10^{-3}$ to $10^{-6}$. Fractional error is the ratio of the estimated error in frequency (time) to the nominal frequency (elapsed time).) The organizations which create and enforce these rules and the functions to which they apply are discussed in section 2.4.

on the other hand, there are important parts of the system where tolerances are much tighter. These tolerances are required in order to satisfy the function to which T\&F is being applied and tend to be limited to specific institutions and/or functions. Examples are given in sections 2.5.1.2.3,3, and 4.

\subsubsection{Documentary Specification System}

Documentary standardization activities in the field of time and frequency are very limited. Those that do occur are associated with the physical standards authorities, offices of weights and measures, and regulatory agencies; and are thus best discussed in sections $2.4 .1,2.4 .2$, and 2.4 .4 below.

\subsubsection{Instrumentation System: Measurement Tools and Techniques and the Instru- mentation Industry}

Figure 1 displays the historical development of accuracy in time keeping devices. Today, a few primary frequency standards based on the cesium atom (see sec. 2.1) form the most accurate physical realization of the definition of time interval. A primary frequency standard is a device which is specifically constructed to permit the evaluation of the major factors which cause the output of the device to deviate from the definition. 
At present, the three most accurate primary frequency standards known have each demonstrated an accuracy of about $1 \times 10^{-13}$. These devices were developed and are operated by the Physikalish-Technische Bundesanstalt (PTB) in West Germany, the National Research Council (NRC) in Canada, and the National Bureau of Standards (NBS) in the United States [2]. These three devices provide, in principle, the best sources of calibration for those other devices needing frequency accuracy, either for its own sake or for establishing an accurate time scale.
Tables 1 and 2 list, from the point of view of accuracy and long-term stability (see sec. 2.3 for definitions), a hierarchy of instruments for generating frequency and time. In some cases the instruments are intended primarily for end-use, but in other cases the instrument may serve either the end-use or to calibrate an instrument of lesser quality. By "end-use" I mean the use of time or frequency for an important socioeconomic function. An example would be the use of an atomic frequency standard for stabilizing the carrier of a TV transmitter. As a further example, quartz and atomic sources often serve both for end-use and for

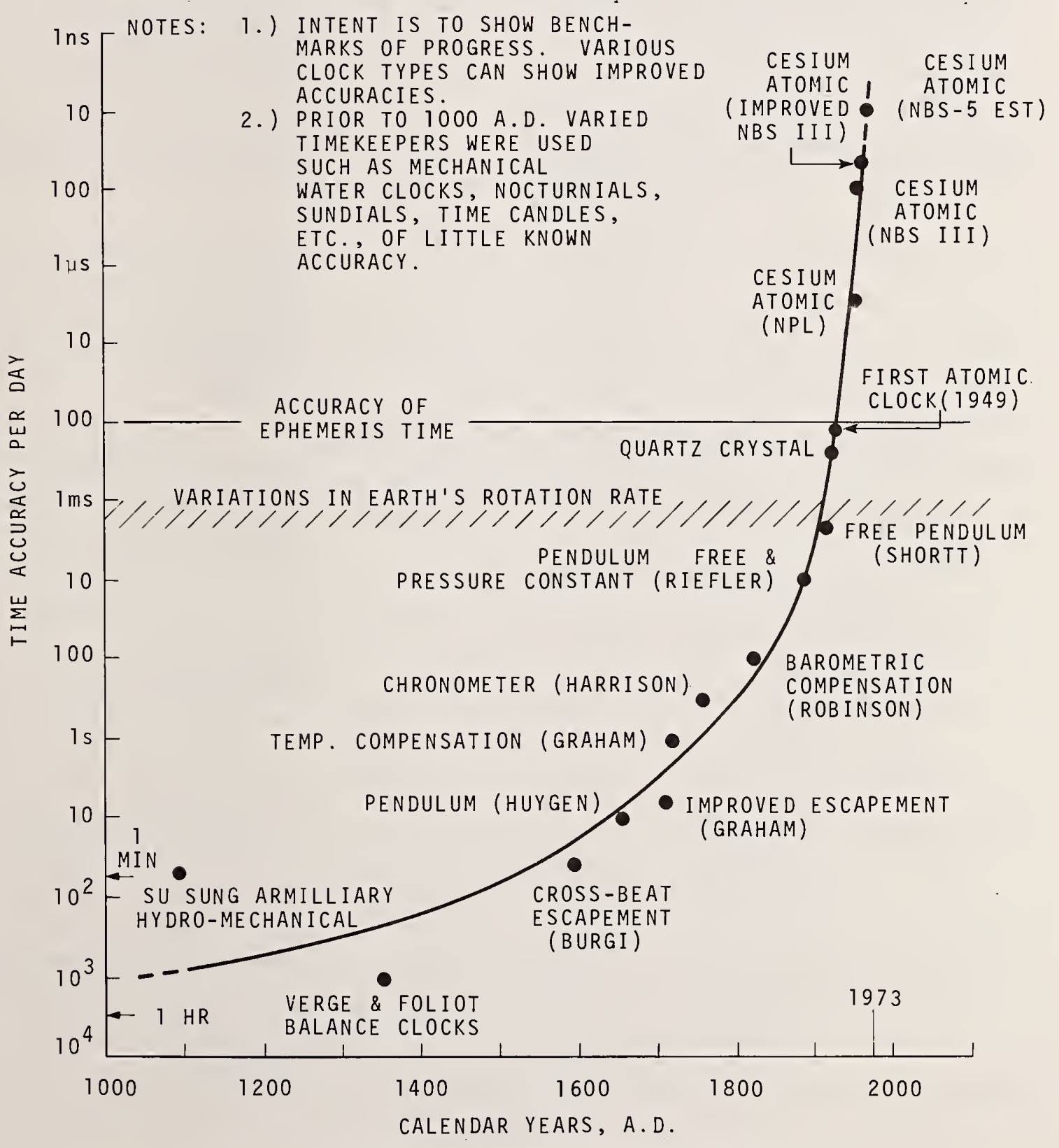

Figure 1. Historical development of timekeeping accuracy 
calibration of lower quality sources. There is ancther way of looking at tables 1 and 2: Frequency and time are used for various social and technological functions. In order to accomplish these functions the various instruments (sources) must be coordinated one with another. For example, two sources of frequency which nominally claim to be equal must, in fact, be equal to within a specified tolerance. The same holds true for sources of time. Table 1 describes the most important types of devices for generating frequency. It gives, in column 2 , the accuracy or precision to which it is useful to equalize their frequencies. It also gives in column 3 , means by which this equalization can be achieved. Table 2 gives the same informa-

Table 1. Instrumentation hierarchy for coordination of frequency

Source of [commercially available] Frequency

Tuning Forks

$1 \times 10^{-2}$ to $1 \times 10^{-3}$

Electric Power Generators

Quartz Oscillators

Atomic Oscillators
Accuracy of Coordination Needed (Fractional)
Coordination: Means of Calibration
Commercial frequency counter; standard broadcasts

Commercial frequency counter or standard broadcasts

$\left(1 \times 10^{-3} \mathrm{~Hz}\right.$ in $60 \mathrm{~Hz}$ )

$1 \times 10^{-3}$ to $1 \times 10^{-10}$

$1 \times 10^{-9}$ to $\approx 1 \times 10^{-13}$
Commercial frequency counter up to $1 \times 10^{-7}$; free-running atomic oscillators or standard broadcasts for $1 \times 10^{-7}$ or better

Commercial cesium standards, hydrogen masers and national primary standards. Rubidium oscillators can be calibrated on site with a commercial cesium standard or a hydrogen maser to an accuracy of about $5 \times 10^{-12}$. For calibration at a distance, use these same sources and line-of-sight microwave or an LF or VLF broadcast. For frequency equalization in the range of $5 \times 10^{-12}$ to $1 \times 10^{-13}$, compare to a national primary standard and use on-site calibration or LF or VLF broadcasts 
tion for the major types of time sources. The reader who is interested in details of T\&F calibration should consult reference 3 .

The following will give some idea of the activity in the manufacture and use of some of these instruments:

The worldwide sales volume last year in the watch industry was about four billion dollars, and a total of about 200 million watches were sold.

The total number of cesium and rubidium standards in use (this includes those used as clocks as well as those that serve just as frequency sources) is about 4,000 to 6,000 . The number of units sold last year was about 1,000. These units were produced by about seven companies and the sales volume was approximately 12 million dollars.

The total number of quartz oscillators in the field and produced per year is vastly greater than the atomic variety. For example, many TV sets use a quartz oscillator. If we confine ourselves to precision quartz oscillators (free-sunning drift rate of not worse than $1 \times 10^{-} /$day) then about eight major U. S. firms sold about 10,000 units in 1974 in the U. S. The corresponding dollar volume was about $\$ 10$ million.

\subsection{3 and 2.2.4 Reference Data and Reference Materials}

Reference data and materials are not of significant separate importance in this field of measurement.

\subsubsection{Science and People}

Most of the people who use T\&F use it as a component part of some other technology. For example, frequency standards provide the carriers for the frequency-division-multiplexing system of the telephone industry. This "other" technology - and not T\&F - is the major business of most of these people. Thus, although we may know a lot about the needs of "their" technology, we generally don't know much about them. For example, we don't know much about their educational level or how much of their time they spend "directly" on T\&F matters.

We do, however, know more about people

Table 2. Instrumentation hierarchy for coordination of time

\begin{tabular}{|c|c|c|}
\hline \multicolumn{3}{|c|}{ Coordination of Time } \\
\hline $\begin{array}{l}\text { Source of } \\
\text { Time }\end{array}$ & $\begin{array}{c}\text { Accuracy of Coordination } \\
\text { Needed }\end{array}$ & $\begin{array}{c}\text { Coordination: Means of } \\
\text { Calibration }\end{array}$ \\
\hline $\begin{array}{l}\text { Regular (escapement) } \\
\text { Watches and clocks }\end{array}$ & $\begin{array}{l}10 \text { sec } \approx 1 \times 10^{-4} / \text { day } \\
{[10 \text { times better than }} \\
\text { usual watch] }\end{array}$ & $\begin{array}{l}\text { Telephone time from NBS or } \\
\text { certain select cities; } \\
\text { Standard radio broadcasts }\end{array}$ \\
\hline Electric Clocks & $\begin{array}{l}1 \mathrm{sec} \approx 1 \times 10^{-5} / \text { day } \\
\text { [More accurate than most } \\
\text { power companies can hold] }\end{array}$ & $\begin{array}{l}\text { Telephone time from NBS or } \\
\text { certain select cities; } \\
\text { Standard radio broadcasts }\end{array}$ \\
\hline Quartz Watches and clocks & $\begin{array}{l}0.1 \mathrm{sec} \approx 1 \times 10^{-6} / \text { day } \\
\text { [stability this good but } \\
\text { can't be set this well] }\end{array}$ & $\begin{array}{l}\text { Telephone time from NBS or } \\
\text { certain select cities; } \\
\text { Standard radio broadcasts }\end{array}$ \\
\hline Precision Quartz Clocks & $\begin{array}{l}1 \mu \mathrm{s} \approx 1 \times 10^{-10} / \text { day } \\
\text { [Quartz not commonly used } \\
\text { as time scale] }\end{array}$ & $\begin{array}{l}\text { Cesium clock: Standard radio } \\
\text { broadcasts }\end{array}$ \\
\hline Atomic Clocks & $\begin{array}{l}\text { From } \approx 3 \times 10^{-3} \text { sec to } \\
\approx 3 \times 10^{-6} \text { sec on yearly } \\
\text { basis } \\
\text { [i.e., } 1 \times 1^{-10} \text { to } 1 \times 10^{-13} \text { ] }\end{array}$ & $\begin{array}{l}\text { NBS or USNO time scales via } \\
\text { portable clock or LF or VIF } \\
\text { broadcasts }\end{array}$ \\
\hline
\end{tabular}


whose major business is, or is strongly related to, developing primary T\&F standards. The National Bureau of Standards estimates that there are currently about 180 people with formal academic degrees (or equivalent experience) who spend most of their time in this work, with the bulk of these people working in foreign laboratories and about five percent of the total in the T\&F Division of NBS. This activity is contained in ten scientific areas:

Area

- Primary Cesium Standards

- Other Cesium Design and Development

- Atomic Time Scales

- Hydrogen Devices

- Saturated Absorption

- Ion Storage

- Rubidium Devices

- Superconducting Cavity

- Infrared Frequency Synthesis

- Other Devices

There are no known professional societies primarily devoted to frequency and time standards.

There are two meetings, held on an annual basis, and devoted to the subject of T\&F. They are the Symposium on Frequency Control sponsored by the U. S. Army Electronic Command, and the Precise Time and Time Interval Planning Meeting sponsored by the U.S. Naval Electronic Systems Command, NASA Goddard Space Flight Center, and the U. S. Naval Observatory. Each conference publishes a Proceedings.

In addition to these two Proceedings, several other publications contain an important amount of information: 1.) the Proceedings of the Conference on Precision Electromagnetic Measurements (sponsored by NBS, the Institute of Electrical and Electronic Engineers (IEEE), and the International Scientific Radio Union), 2.) the IEEE Transactions on Instrumentation and Measurement, 3.) Metrologia (published by SpringerVerlag), and 4.) the Proceedings of the IEEE.

The personnel of the T\&F Division of the NBS publish a great deal of information about $T \& F$. Some of this appears in the abovementioned journals and a great deal more appears in official NBS publications. In the last five years, more than 70 publications on T\&F have been produced by NBS personnel. Three of the most general of these are referenced $[1,3,4]$ in this report. In addition to these, the NBS occasionally con- ducts courses on various aspects of T\&F.

It is also important. to note that there are several educational institutions actively involved in T\&F matters. Major ones are: Harvard University, Massachusetts Institute of Technology, Johns Hopkins University, Columbia University, Stanford University, Laval University (Canada), University of Paris (France), University of Tokyo (Japan), and the University of Mainz (Germany).

\subsection{Realized Measurement Capabilities}

In discussing the measurement capabilities of the National Measurement System for Time and Frequency, the system would be easier to understand if there were one instmonent that was the uttimate standard for T\&F. Following the ultimate standard in this hypothetical scheme would be several instruments - all identical to one another - and each of these would be calibrated by the ultimate standard. The system would have further levels, each instrument in a given level being identical. As the quality of the levels decreased the number of instruments in a given level might increase. Any instrument in any given level would be calibrated by an instrument in the next superior level. Thus, each instrument in the entire system would be calibrated to a degree that was commensurate with its innate quality and each would be traceable to the ultimate standard. At each level of this hypothetical, pyramidal structure there would be end-users, those people who use time or frequency to perform some "socially useful" function. And each user would enter the system at that level which best met his technical needs.

This is not an adequate description of the National Measurement System for Time and Frequency. The reasons it is not are twofold. First, both time and frequency are multidimensional quantities. One user badly needs one aspect while another needs some other dimension. Second, the costs and benefits of a given time or frequency input will vary greatly from user to user. Thus, different users will purchase different inputs al though from a technical point of view the highest quality input would serve them a11. A description of the measurement capabilities of the system requires an approach from several directions. I will begin by discussing several aspects - accuracy, stability, and precision - of the quality of a time or frequency source. These terms will be defined and some aspects of the quality of the major sources of T\&F will be given. In enumerating the sources of T\&F it is necessary to talk about both the generators of T\&F and about dissemination of their 
signals to the user. Finally, an instrument hierarchy does exist in the system and is displayed in tables 1 and 2 .

The reader who is not familiar with the technical details of T\&F may wish to skip some of the section on stability.

The quality of a frequency or a time standard cannot be described by a single number. In fact, the quality of a standard may depend quite strongly upon the use to which it will be put. Even when the situation is restricted by asking "How good is this standard when used for the following purpose? as opposed to "How good is this standard?" it is often necessary to make more than one measurement to adequately characterize the standard. There are three terms which are typically associated with the quality of T\&F standards defined as follows:

Whenever the measurement of anything is discussed it is quite common to find the word accuracy used and, often, misused. A commonly accepted definition of accuracy is "the degree of conformity of a measured and/ or calculated value to some specified value or definition." Thus, the currently accepted definition of the accuracy of time interval (frequency) is that given in section 2.1. A physical realization of the definition of frequency accuracy requires a device whose working substance is atoms of cesium. In addition, the device, usually referred to as a primary frequency standard, is specifically constructed to permit the evaluation of the major factors which cause the output of the device to deviate from the definition. Because these devices are very expensive and complex, very few of them exist. Section 2.2.2 mentions the three primary standards which currently exhibit the best performance. To gain insight into the difficulties of determining the accuracy of a primary standard the reader should consult reference 5 . The term "accuracy" need not be restricted to primary frequency standards; any frequency standard whose frequency has been measured with respect to a primary standard, and which has adequate stability, can have its accuracy specified.

Stabizity is a term used in characterizing both frequency and time standards. Intuitive$1 y$, the frequency stability of an oscillator is the degree to which its output is a pure sinusoid. Conversely, the frequency instability of an oscillator is the degree to which its output deviates from that of a pure sinusoid. What is needed is a parameter which measures the deviation of the output from this ideal. Although there is no single universally accepted measure of frequency (or time) stability, there are two measures of frequency stability that are in wide use. very brief discussion of these two measures is given below. The reader should consult references 6 and 7 for additional details.

The two frequency stability measures are based on a quantity $y(t)$ defined by $y(t) \equiv \frac{\Phi(t)}{2 \pi v_{0}}$ where $v_{0}$ is the nominal frequency of the output and $\dot{\Phi}(t)$ is the time derivative of the instantaneous phase of the output. The deviations of the output from the sinusoidal ideal are contained in the quantity $\Phi(t)$. Thus, $y(t)$ represents the instantaneous fractional frequency deviation of the signal from its nominal frequency, $v_{0}$

The first frequency stability measure is $s_{y}(f)$, where $y$ is the quantity just defined and $f$ is the frequency of one of the spectral components of the output. The quantity $S_{y}(f)$

is known as the spectral density of the instantaneous fractional frequency fluctuations, $y(t)$.

The second frequency stability measure, $\sigma_{y}(\tau)$, depends on a number of variables, one of which is the time duration of a single measurement, $\tau$. $\sigma_{y}(\tau)$ is known as the Allan variance of the fractional frequency fluctuations, $y(t)$.

Without going into great detail about the quantities $S_{y}(f)$ and $\sigma_{y}(\tau)$ some qualitative statements can be made. In practice, the frequency-domain measure, $S_{y}(f)$, is used when the spectral content of most of the fluctuations of interest is at frequencies of a few hertz and higher. The practical application for the time-domain measure, $\sigma_{y}(\tau)$, is for those signals whose fluctuations are at frequencies of about one hertz and less (i.e., whose periods are about one second and longer). For example, if a frequency standard is being examined for its possible application in Doppler radar, measurements of $S_{y}(f)$ would be appropriate. If, however, the frequency standard is to be used as a clock, measurements of $\sigma_{y}(\tau)$ would be needed. Note that many measurements must be made for an adequate characterization of stability, which is true whether it is $S_{y}(f)$ or $\sigma_{y}(\tau)$ which is being measured. The reason is that $S_{y}(f)$ and $\sigma_{y}(\tau)$ do vary with $f$ and $\tau$ respectively. Figure 2 shows a plot of $\sigma_{y}(\tau)$ that is typical of many frequency standards. For the major economic applications of T\&F, attention should be paid to the fluctuations whose periods are about one second and longer. If these requirements are satisfied, then the requirements for "shortterm" stability (periods less than about one second) are usually also satisfied. In this 
report, therefore, I generally refer to stability in terms of $\sigma_{y}(\tau)$.

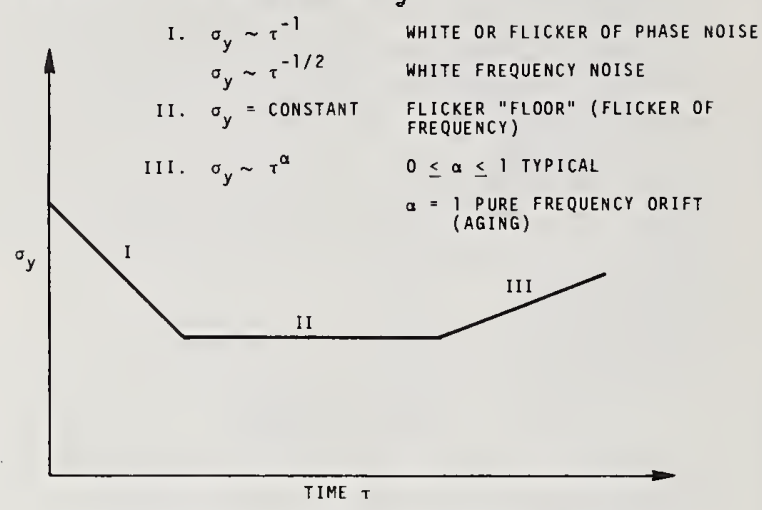

Figure 2. General time-domain behavior of oscillators

The subject of frequency and time stability is closely associated with the subject of electrical noise. For any given oscillator there is some $\sigma_{y}(\tau$ versus $\tau$ (or $\sigma_{y}(\tau)$ display. This curve could be explained in terms of additive and multiplicative noise. When the signal of a frequency generator or a time scale is to be disseminated to some other site, the noise properties of the dissemination mechanism degrade the signal [8]. It is sufficient to note here that a $\sigma_{y}(\tau)$ versus $\tau$ curve can be measured at the user's site, i.e., after the signal has been disseminated. Thus, the noise effects of both the source and the dissemination means are included.

The third term is precision, a word used commonly in referring to measurement quality which must be clearly distinguished from accuracy. Precision is the repeatibility of a given measurement under a specified set of conditions. Many repetitions of a given measurement will produce a series of values and the scatter of these values is a measure of the precision of the measurement. One particularly good measure of frequency precision is $\sigma_{y}(\tau)$. If a set of measurements contains a systematic error, then the precision of the measurement is better than its accuracy. In the limit of no systematic errors, a measure of precision is identical to that of accuracy (as described by the measure in use).

I will be using two other terms: frequency equalization and time synchronization. The discussion of accuracy and stability permits some additional understanding of these two areas. For example, if I have two oscillators that have a fractional frequency accuracy of $1 \times 10^{-11}$ then, by definition, they are equal in frequency to about $\sqrt{2} \times 10^{-11}$. Thus, I have that level of frequency equalization without setting up a dissemination system to actually set one oscillator equal to the other. A claim to accuracy is a very strong claim - one which requires a great deal of careful measurement experience. Without such experience, adequately documented, the users' confidence is justifiably low.

Figure 3, which gives some understanding of the practical importance of knowing an oscillator's frequency, is a display of $\sigma_{y}(\tau)$ versus $\tau$ for typical atomic oscillators of various types. If a person needs good stability over a period of months (maybe even a few years) and doesn't want to calibrate frequently, he will probably need a cesium beam oscillator. But, if he has a network of such oscillators and needs to have them equal in frequency to about $1 \times 10^{-11}$, then the inherent stability (instability) of the oscillators (see the curve labeled commercial Cs in fig. 3) will require that they be compared with each other for about $10^{2}$ seconds or longer. That is, measurements of adequate quality take time. This can be seen from the first parts of the curves ( 1 abeled I) in figures 2 and 3 . It can be seen that the quality of comparison improves with averaging time up to the point of the break in the curve.

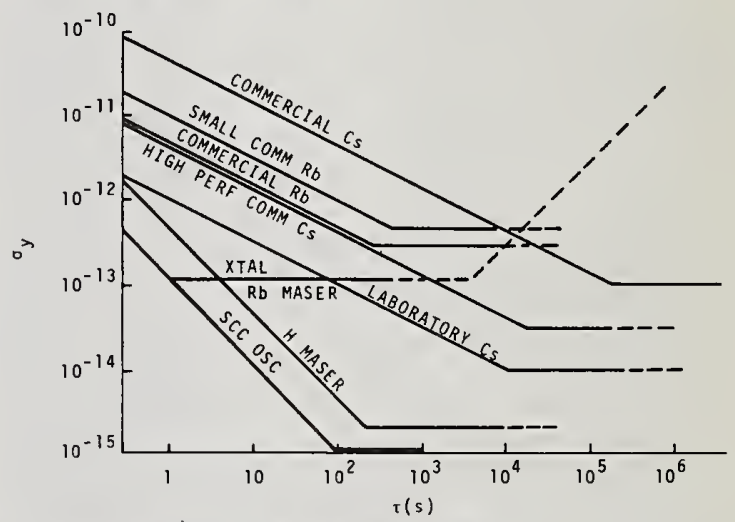

Figure 3. Time-domain behavior typical of several types of oscillators

Consider the flat part of the curves that which is labeled II in figure 2 . This points out that, beyond a certain averaging time, that given by the break point between reginns I and II, it is useless to average longer. A practical example of this brings me back to the network of cesium oscillators to be frequency equalized to a few parts in $10^{11}$. Figure 3 indicates that by averaging for about $10^{2}$ seconds or longer this equalization could be obtained and, in fact, if the averaging were done for $10^{5}$ seconds (about one day), they could be equalized to 
about $1 \times 10^{-13}$. But, as a practical matter, such a group of oscillators would be interconnected by a dissemination system. Any dissemination system has a stability (noise) behavior similar to the curves of figures 2 and 3 .

One dissemination system of great practical importance is the line-of-sight microwave system, owned and operated by the American Telephone and Telegraph Company. The NBS has made extensive studies of the frequency stability of this system. Our present estimate is that it reaches the flat portion (the flicker-of frequency portion) of its $\sigma_{y}(\tau)$ versus $\tau$ curve at a level of about $2 \times 10^{-12}$ for an averaging time of about one week (about $6 \times 10^{5} \mathrm{sec}-$ onds). This indicates that no matter how good the oscillators are, if they are to be frequency equalized by this dissemination system, they cannot be equalized to better than about $2 \times 10^{-12}$.

For time synchronization, the story is essentially the same. To synchronize the "ticks" of one time scale with respect to another takes time. As the averaging time (measurement time) increases the synchronization improves until the point where no further improvement is obtained. In practical cases it is usually the dissemination system that produces the limitation.

The quality of the major sources of T\&F and of the major means of disseminating T\&F are presented below.

Figure 3 gives the stability performance of the major types of frequency standards. Note that there are two non-atomic standards shown. The precision quartz crystal oscillator $(X \operatorname{tal})$ shows excellent performance in short-term, but suffers from drift in longer term. The best quartz crystal oscillators have a drift rate of about $1 \times 10^{-10} /$ day. The superconducting-cavity oscillator (SCC OSC) has the lowest "flicker" level of any known device. Its stability in long-term has not, as yet, received adequate study. Cesium beam standards have the best demonstrated long-term stability. Typical commercial cesium beam standards have demonstrated the ability to hold their frequency to a few parts in $10^{13}$ over a period of a year. Because of this long-term stability, most time scales are based on cesium frequency standards. The stability of a time scale, over a specified averaging time, and based on a specific type of standard, can be estimated from figure 3 .

Accuracy is presently defined in terms of the cesium atom, and at the present state-of-the-art of primary standards this is proper. The reasons are that the cesium device has the best demonstrated ability for evaluation of systematic errors, the pre- cision with which measurements of its frequency can be made is very good, and it has the best demonstrated long-term stability. It may well be, however, that some other type of device will be developed to the point where $i$ ts accuracy capability is better than that of the cesium beam device. If this is so, then given enough experience with this type of device - and presuming that its "working substance" is some other atom (or molecule) - the definition will probably be chanqed.

One last comment about accuracy: a great deal of experience has been gained with commercial cesium beam devices. Many of them have been built and in operation for long periods of time, and primary standards have been available for comparisons. Because of this, a great deal of confidence has been developed about their accuracy. It can be said, with a rather high degree of confidence, that any given commercial cesium beam is accurate to about $1 \times 10^{-11}$. (This statement presumes that the standard meets a few selfcontained performance checks.)

Table 3 displays some basic features of the major frequency and time dissemination systems. One of the main things to be noted is that the performance of any given system, just as any given oscillator, usually cannot be characterized by a single number. For example, the performance of the Loran $C$ system depends very strongly on whether the user is primarily receiving the ground wave or the sky wave. A description of the detailed performance of each system and the various pros and cons of their use is beyond the scope of this report. The reader who desires to pursue the subject in greater detail can find more information in reference 8.

The reader can now return to tables 1 and 2 and re-examine the hierarchy of instrumentation. In this re-examination, one cannot help but wonder what trade-offs - in accuracy, stability, cost and ease of use exist at the various levels. Although I cannot hope to answer this question with completeness (and certainly not with finality) partial answers will be found throughout the rest of this report.

\footnotetext{
The reader who wishes to learn more about the state-of-the-art of primary frequency standards should see reference 9 .
} 
Table 3. Characteristics of the major T\&F dissemination systems

\begin{tabular}{|c|c|c|c|c|c|}
\hline \multirow{2}{*}{$\begin{array}{l}\text { VLF } \\
\text { RADIO }\end{array}$} & $\begin{array}{l}\text { COMMUNICATION/SFB } \\
\text { GBR, NBA, WWVL }\end{array}$ & $1 \times 10^{-11}$ & $\begin{array}{l}\text { ENVELOPE } \\
500 \mu \mathrm{s}\end{array}$ & & GLOBAL \\
\hline & $\begin{array}{l}\text { NAVIGATION SYSTEM } \\
\text { OMEGA }\end{array}$ & $<1 \times 10^{-11}$ & $\leq 10 \mu \mathrm{s}$ & & GLOBAL \\
\hline \multirow{2}{*}{ LF RADIO } & STANDARO FREO. BRDAOCAST (WWVB) & $\begin{array}{l}1 \times 10^{-11} \\
\text { PHASE-24h) }\end{array}$ & $\begin{array}{l}\text { ENVELOPE } \\
\sim 50 \mu \mathrm{s}\end{array}$ & & $\begin{array}{l}\text { USA (WWVB) } \\
\text { LIMITEO }\end{array}$ \\
\hline & $\begin{array}{l}\text { NAVIGATION SYSTEM } \\
\text { LORAN-C }\end{array}$ & $\begin{array}{l}2 \times 10^{-3} \\
\star\end{array}$ & $\begin{array}{l}\sim 1 \mu \mathrm{s}(\mathrm{GNO}) \\
50 \mu \mathrm{s}(\mathrm{SKY})\end{array}$ & & $\begin{array}{l}\text { SPECIAL } \\
\text { AREAS }\end{array}$ \\
\hline \multirow{2}{*}{$\begin{array}{l}\text { HF/MF } \\
\text { RADIO }\end{array}$} & STANDARD FREO. BROAOCASTS (WWV) & $1 \times 10^{-7}$ & $1000 \mu \mathrm{s}$ & & HEMISPHERE \\
\hline & $\begin{array}{l}\text { NAVIGATION SYSTEM } \\
\text { LORAN-A }\end{array}$ & $5 \times 10^{-11}$ & $\begin{array}{l}2.5 \mu \mathrm{s} \\
\text { NOT UTC }\end{array}$ & A PROBLEM & $\begin{array}{l}\text { LIMITED } \\
\text { AREAS }\end{array}$ \\
\hline \multirow{2}{*}{$\begin{array}{l}\text { TELEVISION } \\
\text { (VHF/SHF } \\
\text { RADIO) }\end{array}$} & PASSIVE -LINE- 10 & $\begin{array}{l}1 \times 10^{-11} \\
(24 \mathrm{~h})\end{array}$ & $\sim 1 \mu \mathrm{s}$ & & $\begin{array}{l}\text { NETWORK } \\
\text { CDVERAGE }\end{array}$ \\
\hline & ACTIVE-LINE-I (NBS TV TIME SYSTEM) & $\begin{array}{l}1 \times 10^{-11} \\
(<30 \mathrm{~m} ! \mathrm{n})\end{array}$ & $<100 \mathrm{~ns}$ & & $\begin{array}{l}\text { NETWORK } \\
\text { COVERAGE }\end{array}$ \\
\hline \multirow{3}{*}{$\begin{array}{c}\text { SATELLITES } \\
\text { (VHF/UHF/SHF } \\
\text { RADIO) }\end{array}$} & $\begin{array}{c}\text { STATIONARY SATELLITES (TRANSPONDER) } \\
\text { ONE WAY }\end{array}$ & $\begin{array}{l}1 \times 10^{-10} \\
(24 h)\end{array}$ & $10 \mu \mathrm{s}$ & $\begin{array}{l}\text { OEPENOS ON } \\
\text { FORMAT }\end{array}$ & HEMISPHERE \\
\hline & $\begin{array}{c}\text { STATIONARY SATELLITES (TRANSPONOER) } \\
\text { TWO WAY }\end{array}$ & $\begin{array}{l}1 \times 10^{-12} \\
(24 \mathrm{~h})\end{array}$ & $\sim 100 \mathrm{~ns}$ & $\begin{array}{l}\text { DEPENOS DN } \\
\text { FORMAT }\end{array}$ & HEMISPHERE \\
\hline & $\begin{array}{l}\text { ON-BOARD CLOCK (ACTIVE) } \\
\text { ONE WAY - LOW ALITIUDE }\end{array}$ & $\begin{array}{l}\sim \mid \times 10^{-10} \\
(24 h)\end{array}$ & $0.5-50 \mu \mathrm{s}$ & $\begin{array}{l}\text { OEPENOS ON } \\
\text { FORMAT }\end{array}$ & WORLO \\
\hline \multirow{2}{*}{ SHF RADIO } & MICROWAVE & $\begin{array}{l}\sim 1 \times 10^{-13} \\
\text { PER WEEK }\end{array}$ & $\leq 100 \mathrm{~ns}$ & $\begin{array}{c}\text { PHASE } \\
\text { COMPARISON }\end{array}$ & LOCAL LINKS \\
\hline & VLBI & $5 \times 10^{-14}$ & $\sim \operatorname{lns}$ & $\begin{array}{l}\text { DEPENDS ON } \\
\text { FORMAT }\end{array}$ & HEMISPHERE \\
\hline \multirow{2}{*}{$\begin{array}{l}\text { PORTABLE } \\
\text { CLOCKS }\end{array}$} & PHYSICAL TRANSFER & $\stackrel{1 \times 10^{-13}}{\star *}$ & 100 ns & 1 OAY & $\begin{array}{l}\text { LIMITEO BY } \\
\text { TRANSPORTATION }\end{array}$ \\
\hline & $\begin{array}{l}\text { AIRCRAFT FLYOVER } \\
\text { 2-WAY }\end{array}$ & $1 \times 10^{-12}$ & $\leq 100 \mathrm{~ns}$ & $\begin{array}{l}\text { DEPENDS ON } \\
\text { FORMAT }\end{array}$ & $\begin{array}{c}\text { LIMITEO BY } \\
\text {.TRANSPORTATION }\end{array}$ \\
\hline
\end{tabular}

* one-month average

** ten-day average 


\subsection{Dissemination and Enforcement Network}

\subsubsection{Central Standards Authorities}

Many nations maintain standards laboratories similar to that of NBS. These labs were formed partially in the recognition that the maintenance of physical standards is socially important. They tend to encourage social order by promoting the economy, protecting the consumer, and protecting public health and safety. Because nations are not generally isolated, it is important that many standards be international in scope.

Several international organizations are involved in defining physical standards and in describing the ways in which these standards should be disseminated. Reference 10 gives considerable detail about the international organizations dealing with date (time) and frequency (time interval). I will list just a few of the organizations mentioned in that reference, with the intent of giving the general flavor of international activity.

The Bureau International de 1 'Heure (BIH) is charged with providing a central international reference point for time and related matters. Based on contributions from the time scales of about 13 national laboratories (comprising some 60 atomic standards) the BIH constructs the International Atomic Time scale (TAI) and Coordinated Universal Time (UTC). Time keeping is complicated by the fact that UTC is based both upon the motion of the earth and upon atomic standards. Thus, time-latitude, polar coordinates, stable frequency, and accurate frequency are all inputs to UTC.

The International Radio Consultative Committee (CCIR) makes recommendations with regard to the formats for broadcasting standard frequency and time. Among its recommendations are those specifying the tolerances between national time scales and TAI and UTC. With regard to frequency, the Genera 1 Conference of Weights and Measures (CGPM) in consultation with its subsidiary organization, the Consultative Committee for the Definition of the Second (CCDS) agreed to define the unit of time-interval (frequency) in terms of a certain transition of the cesium atom (see sec. 2.1). Frequency standards are intimately associated with the concept of the frequency spectrum. The allocation (assignment) of carrier frequencies within the frequency spectrum is only meaningful to the extent to which those frequencies can be measured and controlled. The recommendations of the CCIR with regard to standard frequency broadcasts are an important factor in providing international compatibility in frequency measurement and control. This is true despite the fact that the CCIR has no legal authority. It is advisory to the International Telecommunications Union.

In the United States, the NBS has the responsibility for developing and operating the national standard of time-interval. It is also given the responsibility of providing the "means and methods for making measurements consistent with those standards." These requirements are documented in Title 15 of the U. S. Code 8272 , Sec. 2 and in Department of Commerce Order, DO 30-2A. In compliance with these directives the NBS maintains, develops, and operates a primary frequency standard based on the cesium atom. It also broadcasts standard frequencies based on this primary standard.

In the United States, the United States Naval Observatory (USNO) is charged with developing and maintaining the standard of time and other astronomical data which are essential for safe navigation at sea, in the air, and in space. Legally, this responsibility applies only to the activities of the Department of Defense. The legal responsibility for these functions is given to the USNO by the document known as OPNAVINST 5450.90B Dec. 16, 1969, Mission and Functions of the U. S. Naval Observatory. As a consequence of this directive the USNO maintains an atomic time scale based on a large number of commercial cesium beam frequency standards. And, just as the NBS does, it must disseminate its standard. It does this by controlling the broadcasts of several Navy communications stations. The Department of Defense (DOD) has given the USNO the responsibility of managing the T\&F needs of the DOD.

Both NBS and the USNO are major contributors to the TAI and UTC time scales. The NBS contributes accurate frequency and stable frequency and the USNO contributes astronomical information and stable frequency.

The responsibility for enforcing the daylight savings time changes and maintaining the standard time zones in this country is held by the Deparment of Transportation, via Public Law 89-387 and Title 15 of the U. S. Code.

For further details about international and national T\&F organizations and activities see reference 10 .

\subsubsection{State and Local Offices of Weights and Measures}

The State and Local Offices of Weights and Measures appear to deal with matters of timeinterval and date by reference to NBS Handbook 44. This document deals with such devices as parking meters, parking-garage clocks and "time in-time out" clocks. The greatest accuracies involved are about \pm 2 
minutes on date and about $0.1 \%\left(1 \times 10^{-3}\right)$ on time-interval. During a conversation with an official of the Weights and Measures Section of the Colorado State Department of Agriculture, I was told that his office had the legal authority to enforce the specifications in the NBS Handbook. The penalty for violating this code is a fine ranging from $\$ 20$ to $\$ 200$ and/or a jail sentence of up to three months for a first offense. It was his impression that most, if not all, states followed the NBS Handbook 44 specifications and applied about the same penalties.

Recently the Time and Frequency Division of NBS has been helping the Colorado State Standards Laboratory in the calibration of radar speed guns. The calibration system we recommended to them involves the use of a commercial frequency counter and a reference to the WWV broadcast via telephone. The sys tem more than meets their need for frequency accuracy (which is about $1 \times 10^{-3}$ ) and also gives them NBS traceability, the latter being a very important legal consideration. Court cases are more solid when traceability to NBS can be demonstrated.

\subsubsection{Standards and Testing Laboratories and Services}

In the United States, in addition to NBS and USNO, there are a number of commercial, governmental, and educational institutions that maintain standards laboratories, the majority of which (157) belong to an organization known as the National Conference of Standards Laboratories (NCSL). By means of a questionnaire we examined the T\&F activity of the NCSL membership. Some $65 \%$ of these laboratories perform frequency and/ or time calibrations and as we had intuitively expected, they represent an important mechanism for disseminating T\&F in this country. Additional results of this study of the NCSL are given in section 2.5.2.1 and in ref. 11 .

\subsubsection{Regulatory Agencies}

To my knowledge there are only three distinct organizations that have legal authority in regulating T\&F. The Department of Transportation has authority with respect to time zones and daylight savings time (see sec. 2.4.1). The state standards laboratories (sec. 2.4.2) have authority within their own states for time-interval and date measuring equipment. Both of these organizations deal almost entirely with matters of time.

The third organization is the Federal Communications Commission (FCC). Unlike the other two organizations, the FCC appears to deal almost exclusively with matters of fre- quency. The Code of Federal Regulations, Part 73, Radio Broadcast Services (Revised 0ct. 1, 1973) describes the frequency allocations and the frequency tolerances to which various broadcasters must conform. The Code discusses five categories of broadcasts: AM stations, commercial FM stations, noncommercial FM stations, TV stations, and international broadcasts.

There are four major features to the specification:

1.) The upper and lower frequency bounds of each of the five categories are given.

2.) The frequency tolerance for each category is given as an absolute frequency deviation. For example, for AM stations, the deviation shall be no more than $\pm 20 \mathrm{~Hz}$ from the specified frequency.

3.) All broadcasters must check, at least as frequently as once per month, to see that they meet the specification.

4.) The NBS broadcast stations WWV, WWVH or WWVB are the ultimate reference to which the broadcaster must conform.

The allowed frequency deviation can be expressed as a fraction of the maximum operating frequency within the band. The least stringent tolerance is about $1 \times 10^{-3}$ (international broadcasts) and the most stringent is about $1 \times 10^{-6}$ (TV broadcasts).

It must be noted that the FCC can and does enforce these regulations. One of the penalties they can exact is removal of the broadcaster's license. It is my understanding that the broadcaster's license is sufficiently valuable to him that he won't risk being caught with his frequency down - or up, for that matter.

\subsection{Direct Measurement Transactions Matrix}

To understand the National Measurement System for Time and Frequency, there are a number of questions which need to be answered. Among these are:

- What organizations and other groups use Time and Frequency?

- How do they get it?

- Why do they use it?

The Time and Frequency "Flow Matrix" discussed in detail in section 2.5.1 attempts to give a very concise answer to these questions.

Section 2.5.1.1 describes how the matrix was constructed and defines its various categories and descriptors. Section 2.5.1.2 
explains some of the values of its specific entries and draws some general conclusions. The Flow Matrix is an approximation to the National Measurement System for Time and Frequency as it exists today. There are pressures now present which tend to alter some important details of this system. Section 2.5.1.2 also discusses some of these pressures for change. Finally, section 2.5.2 gives examples of the use of T\&F by several major users.

Sooner or later the exceedingly difficult question arises as to what is the value of a given time or frequency input to a user. Usually, a quantitative answer cannot be given, nor is it even possible to give a single answer since the questioner usually wants to know the value of the input in the future as well as now. Very often T\&F is a part of a means to a useful end. For example, stable frequency is an essential input to the telephone system whose useful output is widespread communication. On the other hand, the end-user may have a direct requirement for time or frequency, such as when the public uses time-of-day. Despite the difficulties, some attention should be directed to whether the benefit of a given T\&F input is worth its cost. I defer consideration of this matter until section 3 .

\subsubsection{Analysis of Suppliers and Users}

\subsubsection{Construction of the Flow Matrix}

The rows of the matrix are labeled by the various SUPPLIERS of T\&F. The columns are given the same labels and represent the USERS. As the discussion progresses it will be seen that certain of these categories form the major suppliers and others the major users. There is some overlap, and this approach is an attempt to insure that no important transaction is left out.

Listed below are the sixteen SUPPLIERUSER categories. Note that the categories are sometimes further defined and restricted by the parenthetical note which accompanies them. It is necessary to keep this information in mind when considering the value assigned to the various elements of the matrix. For the definitions of some of the acronyms used here, see section 2.4.

1. Knowledge community (science, professional societies and journals)

2. International metrological organizations (national standards laboratories $\mathrm{BIH}$, and International Bureau of Weights and Measures)

3. Documentary standardization organizations (CGPM)
4. Oscillator, receiver, and clock manufacturers

5. Watch industry

6. NBS (T\&F and other divisions)

7. USNO (T\&F and other divisions)

8. State and local offices of weights and measures

9. Private, and Department of Defense Standards Laboratories and the Defense Communication Agency

10. Regulatory agencies (FCC, ITU and CCIR)

11. Department of Defense (operational military)

12. Other Federal Government (Federal Aviation Administration, National Oceanic and Atmospheric Administration, NASA)

13. Navigation dependent industries (shipping, aviation, aerospace)

14. Communications industry (telephone, specialized carrier, TV, radio)

15. Electric power industry

16. General public ("Hams", time-of-day, private boats and planes)

The question arises as to why these categories were chosen and not others, or perhaps why not others in addition. The question really has two answers. First, the general labels tend to be rather all-inclusive. In examining the characteristics of the National Measurement System as a whole (T\&F as well as all other physical quantities) there were 14 general categories that emerged. The above list is the expression of these general categories (with two of them broken into two parts) for the study of T\&F. Second, the parenthetical elaborations represent detailed knowledge that NBS has gained of the National Measurement System for Time and Frequency.

In July 1969, the staff of the FrequencyTime Dissemination Research Section of NBS wrote a National Measurement System-type report entitled "Study of Time and Frequency Dissemination", to discover if new methods were needed. It identified at least 35 groups and organizations as present and future users of time and frequency information and equipment. This comprehensive study in effect completed the first phase of the National Measurement System Study: the identification of a 11 major users of time and frequency technology.

However, since it was not feasible to study in detail all of these areas within the allocated time frame, a plan was formed to narrow the field of study and at the same time retain the most important users and potential users. Considerations in the selection of the areas to be studied included judgments of: 
The potential of an organization for helping to deal with problems of significant social interest, e.g. pollution and energy, and

The relative dependence of an organization upon advances in time and frequency technology.

Taking all this into account, I formed a list of eight areas to be studied, which included a broad cross-section of the time and frequency community. The areas studied in detail are shown here:

- Standards laboratories

- Users of NBS radio broadcasts

- Telephone industry and specialized carriers

- Military

- Position location

- Aviation industry

- Electric power industry

- Shipping and boating industries

These areas are broad enough that it was possible to extract from them most of the information needed in the 16 categories of the Flow Matrix.

Consider now the numbers that go in each of the elements of the Matrix. For many of the SUPPLIER-USER transactions (i.e. the elements of the matrix) there are two descriptors:

1.) The "volume-of-use" descriptor appearing in the center of an element, and

2.) The "importance" descriptor appearing in the upper left hand corner of an element.

The "volume-of-use" descriptor has four possible levels. They are defined as:

$0=$ Negligible

2 = 0ccasionally use it but not a common part of operations

3 = Use often enough that it forms a basic part of operations

4 = A central part of operations. Used continuously or very regularly.

In these definitions I have avoided an explicit statement as to the relationship between the T\&F input (from supplier) and the social value of an organization's (user's) output.

The "importance" descriptor also has four possible levels, defined as:

1 = Purely a matter of convenience

2 = Economically compelling or strongly desirable

3 = Legally required or alternate sources unsatisfactory.

4 = Matters of life and death or sole source.

These definitions contain some very strong socio-economic judgments. They should be interpreted as referring to the value of the T\&F input in the user's internal operations and not to T\&F's value to the output of the user.

It is necessary to be specific when assigning values to either of the two descriptors as to the nature of the time and/or frequency output from a supplier. It is desirable to distinguish eight specific categories. They are:
A. A T and/or F source (a piece of equip- ment)
B. A disseminated $T$ and/or $F$ signal (an
C. A receiver for T\&F signals
D. A particular dissemination means (equipment) for T\&F
E. Published information about T\&F
F. Consultation about T\&F
G. Regulations and/or specifications for T\&F
H. Requests for T\&F equipment or services

A letter appears in the lower right hand corner of each element. It identifies the output upon which the values of the two descriptors are based. In a few instances because I have more information - I have sometimes identified more than one output. Note, in this case, that it is always the first letter upon which the descriptors are based.

It should be particularly noted here that in one case the "supplier" supplies requests for T\&F equipment or services only, and not T\&F equipment and services themselves.

Only direct transactions were allowed in considering the values to be assigned to the various transactions. For example, if a quartz watch manufacturer provides watches to the general public, that is a non-zero transaction of the 5,16 type, i.e. of the Watch Industry-General Public type. If a quartz oscillator manufacturer provided the watch manufacturer with the quartz oscillators that went into the watches, this would not be an allowable interaction of the type 4,16 . Therefore, if no direct interaction "exists then the "volume-of-use" descriptor is zero. And, obviously, so is the "importance" descriptor. It should be carefully noted again that any given ranking was based only on one output from the supplier. In many cases a given supplier provides more than one input to a given user; I have 


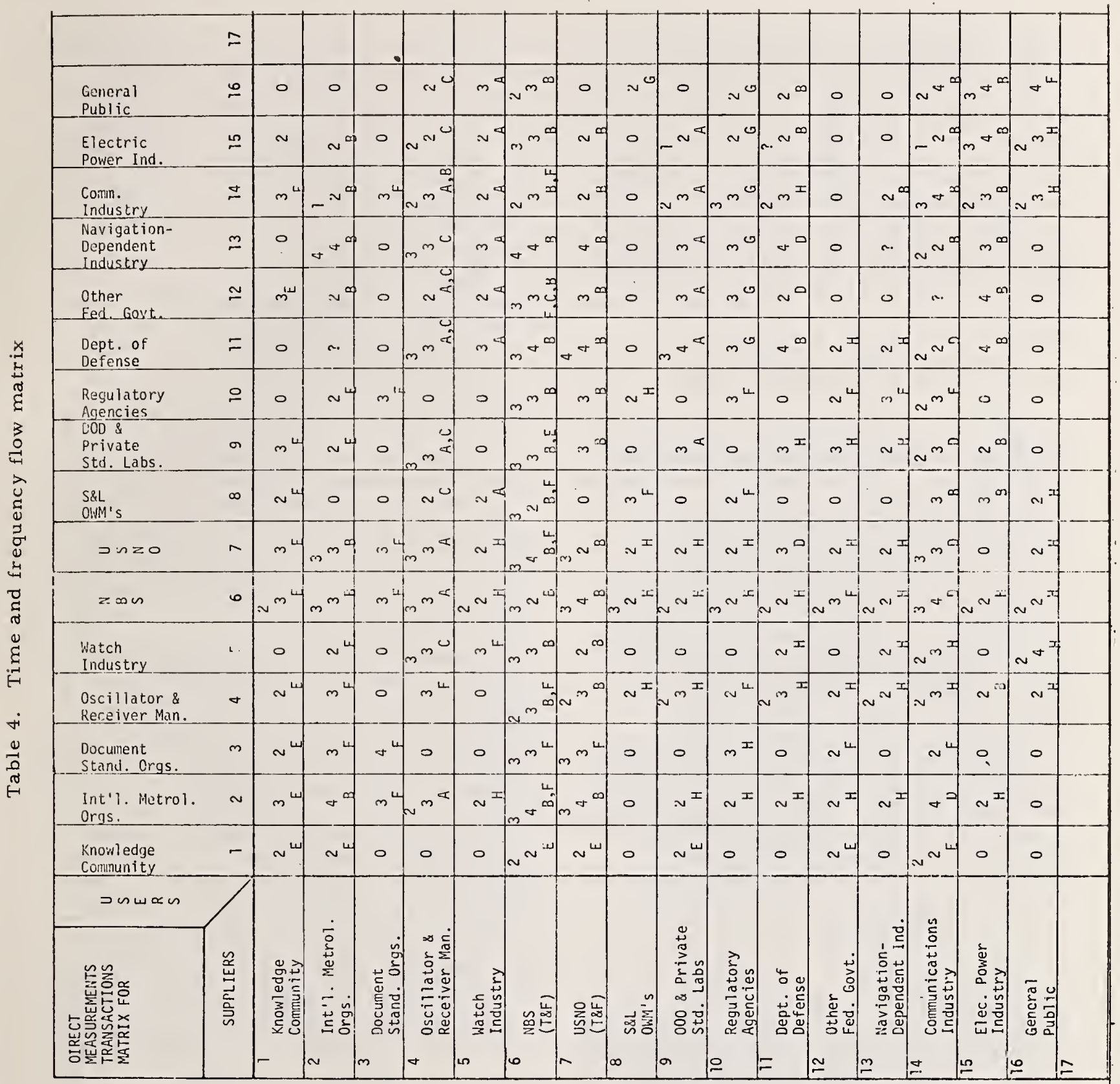

17 
stressed the most important input in each case. The hope is that this will define the primary characteristics of the system.

For the majority of the elements only one number appears, it being my estimate of the "volume-of-use" descriptor. I did not attempt to estimate the "importance descriptor", feeling that my knowledge was insufficient for more than one estimate.

A word of warning: the reader should not attempt to interpret the T\&F Flow Matrix in terms of the social value of T\&F to the end user. The intent of the Flow Matrix is simply to define some characteristics of T\&F flow from supplier to user.

\subsubsection{Nature of the Suppliers and Users}

There are three elements comprising this section: first, some examples of how values were assigned to the descriptors; second, some general conclusions about who are the major suppliers and users; third, changes which have occurred or will probably occur in the supply and use of T\&F.

The purpose of the first is to give the reader a feeling for the considerations involved and not to list the values assigned to all the elements. In the second subsection, I generalize about the function/s that time and/or frequency perform for the major users. Third, I discuss whys and hows of actual and possible changes.

The question of change quickly gets into socio-economic considerations. Nevertheless, I still attempt to confine this to its meaning to the users' internal operations, the problem of cost-benefit analysis and the end user being reserved for section 3 .

\subsection{Examples of Assigning Values to the Descriptors}

Examples of seven of the eight types of T\&F output listed in section 2.5.1.1 are given here.

An example of a frequency source occurs in transaction 4, 11 (Oscillator Manufacturers-Department of Defense). The military uses its atomic oscillators often enough that level 3 in the "volume-of-use" descriptor applies. Calibration with a standard frequency signal is often not possible, or at least not desirable, so they need the frequency accuracy of atomic oscillators which they cannot produce themselves. Thus, the "importance" descriptor is rated 3 .

An example of a time signal is in transaction 6,73 . The yachting community uses celestial navigation and therefore date, for position location on the open sea. When it is needed, it is used at least once per day, so level 4 of "volume" applies. When celestial navigation is being used it could be a matter of 1 ife and death to obtain an adequate "fix". It also is sometimes true that the NBS (WWVH) signal is the only one available. Thus, I have assigned a value of 4 to "importance". If electronic position location equipment (Loran-C, Omega) is also on board and working, then this "importance" ranking would not be correct. Since electronic position location is at least a potential alternative, some readers may still object to a ranking of 4 for "importance". I stress again that the Flow Matrix is to be interpreted as a "snap shot" of the present. Another example of signal as an output is 7,6 . The NBS compares its time scale with that of the USNO on a very regular basis, thus level 4 of "volume" applies. "Importance" is given a value of 3 because the high quality of the USNO time scale means that not to do so would be exceedingly unwise.

A great many jewelers 1 is ten to the WWV time-of-day broadcast in order to calibrate their watches and clocks. To do this, they must have a receiver. For the 4,5 transaction, "volume" is 3 . Because the jewelers cannot, in general, build their own receivers, "importance" is also 3 .

The American Telephone and Telegraph Co. owns and operates a very extensive, highquality, line-of-sight microwave dissemination system. The major TV networks maintain rubidium frequency standards in their studios, which are used to frequency stabilize the broadcasts. The stability (roughly speaking) of these standards is disseminated over the microwave system and the signals are regularly monitored by NBS. Some of the standards laboratories of the U. S. Navy are, or very soon will be, using this system to calibrate the frequencies of their own oscillators. Since this will be a basic part of their T\&F operations, the 14, 9 transaction is rated 3 for "volume". Because of the high quality, relatively low cost, and traceability to NBS of this service, we consider its use strongly desirable. The "importance" is judged to be 2.

Many people use NBS T\&F publications but often it is not a basic part of their operations, e.g. the science community often uses it as background knowledge. Thus the "volume" ranking of 6,1 is 2. From the point of view of the National Measurement System for Time and Frequency, it is strongly desirable that this information be available, so I have assigned a value of 2 to "importance".

Consuztation is a very important part of the activities of many T\&F suppliers. I have chosen, however, not to assign any of 
the rankings in this matrix on the basis of this output.

Regulations set forth by the FCC for the frequency accuracy of broadcasting have legal force and require regular attention by the broadcasters. Therefore, both the "volume" and "importance" descriptors of 10 , 14 are rated 3 .

By keeping its average frequency very near $60 \mathrm{~Hz}$ the electric power industry of this country is a profoundly important part of general-use time keeping. The public has come to expect this service and sometimes, in fact, the public"request" it. Accordingly, the "volume" measure of the 16, 15 transaction is 3 , and the importance level is 2 .

\subsection{Major End Users and Their Suppliers}

The National Measurement System for Time and Frequency is a complicated system.

The Flow Matrix was designed to make the flow of T\&F outputs comprehensible, but even with this it is difficult to grasp the essence of the T\&F flows. One important thing we can do towards understanding the Matrix is to identi$f v$ the major end users and categories which supply them. An end user category (1, and 10-16) is one which uses T\&F as a means to an end and not as an end in itself. Thus, the telephone industry (part of category 14) is an end user because it uses accurate frequency to control its frequency division multiplexing system. The NBS is not an end user because it uses virtually al its inputs to improve or check its ability to generate and disseminate T\&F.

It is meaningful to define a major end user as one for whom both descriptors are rated 3 or higher, thus $10-16$ are major end users. The suppliers of these major end users are categories 2, 4-7, 9, 10, 11, 14, and 15 .

The general public (category 16) may be classified as both a major end user and supplier in that it reads its own watches and clocks. This is a skill usually taken for granted but it would greatly alter society should this ability be limited to a few people.

It might be questioned whether the regulatory function as performed for example by the FCC, can legitimately be considered a T\&F input. Since it clearly restricts the system and in some ways gives it stability, I contend that it is useful to do so.

In user categories 10 through 16, there are three recurring functions which T\&F performs for the user: communication, navigation, and coordination. The ability to divide frequency and time/space provides the communications function and is of major importance in categories 11, 13, and 14 .
The relationship between time and distance provides the navigation (position location) function which is vital in categories 12 and 13. The aspects of constant rate and the ability to facilitate simultaneity provide the coordination function which is basic to categories $11,12,15$, and 16 .

Defining the needs for accuracy and/or precision could be accomplished by adding another descriptor to the Matrix, but in my opinion, the value added would not be worth the additional clutter. This is a topic which arises in discussing change and appears in the next section.

\subsection{Directions of Change in the National Measurement System for Time and Frequency}

This section examines three major technical areas where changes are occurring or will probably occur. These areas are as follows:

1. By 1980-1985 there will probably be a widespread network of clocks which are synchronized with respect to each other to between 1 and 10 microseconds.

2. Within that period there will probably be a widespread network of terminals that are equalized in frequency with respect to each other to about $1 \times 10^{-11}$. Very likely, all of the clock locations of item 1 will be among these frequency equalized terminals. There probably will be many others in addition al though the needs for frequency equalization beyond the $1 \times 10^{-10}$ level will usually have a strong relation to timing activity.

3. There may be significant pressure from the public for a 100-fold improvement in the accuracy of time-of-day, widely available, for setting watches and clocks.

As in most situations of possible change, there will be pressures (socio-economic as well as technical) for preservation of the status quo as well as for alteration. My comments contain inherent socio-economic considerations but I will confine my detailed discussions to technical matters. A brief economic rationalization behind these predictions may be found in section 3 .

\subsection{Time Synchronization and Position Location}

There exist today, in addition to portable atomic clocks, three (widespread) means for synchronizing clocks to $10 \mu \mathrm{s}$ or better. In order of accuracy, they are: 1.) Omega 
(about $10 \mu \mathrm{s})$, 2.) Loran C (about $1 \mu \mathrm{s}$ ), and 3.) the Defense Satellite Communication System (about $0.3 \mu \mathrm{s}$ ). Omega and Loran C are both networks of transmitters used for navigation purposes. The Defense Satellite Communication System is a network of satellites used for the purpose of communication. A11 three of these systems are expensive (a minimum of $\$ 5000$ per receiving site for the least expensive system) and difficult to use. The NBS broadcast stations WWV and WWVH provide a widespread means of timing that is simple to use and of low cost (about $\$ 200 /$ site). However, this service is only capable of about 100 microsecond synchrorization.

There is presently a debate as to whether there is a requirement in data transmission for a communication network that has nodes that are synchronized to a tolerance in the range of 1 to $10 \mu \mathrm{s}$. The opponents of such a system say, for example, that it would not be economically useful because it is more efficient to time the nodes on a pair-bypair basis by sending synchronizing pulses along with the data. They claim that since storage buffers are needed in the timed network as well as in the pair-by-pair system to adjust for different fixed delays, it is wasteful to continuously maintain a synchronized network. The advocates admit that buffers would still be needed but argue that for a many-node switched system, the timed network offers an important increase in flexibility.

This argument becomes quite involved; however, I believe it will be settled in favor of the proponents and within five to ten years, a widespread time synchronization capability will be available. This will exist in the form of one or more systems that can synchronize a network of clocks to a tolerance of from 1 to $10 \mu \mathrm{s}$. One such possibility is a set of nodes interlinked by line-of-sight (LOS) microwave lines such as is now being tested by Bel1-Canada. In this case, the synchronizing system and the clocks to be synchronized tend to become indistinguishable.

Two general comments about the feasibility and utility of such a system are appropriate. First, LOS microwave transmission has a proven path stability of the order of tens to hundreds of nanoseconds over the period of a day. This applies to paths of from 20 to 2000 miles. (If, of course, there is more than one path between two points and a switch is made between paths, then the delay change will be vastly greater.) This means that for LOS microwave, path instability is not limiting at the $1 \mu \mathrm{s}$ level. Second, a widely available time scale does have the capability of coordinating systems which are time-dependent but which were initially independent. Thus, if a timed network develops within the telephone system, there may be socio-economic advantages to making this time available to other time-dependent systems.

Partial support for my opinion that the 1-10 $\mu$ s timed network would be useful comes from a recent polling of T\&F experts. In this poll there was a rather strong opinion that such a system, if available, would be in extensive use between 1980 and 1985. This poll is discussed in section 3 .

One of the things that would aid the technical-economic feasibility of such a system is good, low cost, frequency equalization, reviewed in section 2.5.1.2.3.2.

Even more sophisticated synchronization systems are being proposed for purposes of position location. The most ambitious of these is the Global Positioning System under development by the U. S. military, based on a global network of satellites, each carrying an exceedingly stable clock. The goal of this system is to be able to locate position anywhere in the world to a repeatability of about ten feet. This corresponds to being able to predict satellite-to-ground path delay at least as well as 10 nanoseconds for any given path, at any given time, on any given day. The NBS knowledge on this matter suggests that the present state-ofthe-art in predicting satellite-to-earth path delay is no better than 10 nanoseconds. The designers of the system hope to achieve this performance without synchronizing the satellite clocks more often than once in 2 weeks. This translates into a frequency stability requirement of about $1 \times 10^{-14}$ for a 2-week averaging time.

\subsection{Frequency Equalization}

It is helpful to briefly review the major needs for frequency equalization in the order of increasing needs for accuracy and/ or precision. The approximation used here is that the needed calibration system is about ten times more accurate or precise than the inherent capability of the device to be cal ibrated.

The typical mechanical wrist watch is capable of maintaining time-of-day accuracy to about one minute over one day's time. An error in average rate (frequency) of about $1 \times 10^{-3}$ would produce this much time error over one day's time. Thus, a source of frequency calibration should be accurate to about $1 \times 10^{-4}$.

The newer generators in the electric power industry are capable of having their frequencies reset to about $1 \times 10^{-2} \mathrm{~Hz}$, or 
roughly $1 \times 10^{-4}$ of the nominal $60 \mathrm{~Hz}$. It is therefore desirable to have a frequency reference at $60 \mathrm{~Hz}$ which is accurate to about $1 \times 10^{-5}$.

The FCC applies a legally-backed requirement on the frequencies of all broadcasts. As discussed in section 2.4.4 the most stringent requirement, about $1 \times 10^{-6}$, applies to the TV broadcasters. Because the law requires that the calibration be traceable to NBS, the calibration source should be accurate to about $1 \times 10^{-7}$. There is now a significant possibility that the FCC will require the operators of cable TV systems to maintain their carriers accurate to $1 \times 10^{-8}$. This would make a source accurate to $1 \times 10^{-9}$ very desirable. If such a rule is imposed it would probably come to apply to a11 TV broadcasts.

Note that frequency control or measurement requirements beyond about $1 \times 10^{-6}$ $1 \times 10^{-7}$ press the limit of widely available, lowest cost mechanism: WWV-WWVH.

There is a specialized but very widespread application for frequency equalization within the telephone system: frequency division multiplexing (FDM) requires that frequency be equalized at about 50 places in the U.S. to approximately $1 \times 10^{-10}$. The Bell System appears to be satisfying their own need in this regard (for more detail see sec. 2.5.2.3). There is an international organization which debates matters of this nature, the CCITT (Consultative Committee on International Telephone and Telegraph). In a recent meeting, the Committee agreed to recommend a frequency tolerance of $1 \times 10^{-11}$ for internationa 1 coordination of the FDM networks of the various telephone systems. The actual technical need for now and the forseeable future is more like $1 \times 10^{-10}$. [12]

The state-of-the-art frequency drift of quartz oscillators is about $1 \times 10^{-10} /$ day. Thus, for the telephone application and even for the probable new FCC requirement on TV, it is necessary to use atomic oscillators in the operation of the system or at least to have easy access to them.

This brings me to another very important point. There are some applications for frequency equalization in the range of $10^{-8}$ to $10^{-10}$ wherein it is undesirable to be "hooked in" to a frequency equalizing network. The portable clocks of the Global Positioning System are one example; part of the FDM network of the telephone system is another. 0scillators meeting this requirement now cost about $\$ 5000$ or more. There would probably be a significant market for a device in the range of $\$ 1000$ to $\$ 2000$ (see sec. 3.2).

Beyond about $1 \times 10^{-10}$ there does not seem to be large technical need for frequency equalization per se. Past this level, frequency equalization requirements become a part of the requirements for time synchronization. For example, if it is desired to maintain clocks in synchronism to $1 \mu \mathrm{s}$ and not resynchronize more often than once per day, then the frequencies of the clocks must be equal to one another to somewhat better than $1 \times 10^{-11}$.

Just as for time synchronization, it is useful to look a little further into the future. A single link of an LOS microwave system does have a day-to-day path stability of about 10 nanoseconds. If a person wanted to take full advantage of this for the purpose of time synchronization, he would want oscillators which were stable, averaged over one day, to better than $1 \times 10^{-13}$ and would need them equalized to about this level. This is pressing the state-of-the-art of commercially available atomic frequency standards. For information on the state-of-the-art of commercial and laboratory frequency standards the reader should consult reference 13 .

\subsection{Improved Setting of Watches and Clocks}

The time of day, provided by watches and clocks, may be obtained nearly anywhere, anytime. The electric power industry (EPI) provides fairly accurate average frequency (averaged over one day), and as electric clocks are phase accumulators (adding up successive time-intervals), time correct to the nearest minute is fairly easy to come by.

Conversely, it is very difficult to set the position of the second hand with respect to the minute and hour hands. Thus, the accuracy with which time-of-day can be obtained from the typical watch or clock is roughly 30 seconds. The basic use of the second hand has been to make relatively accurate (about 1 second) measurement of fairly short time intervals (a few tens of minutes at most).

It now appears that we are within five years of a significant change in the watch and electric clock situation. With the availability of watches and clocks with digital displays it will be easy to set the seconds reading with respect to the minutes and hours reading. Therefore, for the first time on a widespread basis the seconds display can have good accuracy, not only because a change of one second is clearly resolvable, but because the rates (frequencies) of the watches are accurate enough that their probable daily error is approximately one second versus one 
minute, as with the usual watch.

The point is not that many people need time-of-day accurate to one second, but rather that, for the first time, a great many will become aware of the fact that there are variations of as much as 30 seconds between sources which they had heretofore considered accurate.

Will many people care about this improved accuracy? If they do, the present availability of proper calibration is inadequate and we can expect to see a significant upgrading of the time-of-day service offered by the telephone industry. It may also place an additjonal burden upon the telephone time-of-day service of NBS. I discuss this matter again in section 2.5.2.2.

As stated earlier, the electric power industry is a very important source of time, attempting to hold its average frequency close enough to $60 \mathrm{~Hz}$ that the accumulated time error over one day's time is no more than two seconds. But I have been informed that in areas where the power system is overloaded the time can be in error by as much as 30 seconds. It may therefore be that the relationship of the electric power industry to time-of-day is about to change.

\subsubsection{Highlights of Major Users}

\subsubsection{Standards Laboratories}

The study of the standards laboratories was conducted by sending a questionnaire to each of the members of the National Conference of Standards Laboratories (NCSL) [11]. As of February 1, 1973, NCSL listed 257 standards labs in this country, and of these, 157 are NCSL members. Some $68 \%$ of the NCSL membership responded to the questionnaire.

of the responders, $96 \%$ perform regular frequency calibrations and $80 \%$ do timeinterval calibrations. Presuming that those that did not respond do neither frequency nor time calibrations, about $65 \%$ of the NCSL performs regular frequency calibrations. Assuming that the non-NCSL labs have the same distribution as the NCSL 1abs, then $65 \%$ is the approximate participation of all standards labs in this country in frequency calibration. If the extreme assumption is made that none of the non-NCSL labs perform frequency calibrations, then approximately $40 \%$ of a 11 the standards labs in the country do this work. At any rate, the standards laboratories of this country appear to be an important means of obtaining frequency and time-interval calibrations.

of those NCSL members performing frequency calibrations, $70 \%$ of them required accuracy better than $1 \times 10^{-6}$. Of those responding, about $11 \%$ own cesium beam frequency standards, $5 \%$ own rubidium standards, and $85 \%$ regularly monitor one or more of the NBS standardfrequency broadcasts. Summing the estimates of the individual respondees, I estimate that these 98 labs perform about 60,000 frequency calibrations per year.

\subsubsection{Time-of-Day to the Public}

In 1974, about four billion telephone calls were made to obtain either time-ofday (TOD), weather information, or both [12]. It's estimated that the number would have been about two billion if the only service offered was TOD.

The service is available through the telephone system by means of about 1,000 TOD machines, based on a pre-recorded tape, placed in telephone company central offices. The recording is synchronized to TOD (UTC) by receiving the broadcast from the NBS radio station WWV.

There are two types of TOD machines in use, the major difference to the user being the accuracy with which time is received. The device giving TOD at the lower level of accuracy announces time to about the nearest one minute. This unit begins announcing a given minute 25 seconds before that minute occurs and continues the same announcement for one minute. Thus the time can be as far off as about 30 seconds.

The device which provides the higher accuracy announces the time every ten seconds and says something like, "At the tone the time will be -.-." This device has a precision of better than $0.1 \mathrm{~ms}\left(10^{-4} \mathrm{sec}-\right.$ onds). The accuracy available to the user will vary from telephone to telephone and from day to day. As received at those offices that deliver the time every ten seconds, the time will be accurate to about five to $15 \mathrm{~ms}$. This depends on the propagation delay which is primarily determined by the distance between the WWV transmitter and the office. It is my understanding that an approximate propagation delay correction is made at some of these offices. If so, the time disseminated from the TOD machine should be accurate to about $1 \mathrm{~ms}$. The time as received by the telephone user will, however, be much less accurate, because the telephone network can have large and changeable time delays. Personnel at NBS have done a few experiments with this "every ten seconds" service and find that it is usually accurate, at Boulder, Colorado, to about $100 \mathrm{~ms}(0.1$ seconds). The average user of this "every ten seconds" service would usually find the accuracy at least this good; however, no one is giving the user any guarantees on the 
accuracy of the system.

A study based on a very restricted sampling indicated that one of every 134 users wanted one second accuracy some of the time. If, however, digital watches become common, perhaps a greater number of people will request this accuracy (see sec. 2.5.1.2.3.3).

\subsubsection{Technical Requirements for Frequency Equalization within the FDM Network of the Telephone Industry}

In the U. S. telephone industry, essentially every phone call that traverses more than about 50 miles is carried by what is known as the frequency division multiplexing (FDM) system. It has some rather stringent frequency equalization requirements. In order to recover the message at the receiving site, an operation known as "reinserting the carrier" must be performed. If the call travels a long distance, such as from coastto-coast, as many as five complete stages of multiplexing may be needed. Each of these stages involves the operation of carrier reinsertion. An oscillator used for reinserting a carrier must be closely equal in frequency to the oscillator which was used for transmission. An inequality between the frequencies of the two oscillacors tends to garble the message. The present specification in the telephone industry is that the offset in frequency between sending and receiving ends be not more than $2 \mathrm{~Hz}$. If the full five stages of multiplexing are used then the absolute frequency tolerance on each oscillator is $0.2 \mathrm{~Hz}$. In this case, the nominal frequency of the highest-frequency pair of oscillators in the chain is about $60 \mathrm{MHz}$. Thus, the fractional tolerance on this pair of oscillators is $3.3 \times 10^{-9}$. The nominal operating frequencies of the other oscillator pairs in the chain is less and the fractional tolerance is correspondingly less. [12]

The need for frequency equalization has grown markedly over the years, because the number of levels of multiplexing has greatly increased and the tolerable frequency offset has grown smaller. Figure 4 shows the increasing need for frequency equalization.

The needed frequency equality is achieved by sending signals, pilot tones (around the country on the telephone facilities) to which the various oscillators can be slaved. For some 40 years, up until about 1973, the sources of these pilot tones were quartz oscillators, kept stable in long-term by tracking the broadcasts of NBS. During the 1960 's and the early part of the 1970's, the NBS station WWVB was used as the reference.

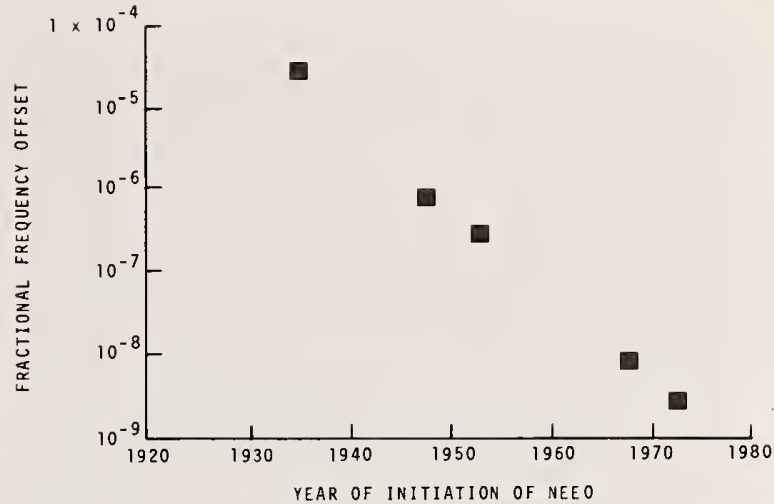

Figure 4. Development of frequency accuracy in FDM system of telephone industry

With the appearance of the latest (fifth) level in the FDM hierarchy in 1973, the pilot tone system based on quartz oscillators has become inadequate. Because of this, the American Telephone and Telegraph Company (AT\&T) is putting a new pilot tone system into operation.

This new frequency equalization system will be used by the entire telephone industry (Bell System and independents) as was the older system. It will be based upon a group of three commercial cesium beam oscillators, one of which will be "on line", the other two serving as backup, permitting the detection of a fault in any of them.

Two signals will be sent out from this facility - $20.48 \mathrm{MHz}$ and $2.048 \mathrm{MHz}$ - to each of some 30 to 50 sites around the country. The cesium oscillators will be located at Hillsboro, Missouri. These signals will be disseminated on the line-of-sight (LOS) microwave system of AT\&T and on the three highestquality coaxial facilities in their system.

The 30 to 50 sites to which these pilot tones will go will be equipped with sophisticated quartz crystal oscillators which are known in the industry as Jumbo Frequency Supplies (JFS), devices which have a freerunning drift rate of less than $1 \times 10^{-10} /$ day.

The oscillators (carrier supplies) for the FDM system are located in more than 25,000 telephone offices which are known as Central Offices, 2, 000 of which are designated as Toll offices. These Toll offices require carrier supplies for the FDM system

In the hierarchy of the old system, the next level below the pilot tones was known as the Office Master. These locations are also known as Primary Frequency Supplies (PFS). The PFS is a device based on a quartz oscillator (actually two quartz oscillators) which costs about $\$ 2500$ per unit and which has a free-running stability of about 
$1 \times 10^{-8} /$ day. In the oscillator hierarchy, this second level is the lowest level in terms of quality of oscillators used; there are no lesser quality oscillators in the FDM system. However, in view of how the various Toll Offices are interconnected, it is roughly correct to say that there are five levels in this hierarchy, including the pilot tone. The PFS's are phase-locked together in groups of about four. (Bell System policy is to try and avoid cascading more than four PFS's in one chain.) Thus, the first PFS in the chain is phase-locked to the pilot tone, the second PFS is phaselocked to the first, and so on. This phaselocking procedure was a basic difficulty with the old frequency equalization system because transients in the system (usually due to routine system testing) tended to break the lock. The further down a chain a given PFS was located the more susceptible it was to these transients. Apparently, the disturbance was so bad that at times, fractional deviations in frequency as large as $1 \times 10^{-6}$ occurred.

The second level of the hierarchy of the new frequency equalization system is the JFS mentioned above, the first level being the cesium beam oscillators. Unlike the old system, this second level will not be phaselocked to the pilot tones. The JFS's will instead be pseudo frequency-locked in such a manner that they are offset from the pilot tones by $1 \times 10^{-10}$. In the old system, transients occurred in the pilot tones, whereas the new system should have less trouble with "phase hits". The pilot tones of the new system will be more stable in long-term and this should prove helpful. The rest of the new system, as originally planned, will be phase-locked as before. Here, a JFS will be the initial source in the chain of phase-locked oscillators.

Some within the Bell System feel that this new frequency equalization facility will still not adequately solve the "phase hit" problem. Thus, some consideration is being given to further breaking up the phase-locked chains. By introducing an oscillator which is sufficiently stable in long-term, say $1 \times 10^{-10}$ for periods of a week or longer, a pseudo frequency-1ock could be substituted for one of the phase-locks.

A final point: it may be that it is now economic to substitute low-cost atomic oscillators in the FDM system for part of the quartz oscillators in order to further break up the present phase locking. An atomic oscillator which could be sold for no more than $\$ 2000$ would probably be quite proper from a cost-benefit viewpoint. How many of these oscillators might be required?

The present policy of the telephone industry is to try and avoid cascading more than four oscillators into a single chain. If, on average, there are four oscillators per chain, then there would be about 500 chains in the total system. If the lead site in each chain were atomic, then 500 atomic oscillator sites would be required. Since each site requires two oscillators, the total number of atomic oscillators would be 1,000 .

In summary, the new frequency equalization facility for the FDM network has the following characteristics:

1.) Frequency, accurate to about $1 \times 10^{-11}$ will be available to the telephone industry at about 50 places widely dispersed around the U. S.

2.) At each of these sites, frequency that is usually accurate to about $1 \times 10^{-10}$ will be dispersed to about 15 chains of phase-locked oscillators.

3.) The frequency accuracy available from these oscillators is difficult to predict. It can be said, however, that it tends to degrade, the lower a particular oscillator happens to be in a chain.

4.) The lowest fractional accuracy that can be tolerated in the FDM system is about $2 \times 10^{-6}$ and at certain levels of the multiplexing hierarchy it must be at least as good as $3 \times 10^{-9}$. (I use the word accuracy rather than precision to emphasize that the pilot tones are based on a cesium beam oscillator.)

5.) It seems that it would be cost beneficial to introduce about 1,000 atomic oscillators into the system to further alleviate the "phase hit" problem. To be economic, these oscillators could probably cost no more than $\$ 2000$ each.

\subsubsection{Two Electronic Position Location Sys tems}

\subsection{A Loran-C Sys tem}

In section 2.5.2.5 I discuss celestial navigation as a means of locating position. It is pointed out that there are electronic means of position location that are much more accurate, albeit much more expensive. 
This section discusses two such systems and their requirements for time and frequency. There are several other versions of electronic navigation systems; however, the two specific examples described here reveal the principles upon which any such system is based.

The first method uses the Loran-C navigation network operated by the U. S. Coast Guard. This system consists of about 35 transmitters located in eight geographical areas: U. S. East Coast, Mediterranean, Norwegian Sea, North Atlantic, North Pacific, Central Pacific, Northwest Pacific, and Southeast Asia. Thus, al though the availability of the system is limited to these general geographical areas, there is sufficient coverage that the system is of great utility.

For precise position location with systems of this type, the signals received from the transmitters must, primarily, be due to the ground wave. For the Loran-C system, whose transmitters operate at a carrier frequency of $100 \mathrm{kHz}$. The sky wave begins to seriously interfere with the ground wave for distances beyond about 1000 miles from the transmitter. This system and others of its type, such as Omega, are based on two facts: first, all of the transmitters broadcast with nearly equal phase, and second, the geographical location of each transmitter is accurately known. With Loran-C, as with all electronic navigation systems, the site at which position is to be determined must have a proper radio receiver and have or have access to, electronic computation equipment.

The specific system under discussion is known as a rho-rho-rho system, meaning that the absolute distance from the receiving site to each of three transmitters is measured. Imagine for the moment that only two transmitters are used. Around each of the transmitters, circums cribe a circle, the radius of which is equal to the corresponding measured distance; except for the special case where the two circles are tangent to one another, they will intersect at two points. The position of the receiving site is located at one of these two intersections. Even a very rough idea of where the receiving site is with respect to the transmitters will usually suffice to determine at which of the two intersections the receiver is located. The radio equipment at the receiving site is used - in conjunction with the fact that the transmitters are broadcasting in phase - to determine the needed distances. This application of the Loran-C system is not the usual one. Normally it is only the difference in time of arrival of the two signals which is measured. The system under dis- cussion actually uses more information because, knowing the total propagation time of each signal, the user also could calculate the difference in time of arrival.

One of the components of the receiving equipment is a very stable frequency standard operating as a clock, the purpose of which is to measure the time delay between the time of broadcast of a particular signal and its reception at the receiving site. To do this it must not only be operating at the same frequency as that of the transmitters, it must also be in phase with them.

With this information we can now examine the performance and T\&F requirements of this specific rho-rho-rho system. If the clocks at the receiving site and all the transmitters were exactly equal in frequency and phase, and there were no electrical noise, then a rho-rho system (only two transmitters) would provide all the position accuracy required. None of these conditions, however, is true. The biggest common deficiency is probably that of the clock at the receiving site. As a partial and important compensation for real-1ife deficiencies, a third transmitter is used, providing a measure of redundancy which makes the limitations less severe.

To provide good clock performance at the receiving site, a cesium beam frequency standard is used. (The Loran-C network is also based on cesium standards at each transmitter.) Expressed in terms of time, these transmitters are kept in phase to about $0.1 \mu \mathrm{s}$. Just from the point of view of the transmitters this corresponds to a distance measuring accuracy of about 100 feet.

Consider now the limitations of the performance of this Loran-C system imposed by the imperfections of the clock at the receiving site. Knowledge of cesium beam performance permits a general comment: commercial cesium beams have an accuracy of about $1 \times 10^{-11}$. Assume that this is, in fact, the frequency difference. If the receiving clock were set exactly in phase with a transmitter at a given time then it would be out of phase by $0.1 \mathrm{\mu s}$ some two and one-half hours later. The error due to the receiving clock would be essentially equal to that due to the small phase inequality of the transmitters. If the frequencies could be equallized to $1 \times 10^{-12}$ then the elapsed time to accumulate a $0.7 \mu$ s error would be one day.

The manufacturer of this system claims that the diameter of the circle of probable error is about 65 meters (200 ft.). Accuracies of this magnitude are apparently quite useful but other information at our disposal indicates that a reduction of the circle of probable error to about ten meters would be desirable. The total cost per receiving 
site for this particular system is currently about $\$ 50,000$.

\subsection{The TRANSIT Satellite System}

The TRANSIT system is a group of three satellites which orbit the earth about once every 90 minutes. It belongs to the $\mathrm{U}$. S. Navy and is operated, under contract, by the Johns Hopkins University. (This is part of the total military time and navigation system mentioned in other sections of this report called the Defense Satellite Communication System and is available to civilian as well as military users.)

The TRANSIT method is based on the Doppler effect, the well-known experience that the frequency of a constant frequency source appears to change as the source moves with respect to the observer. In this system the satellites are the source of constant frequency and - just as in the Loran-C method - the receiving site must have a source of stable frequency.

The source of frequency on the satellite is a precision quartz oscillator which may at first seem surprising, since quartz oscillators are significantly unstable in longterm. Quartz does, however, have excellent short-term stability (see fig. 3) and the oscillator is kept stable in medium and long-term by being slaved to an atomic standard. Every time a TRANSIT satellite passes within range of the Johns Hopkins University its frequency is checked with corrections made if it is out of tolerance. The Johns Hopkins oscillators are also controlled, in long-term by the cesium beam standards that comprise the time scale of the USNO.

Each TRANSIT satellite broadcasts a constant frequency and the coordinates of its position in orbit, which are very well known: At any given instant, the observed Doppler shift depends on the angular coordinates of the satellite with respect to the observer. Thus, it has been possible to compile a catalog of computed Doppler data, or "Doppler curves," for a network of points that covers the entire earth. Under suitable conditions, the system is able to, locate position to. within three to five meters.

To obtain his position, the observer feeds three pieces of information to the computer: 1.) the observed Doppler curve as the satellite passes within range of reception; 2.) data on the satellite position as broadcast by the satellite; and 3.) a rough estimate of the observer's own position. The computer then begins a series of iterative calculations. It "looks" in its catalog to see what the observed Doppler curve would be if the observer is, in fact, where he thinks he is. Next it compares the actually observed Doppler curve with that in the catalog. Usually a fairly large discrepancy exists, and if it does, the computer makes a new guess as to the observer's actual position. The comparison is again made with the procedure continuing until the discrepancy is reduced to an acceptable level. Using the data from a single pass of a satellite, position at sea can be determined to an accuracy of. 70 meters.

Since there are three TRANSIT satellites and each orbits the earth every 90 minutes, it is possible to make about 30 observations in a 15 hour period. If the position to be determined is on land and not on sea, then each "fix" can be used to improve the estimate. Thirty observations will yield a position accuracy (radius of the circle of probable error) of about three to five meters, and we are told that this is quite adequate for geophysical purposes.

Since the data taken is of changes in frequency, and not phase differences, the requirements for the receiving oscillator are different than for the Loran-C system. What is required is an oscillator that has good short and medium-term stability. Good longterm stability is not required, so the receiving site uses quartz or rubidium, and not cesium oscillators (see fig. 3 ). To be specific, the total observation time for a single pass of a satellite ranges from six to 18 minutes depending on the observer's geographical location, making the averaging time (the $\tau$ of fig. 3 ) of interest about ten minutes (600 seconds).

An essential feature of the system is the broadcast of the satellite's position, which must be known to a high accuracy at any given time over an indefinitely large span of time. This is only possible because the orbits are well known and because the USNO has an excellent ability to keep time.

The system is quite expensive. The total equipment cost, for just one receiving site, is estimated at $\$ 50,000$ which does not include the cost of the satellites or the necessary supporting facilities such as the time keeping system of the USNO.

\subsubsection{The Use of Date by the Shipping and Boating Industry}

To determine position at sea by celestial navigation, the navigator needs to know his angular position with respect to one or more prominent celestial bodies. He also needs to know the date [14].

The traditional answer as to what accu- 
racy of date is needed is 0.5 seconds. (An error of one second in knowing date is equivalent at the equator, to about 0.12 miles in position.) But, the experience of the U.S. Navy is that - even with date accurate to one second or better - the accuracy of the average celestial fix is only about six miles. In other words, the inaccuracies of the usual sextant reading predominate over the errors in date. This means that an error in date by two or three seconds would, usually, not significantly degrade the fix.

Celestial navigation is an application that needs date: just time-of-day won't do. If a navigator is mistaken in what day it is by one day, he will be incorrect in his calculations by approximately four minutes, or a position error of the order of 70 miles. I was told that standard time broadcasts are used, almost without exception, to obtain date. Clocks or watches are, of course, also carried.

The commercial vessels that navigate the open sea are a very important part of our economy although they represent only a tiny fraction of the total number of vessels in this country. In 1972, there were about 5.9 million registered vessels in this country of which about 157,000 were large enough to be safely taken into the open sea. Only a very small fraction of the total navigate the open sea on a regular basis. I estimate the number of ships and boats that commonly need to determine their position in the open sea to be 4,000 as a minimum and 50,000 as a maximum, not including military vessels. Probably not more than one to two thousand of these are commercial vessels (owner-operated for a profit).

Open sea navigation appears to be in a transitional phase between celestial navigation and electronic navigation as the predominant means of position location. The commercially available electronic means are Loran A and C, Omega, and the TRANSIT satellites.

Evidently, almost all commercial operators own Loran A or C equipment or both. Probably $50 \%$ of the ocean-going yachts carry Loran and/or Omega equipment. There have been about 4000 non-military Omega receivers sold. I estimate there are at least 40 regular users of the TRANSIT satellite service.

Despite the large amount of electronic navigation equipment that has been sold, I would guess that at least half of the navigators (non-military) use celestial navigation as their first-line position location method. Nevertheless, I predict that by 1980, electronic systems will be the first-line method used by the majority of open sea navigators.

\section{IMPACT, STATUS AND TRENDS OF MEASUREMENT SYSTEM}

\subsection{Impact of Measurements}

\subsubsection{Functional, Technological and Scien- tific Applications}

I shall reiterate the three basic functions of a time standard given in section 2: 1.) to set a rate; 2.) to establish a time scale for purposes of time-interval and simultaneity; and 3.) to relate distance to time. Section 2.5.1.2.2 generalizes about the T\&F Flow Matrix and states the three most common functions that T\&F performs for the major end users: 1.) communications; 2.) position-location; and 3.) coordination. Specific applications of T\&F may be found in sections 2.5.1.2.1 and 2.5.2. The following is a more detailed elaboration:

- Local oscillators in TV sets (including channel tuning)

- Rate and time-interval, and initiation and termination of events in data processing

- Controlling the duration of physical and chemical processes

- Transfer of accurate frequency to oscillator manufacturers

- Labeling geophysical events

- Automatic turn-on/turn-off of appliances

- Timing therapeutic and observational procedures for health care

- Billing for telephone usage

- Labeling the time of occurence of important communications

- Aircraft collision avoidance (a potential application for a precisely synchronized network of clocks)

The very great precision and accuracy of T\&F standards give them a prominent position in both science and basic metrology. A scientific application is one where there is no obvious technological benefit but where the state of knowledge about nature is increased. Basic metrology is a technical application that might alter the foundations of the measurement system and/or alter the present primary standards. The unit of timeinterval, the second, has a strong relationship to two other physical units, namely, length and voltage.

The measurement of frequency and wavelength of certain stabilized infrared lasers 
has progressed to the point that it is now feasible to derive the unit of length from the frequency unit. This can be done by using the present (or better) frequency and wavelength knowledge to define a value for the speed of light (a value which would also be consistent with the present accepted value). Thus, instead of two standards, one each for frequency and length, there would be only a frequency standard and the unit of length would be based on it $[15,16]$. Generally speaking, frequency measurements are being pushed to higher portions of the frequency spectrum [17]. These are frequencies where the sources had been characterized by wavelength measurements only. It is the recent presence of frequency-s tabilized lasers in this region that makes such frequency measurements meaningful.

Frequency' is related to voltage via the Josephson effect. The details of the relationship have been sufficiently worked out so that in some countries, including the U. S., the working standard for d.c. voltage is the Josephson junction [18].

The present experimental relationship between frequency and the two quantities temperature and mass, is not as strong as for length and voltage. Nevertheless, the potential importance to basic metrology is sufficiently strong to deserve mention. It has already been possible to use the Josephson junction as a transducer between temperature and frequency [19]. Certain experiments in x-ray spectroscopy have suggested the possibility of defining the unit of mass in terms of the unit of length [20]. If this should prove possible, then the relationship between length and frequency would allow mass to be defined in terms of frequency. Taken al1-in-all, there is a real possibility for a reduction in the total number of independent primary standards necessary to form a realization of the basic physical units.

The definition of the second in terms of a certain cesium transition and the relationship between frequency and wavelength (the speed of 1ight) express some fundamental constancies of nature, namely, the equivalence of atoms of a given species and the apparent constancy of the speed of light. The study of the clock transition in hydrogen ${ }^{1}$ is another careful test of the equivalence of atoms of a certain species. Generally speaking, the whole field of spectroscopy, which is highly dependent on frequency standards, is a study of the structure and stabil-

\footnotetext{
TAn atomic or molecular transition used for a time standard is often known as a clock transition.
}

ity of atoms and molecules and of their interactions with their surroundings.

Very-Long-Basel ine-Interferometry measurements, which require very stable frequency standards, yield important information about both the earth and its celestial surroundings. These measurements can be used to accurately determine the position of specified points on the surface of the earth, thus detecting crustal motions which may have an important bearing on earthquake prediction [21].

In Einstein's Theories of Relativity there are two predicted effects that have a direct bearing on time standards. The Special Theory of Relativity states that two clocks, running at identical rates when at rest, wil1 display different amounts of elapsed time when in relative motion with respect to each other. The General Theory of Relativity predicts that two clocks, running at identical rates when sitting side-by-side, will run at different rates when they are ac different gravational potentials. Using atomic time standards, a rough verification of both of these effects has been obtained $[22,23]$. Both effects are so small that a significantly improved test requires either a major improvement in the time standards used or a change in the nature of the experiment. Another experiment, scheduled to be performed in 1975, will test the gravitational effect using a hydrogen maser on board a rocket. This should provide a test of the predicted effect to a fractional accuracy of about $1 \times 10^{-5}$ [24]. The accuracy of the present test is about $1 \times 10^{-2}$. An experiment under consideration would use one of the two NBS primary standards (the second best) on board an orbiting space vehicle to test the predicted effect of relative motion (time dilatation) to an accuracy of about $1 \times 10^{-5}$ of the predicted magnitude. The present accuracy is about $1 \times 10^{-1}$ [22].

\subsubsection{Economic Impacts - Costs and Benefits}

To establish the value of a particular institution or technology, it is tempting to ask what society would be 1 ike without that institution or technology. For major institutions such as the telephone industry, or technologies such as T\&F, such a question is meaningless. It is inconceivable to think of completely eliminating the functions performed by them. There are always alternatives. There are always other people or groups of people and always other instruments or configurations of instruments to perform the original function. The functions may not be performed identicaliy, costs may vary, and costs versus benefits may be better or 
worse.

The question is often asked, "Are you spending your resources optimally?" This is an exceedingly difficult question to answer. It has two aspects. The first is to define the costs and benefits associated with the present allocation of resources. The second is to compare the present cost-benefit situation with that of possible alternatives.

It may often be possible to specify the dollar costs of a given T\&F delivery system. It is usually more difficult to get agreement on quantifying the benefits of a given system. Usually the cost-benefit situation for alternatives is even less well known. often this is because nobody has tried the alternative system. Until a person has determined costs and benefits for both the present allocation of resources and alternatives he is not able to say whether the present allocation is optimum.

It is presumptious for me to try to talk about whether resource allocation in the National Measurement System for Time and Frequency - as a whole - is optimum, or even to try to define costs and benefits for the present system. I will not attempt either of these things. The Flow Matrix of section 2.5.1 indicates the major users of T\&F and gives some indication of T\&F:s importance to their internal functioning. Some very subjective judgments are required to assess the social value of the output of the major users; even more difficult would be attempts to attribute a definite proportion of that value to the T\&F input.

I will instead devote the rest of this section to providing the reader with a general feeling that T\&F is economically important. I will attempt this by doing two things. First, for some major institutions that are known to make large use of T\&F, their total capital investment and yearly revenue will be cited. Second, I will give some examples of how much it costs certain institutions to obtain a given time or frequency service. With regard to this second consideration, presume that the dollar value of the benefit of a given service is at least as large as the cost. This then establishes a minimum value for the benefits of that service to that institution.

\section{General Capital Investment and Revenue}

In 1973, the total capital investment of the telephone and telegraph industry was roughty $\$ 100$ billion and the revenue was around $\$ 27$ billion [25]. Of this $\$ 27$ billion about $\$ 9$ billion came from longdistance calls [26].

For the aviation-aerospace industry, the the present investment in just electronic systems (airborne and supporting) is approximately $\$ 28.5$ billion. Last year's revenue for just the commercial aviation part of the industry was about \$12 billion [27].

In 1970, the capital investment of the U. S. electric power industry was approximately $\$ 93$ billion with revenue of $\$ 22$ billion [28].

For the commercial shipping industry in 1971, the value of U. S. cargo ships was around $\$ 10$ billion. The total value of the goods shipped to and from the U. S. was $\$ 51$ billion [29].

\section{T\&F Costs}

The NCSL standards laboratories responding to our questionnaire estimated a total capital investment in T\&F equipment of $\$ 3.5$ million. The total yearly operations costs were estimated to range between $\$ 540$ thousand and $\$ 940$ thousand [11]. Using ten years for total depreciation, I estimate the total yearly T\&F costs for these laboratories to be $\$ 1.1 \mathrm{mil1i}$.

Estimating the annual local telephone call revenue and call volume respectively to be $\$ 18$ billion and 180 billion, one can derive the yearly cost to the public to obtain the time-of-day $[25,26]$. From these numbers, the average cost per local call is about $\$ 0.10$. For 2 billion TOD calls per year the total cost would then be around $\$ 200$ million. (See sec. 2.5.2.2.) Since a TOD call is of brief duration, a more conservative estimate would be the cost of one message unit (currently about $\$ 0.05$ where this system of charging is used) times the number of calls. This gives an approximation of $\$ 100$ million per year.

I have made an estimate for the total T\&F equipment cost for the new frequency equalization network for the FDM system of the telephone industry. Using the notation in section 2.5.2.3, with roughly $\$ 0.06$ million for the cesium atomic oscillator facility, $\$ 2.1$ million for the JFS sites, and $\$ 5.0$ million for the PFS sites, the total is roughly $\$ 7$ million.

In the aviation-aerospace industry, the total amount of capital equipment directly attributable to T\&F is approximately $\$ 3.4$ billion. The annual expense for maintenance of this equipment, including calibration, is about $\$ 63$ million [27].

For the commercial shipping industry there are typically three types of equipment on board for position location: two chronometers per vessel costing $\$ 2000$, receivers costing $\$ 400$, and electronic navigation equipment costing $\$ 6000$. The total expense per vessel 
would be approximately $\$ 8,400$ if there are nearly 1,000 commercial vessels that perform open sea navigation [14], the total T\&F equipment charge is about $\$ 8.4$ million. (See sec. 2.5.2.5.)

Assuming that 3,000 yachts use celestial navigation equipment and 1,500 of these also own electronic navigation equipment, a figure of $\$ 6.5$ million may be assigned to the sea-going yachting community for T\&F equipment.

It would be nice to know whether the U. S. is becoming, relatively, more or less dependent on T\&F. There are some indications that it is becoming more dependent. The growth of electronic position location activity is one indication. Another indication comes from the study of the communications industry. As a part of the study of the National Measurement System for Time and Frequency, we learned something about the general economic features of the communications industry [30]. This study revealed that the relative expend$i$ ture of U. S. business for telephone service approximately doubled in the period from 1947 to 1967.

\subsubsection{Social, Human, Man-on-the-Street Impacts}

Clocks and watches vastly increase a person's ability to coordinate his activities with those of others. That ability to coordinate is further increased by electronic communications which are inherently dependent upon time and frequency technology. Strongly related to telecommunications is public safety and the vast variety of job opportunities and cultural activities available in industrial society.

The common telephone is probably the most ubiquitous of all the uses of T\&F. But less sophisticated applications such as parking and taxicab meters are also pervasive. Telecommunications enters in specific industries such as aviation, rail transportation, and shipping, and is vital to the national defense. A more restricted but very important T\&F application is for position location. This application is essential to the shipping and aerospace industries. Offshore oil well drilling is another - and increasingly important - application. The electric power industry, while less dependent on T\&F than communications and position location, is also an important user.

All in all, the ability to live in large cities and to maintain a large per capita material standard of living is significantly (even if, abstractly) based on time and frequency.

If there is any brief statement that will summarize the social function of time and frequency, it is that they are the great coordinators, the great organizers. If one takes a general look at the historical development of technology and its relation to society, one sees a continually increasing organization of things and of people. [31]. Like it or not, if the material standard of living throughout the world is even to be maintained, this level of organization will probably increase. Time and frequency will almost surely play an even greater part in that organization.

\subsection{Status and Trends of the System}

The present status of the National Measurement System for Time and Frequency should be viewed in several ways: through instrumentation (sec. 2.2 and 2.3), calibration hierarchies (sec. 2.3 and 2.4 ), functions that T\&F performs (sec. 2.1 and 2.5), and institutions that supply and use T\&F ( $\mathrm{sec}$. 2.5).

Is the present National Measurement System for Time and Frequency adequate? If the same functions could be provided for less cost, or more service could be provided for equal cost, then the answer would be no. In general, however, the problem is not so easily described.

Adequacy is a word that implies a strong value judgment. I would prefer to avoid using the term and simply attempt to describe the probable changes in the system. Previously I have talked about technical aspects of actual and probable changes; in this section I will go into some of the socio-economic forces behind these changes. The probable changes lie primarily in three areas (see sec. 2.5.1.2.3): 1.) the development of one or more networks of clocks maintained in synchronism to within 1 to $10 \mu \mathrm{s} ; 2$.) a significant increase in the market for frequency equalization at levels of $1 \times 10^{-8}$ and better; and 3.) a possible need for a more widespread time calibration network at an accuracy of about 0.1 seconds. This possible need for better time-of-day calibration was discussed in section 2.5.1.2.3.3 and only the first two areas require further discussion.

My predictions for change are based on two types of data: 1.) detailed studies of certain industries; and 2.) a polling of expert opinion about the probable future of T\&F technology (Delphi. Study). The four industrial studies examined are of the telephone industry, the electric power industry, the aviation industry, and industrial and' other standards laboratories.

The Delphi Study was performed under the 
auspices of the Technology Forecasting and Assessment Subcommittee of the Communications Group of the IEEE. Appendix A.2 includes the questionnaire and background information sent to each of the prospective participants. A major reason for this approach is that socioeconomic forces are likely to be extremely important in determining what changes actually occur, and I felt this was a good way of attempting to include these considerations. [32].

The questionnaire was sent to each of 107 prospective participants equally divided between seven sectors:

\section{1.) Telephone industry \\ 2.) Communications services other than telephone}

3.) Navigation - transportation industry

4.) Oscillator manufacturers

5.) Communications equipment manufacturers

6.) National standards laboratories

7.) Science

The questionnaire consisted of three sets of questions. The first two dealt with eight very specific T\&F resources that might come into existence in the future. In the first set the participants were told to assume that each resource would be available. The task here was to estimate the probability of significant use of each resource. (The results of question set one are given in fig. 5.) $)^{1}$ The second set took a step backwards and assumed that none of the eight resources actually exist now. The task for this question set was to estimate how much "pressure" the participants' sector would exert to bring them into existence. The third set dealt with general technologies (each dependent on T\&F) and their probable future importance to the sector in which the participant was employed.

The major motivation for the second set was to partially check the validity of the answers to the first set. The result was usually a very strong positive correlation. The primary purpose of the third set of questions was to check on my prediction that there is likely to be a very extensive alldigital telecommunications network in the U. S. by $1980-1985$.

The first column ("Negative" Responses) is formed by adding the "Virtually Impossible" and "Relatively Unlikely" responses. This is done for each of the years 1980 (cross hatch) and 1985 (solid). The "Positive" Responses column is formed in a similar way. For either of the years, the reader should compare the relative sizes of the "Positive" and "Negative" responses.
To give the reader a feeling for the economic rationale behind the first two areas of probable change, I will examine the four detailed industrial studies at lenath.

The forecast of a widespread network of clocks, synchronized somewhere in the range of 1 to $10 \mu \mathrm{s}$, is based in large measure on a study of the telephone industry [12]. This prediction, in turn, rests on the forecast of a widespread, al1-digital, telecommunications network.

There are some large economic advantages to digital as opposed to analog transmission, but to adequately realize these advantages, the switching offices (at least the major ones) must operate digitally. In reference 12 (which is quite detailed) I show that there is already a powerful trend toward digital transmission. In addition, there are advanced plans to replace a major part of the analog switching network with digital switching. The implementation of these switching changes will begin to occur in 1976. Both the transmission and switching aspects of the all-digital network have timing requirements. But, does this mean that a network of synchronized clocks (to 1-10 $\mu \mathrm{s}$ ) is economically justifiable? I believe that there are at least three reasons to think that it is.

First, such a system would make the access to an all-digital telephone network much easier, probably proving economical for the telephone industry in the long run. In addition, the actions of the federal government in recent years indicate that the telephone industry will probably be forced to permit greater access to $i$ ts (the telephone company's) system. If so, the timed network would facilitate this access. Second, one major telephone system (Be11-Canada) already has a small version of such a system in operation. Third, there was a strong consensus (displayed in item 7 of fig. 5) in response to the Delphi Study that such a system would be put to significant use. Another important supporting factor is the potential use of such a system by the military. One group within the Defense Communication Agency feels that such a timed network would be very valuable. Within the continental U.S. . the telephone industry provides the bulk of military communications, a possible factor in encouraging the telephone industry to install such a system.

The telephone industry probably has the greatest motivation and the most resources for setting up an extensive network of synchronized clocks. This is not, however, the only means by which such a network could come into being, and in fact, there aiready exists a network of clocks synchronized to better than 1 us. This network is operated 
[For details about the interpretation of this figure see Appendix A.2]
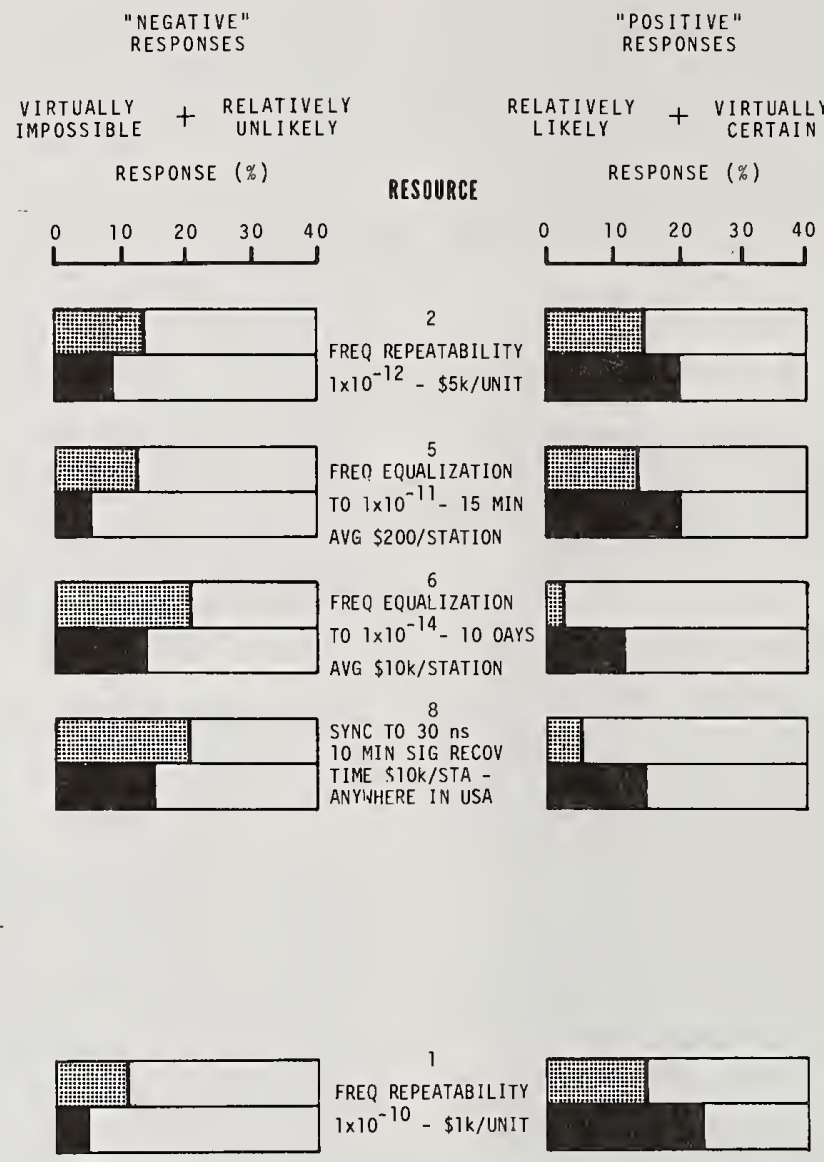

1
FREQ REPEATABILITY $1 \times 10^{-10}-\$ 1 k /$ UNIT

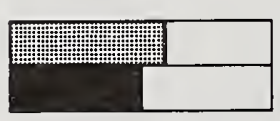
3
FREQ REPEATAB ILITY
$1 \times 10^{-14}-\$ 15 \mathrm{k} /$ UNIT
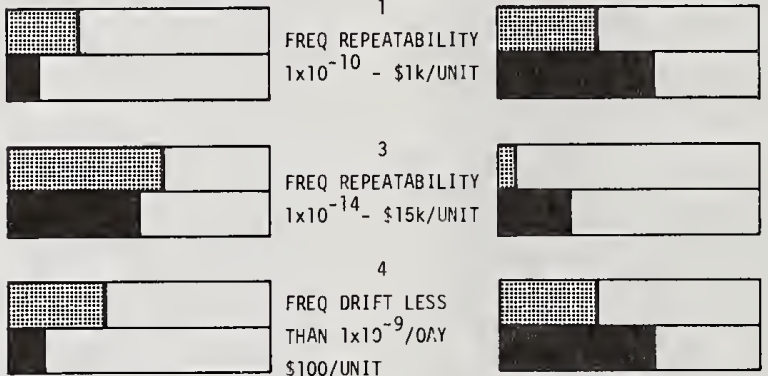

4 FREQ DRIFT LESS THAN $1 \times 10^{-9} / 0 R$. $\$ 100 /$ UNIT
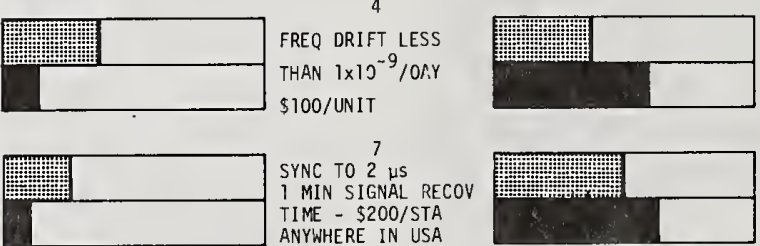

7 SYNC TO 2 HS
MIN SIGNAL RECOV TIME - \$200/STA ANYWHERE IN USA

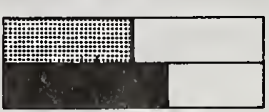

1980

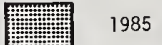

Figure 5. Responses to set 1 of the Delphi questionnaire 
by the Department of Defense and is synchronized by the Defense Satellite Communications System. The satellites obtain a time reference from the USNO. The system contains a total of about 33 clocks, with 9 in the continental U. S., the rest spread around the world.

In conjunction with NASA, the T\&F Divison of NBS is planning to provide a timing service based on satellite broadcasts and covering the entire U.S., beginning about 1979. Present evidence indicates that the service will allow time to be recovered on the ground to an accuracy of a few microseconds. The cost (in 1975 dollars) will be about $\$ 200$ per site.

It now appears that two other major industries would make use of the 1-10 $\mu$ s network if the clocks were strategically available. The electric power industry has one present and one potential use for such a system. The present use is for fault location: a clock accuracy of 1 us would permit location of a fault to within a thousand feet. A network that was synchronized to the order of 10 to $20 \mu \mathrm{s}$ would allow the measurement of phase angle of the current and voltage to about one degree, possibly capable of providing better system control than the present method. The previously estimated cost (for the NBS satellite services) of $\$ 200$ per station would probably be economic for the phase angle application and maybe for fault location.

The aviation industry is in need of an improved but low-cost air-collision avoidance system. One such system using a network of timed clocks has been proposed which requires a timing accuracy of 1 us or better [33].

One final application is the accurate location of position on the surface of the earth. Section 2.5.2.4 describes a position location system that makes use of transmitters carefully controlled in phase. These stations require phase control to about 0.1 us. However, a widely available, lowcost capability of a few microseconds, such as provided by the NBS satellite service, would be a welcome complementary system. Time dissemination systems and position location systems are intimately related, relying on precisely controlled phase of their transmitter(s). The National Bureau of Standards has attempted to show that a position location system can do double duty, serving sometimes for time dissemination as well as position location. Some systems have very wide coverage, such as Loran C and Omega, and are almost always federally owned and operated. In such cases, it is more economic for the taxpayer, to design an easily usable time signal into the system right from the beginning.
In summation: there are several major organizations which would probably use a widespread 1 to $10 \mu \mathrm{s}$ timed network if it existed, but the telephone industry is the most likely to set up such a system. The planned NBS satellite service will be sufficiently low in cost and easy to use that it should attract a great number of users.

Consider now the probable market for an improved frequency equalization capability. The NBS stations WWV-VH provide such a service at the $1 \times 10^{-7}$ level as do a few other standard frequency broadcasts. The service is widely available, easy to use, and at the fairly low cost of about $\$ 250$ per site. At a level of $10^{-7}$ and better, the costs go up to a little over $\$ 2000$ per site, and at about $1 \times 10^{-9}$ the amount of operator effort and skill begins to rise sharply.

I have identified six areas where frequency equalization to better than $1 \times 10^{-8}$ but probably not better than $1 \times 10^{-10}$ is needed:

1.) The FDM system of the telephone industry needs about $1 \times 10^{-10}$ ( see sec. 2.5.2.3).

2.) The Dataphone Digital Service of AT\&T needs $2 \times 10^{-9}$ or better [34].

3.) At least 70 of the NCSL-member standards laboratories need better than $1 \times 10^{-6}$. Unfortunately, we don't know how much better. However, we do know that 17 laboratories in this group own either cesium or rubidium standards or both.

4.) According to reference 33, that version of an air-collision avoidance system, ACAS, needs $1 \times 10^{-8}$. Unlike the previous three items, this system is hypothetical. It has been proposed to the FAA but is not under construction.

5.) If the more stringent specification on TV broadcasts now being considered by the FCC goes through, the requirement will be about $1 \times 10^{-9}$ (see sec. 2.4.4).

6.) The portable units in the military's Global Positioning System (GPS) have a requirement in the range of $1 \times 10^{-8}$ to $1 \times 10^{-10}$.

Each needs a method requiring a very small amount of operator time with five of the six needing one requiring little operator skill. Five of the six could use either a dissemination technique or a low-cost oscillator that is sufficiently accurate. Because of the military need for portability, the GPS and certain other military applications would need an accurate oscillator. The TV "color burst" system, which has been extensively developed by the T\&F Division of NBS, 
is technically suited to meet the needs of the first five areas. It has been shown to yield frequency comparison (which is basically equivalent to equalization) to a few parts in $10^{11}$, with only 15 minutes of averaging time. The cost per site is present1y about $\$ 500$. Items 1 and 5 in figure 5 give additional support to the idea that frequency equalization needs at this level of precision or higher are likely to exist. I claim that the market exists today in areas one through three.

It is important to predict the size of the potential market in these six areas. For the first, I have already estimated 1,000 (see sec. 2.5.2.3). The second application could probably use about 200 by 1977 . A guess for the third area is 30 . If the fourth application came into existence, the requirement would exist in each of about 2,300 commercial jet airliners and about 100 ground stations [27]. In the fifth area, there are presently over 920 commercial TV broadcast stations and each is a potential user. The sixth area is poorly determined, but potentially is extremely large: NBS personnel estimate the total military navigation market to be about 50,000 , most of which would be in the GPS system.

There appears to be a potential market for a $1 \times 10^{-10}$ to $1 \times 10^{11}$ "dissemination" system at a cost of $\$ 1,000-2,000$ per unit of 4,500. That for an oscillator accurate to $1 \times 10^{-10}$ at about the same price should be over 50,000.

Finally, major needs for frequency equalization beyond the $1 \times 10^{-10}$ level will probably be a part of a need for time synchronization (see sec. 2.5.1.2.3.2). If the timed network discussed in this section comes into existence, requirements for frequency equalization to about $1 \times 10^{-11}$ will probably accompany it, existing at up to 2,000 sites by 1985-1990.

\section{SURVEY OF NBS SERV ICES}

\subsection{The Past 1}

\subsubsection{Developments up to 1923}

In 1911 the development of radio technology had come to the point where NBS was

\footnotetext{
IThe history of NBS T\&F activity given above is drawn in large part from the very detailed and excellent history written by Mr. Wilbert F. Snyder of NBS. The information used here was taken from chapter 8 of Mr. Snyder's history of radio work at NBS which will be published sometime in 1977 and is listed here as reference 35 .
}

asked to perform its first wavemeter calibration. (For many years the measurement of frequencies associated with radio transmission was performed by devices known as wavemeters. It wasn't until 1923 that devices of this type came to be known as frequency meters.) This initial calibration was performed with a resonant LC circuit. For the first few years, the calibration of the circuit was in terms of low frequency inductance and capacitance ( $L$ and $C$ ) measurements made upon the inductor and the capacitor. By 1918 the $L$ and $C$ of the wavemeter were being determined by calculation. The accuracy of the total measurement was no better than about $1 \times 10^{-2}$ at this time. The accuracy was established by comparison with the rotation rate of the earth about its axis, this being the accepted definition of frequency until 1956. The calibration of the LC wavemeter with respect to the rotation of the earth is circuitous but interesting: the frequency of the resonant circuit is given by the formula $f=1 /(2 \pi \sqrt{L C})$. Both the $L$ and $C$ were expressed in terms of their geometry and absolute dimensions. This relationship to length is then convertible to the inverse of time interval (i.e. frequency) via the invariant relationship between the wavelength of an electromagnetic wave and its frequency the speed of light.

One of the basic problems of determining the accuracy of a given frequency measurement has aTways been that of relating the frequency to be measured to the prevailing definition of frequency. The difficulty is that they are often different in frequency by orders of magnitude. For example, the frequency of the rotation of the earth on its axis is about 12 micro hertz. A typical resonant frequency for a tuning fork is one kilo hertz. Thus, the frequency ratio is about $10^{8}$. In practice what usually happens is that one or more transfer standards are interposed between the device to be calibrated and the device which is the physical realization of the definition of frequency. A good example of this occurs when, in later years, the LC wavemeter was calibrated by a tuning fork. ${ }^{2}$ In this instance the tuning fork was, in turn, calibrated by a pendulum clock and finally the pendulum was calibrated by the earth's rotation. This calibration and apparently some basic limitations of the LC circuit, limited the accuracy of the LC wavemeter to about $1 \times 10^{-3}$, despite the fact that the accuracy of calibration of the tuning fork was a little better than $1 \times 10^{-4}$.

2By 1917, tuning forks were being used as frequency standards by the Sound Division of NBS. By 1922, these devices were also used in the calibration of the LC wavemeter. 
The problem was the same in measuring time because the period of one rotation of the earth (one day) is too long for many human applications. A period of about one second is a more appropriate base unit. What was needed was a "flywheel" which could provide a shorter base unit but could still be calibrated in terms of the earth's rotation. A practical flywheel is one which repeats its basic behavior - "motion" - for at least one day. Pendulums served this function very weil for about two hundred years (see fig. 1).

Thus, both frequency and time measurement are faced with the fact that the frequency (period) of the device to be calibrated is usually grossly different than that of the source of calibration.

Today, the definition of time interval (and therefore frequency) is in terms of a cesium atom transition at about $9.2 \times 10^{9} \mathrm{~Hz}$. Yet the problem is much the same. A useful base unit of time interval is now about $10^{10}$ times longer (instead of shorter) than the definition in terms of cesium. Also, many important frequency applications are for frequencies much less than $9.2 \times 10^{9} \mathrm{~Hz}$. Thus, frequency "dividers" must be used to translate the frequency of the primary standard to lower frequencies and longer time intervals, and frequency multiplication must be performed to measure those frequencies that are higher than that of the primary standard.

The LC wavemeter was to serve as the NBS standard for radio frequency for about eleven years, from 1918 to 1929, although by 1920, quartz crystal oscillators - which would replace the LC wavemeter - were becoming of technological importance. The real push for measurement of radio frequencies did not come until the early 1920's with the advent of radio broadcasting: closely associated with this was the development of quartz oscillator technology.

The first NBS experience with crystal oscillators came in 1920 with a requirement for calibration of four of them. These oscillators were the first of many sent to NBS by Professor W. G. Cady of Wesleyan University. In 1923, NBS calibrated seven of Professor Cady's oscillators, ranging in frequency from $14.5 \mathrm{kHz}$ to $763 \mathrm{kHz}$. These same oscillators had also been studied by six other laboratories, five of which were in Europe. The general agreement among laboratories was of the order of $1 \times 10^{-3}$ - quite an achievement considering the early stage of quartz technology and the difficulty of the measurement.
4.1.2 Frequency and Time Standard Develop- ment in the Period 1923 to 1947 Including the Activities of NBS Station WWV

By 1924, NBS was studying quartz crystals for use both as standard frequency oscillators and as a means of controlling the transmissions of radio broadcast stations. This work was sorely needed because, by 1922 , there were $570 \mathrm{U}$. S. broadcasting stations operating within a $1000 \mathrm{kHz}$ band. At this time, the ability of a broadcaster to control the frequency of his transmission was insufficient. A real problem existed in reducing broadcast interference and NBS took two basic approaches towards its solution. The first was the development of frequency reference test sets, and the second was the estab1 ishment of a standard frequency broadcast station. This station, now located in Fort Collins, Colorado, whose call letters were (and still remain) WWV, went on the air March 6, 1923.

By late 1925, NBS had developed a broadcast frequency test set which could be used in the field, an oscillator with a quartz crystal as its resonant element. In February, 1927, the Congress created the Federal Radio Commission with the hope of reducing interference between broadcast stations. This organization, renamed the Federal Communications Commission in 1934, specified a tolerance of 500 hertz on the carrier frequencies of broadcast stations. The National Bureau of Standards was given the responsibility of checking whether this specification was being met. The NBS studies into the temperature stabilization of quartz crystal oscillators (beginning in 1927) resulted in helping to meet this responsibility to the Federal Radio Commission and in improvement in the NBS frequency standard.

In February, 1927, NBS organized a conference among U.S. laboratories for the purpose of further development of quartz oscillator frequency standards. Three of the eight laboratories involved (Naval Research Laboratory, Bell Telephone Laboratory, and NBS) began a comparison of seven quartz frequency standards. By 1929, this resulted in oscillators and measurement techniques showing a frequency accuracy of $1 \times 10^{-5}$.

Quartz oscillator technology has been fundamental to the telephone industry for over 50 years. Indicative of this is the fact that NBS contracted with Bel1 Laboratories to construct four temperature-controlled, $100 \mathrm{kHz}$ quartz oscillators to form the heart of a National Primary Standard of Radio Frequency. These devices were delivered to NBS in August, 1929. The technology had developed to the point that frequency differences between the oscillators as small as $1 \times 10^{-8}$ could be detected.

A submultiple output of $1000 \mathrm{~Hz}$ from the frequency standard system was used to drive 
a clock synchronized to mean solar time from the USNO via radio broadcast. One very important result of this cooperation with the observatory was that the quartz frequency standard system was found to be drifting at the rate of about $1 \times 10^{-7}$ per month.

Even with this limitation in long-term stability, quartz oscillators had become of great importance to radio broadcasting. In particular, they served both as a means of calibration and as a control of station WWV. It is important to trace the development of this station along with quartz oscillators and, later, atomic oscillators with which it is so closely associated.

By 1926, the development of quartz osci1lators and the general development of frequency metrology had resulted in several broadcast stations that could be used as reference standards. In that year, for various reasons, NBS suggested the termination of the WWV broadcasts, which caused such serious objection from WWV's users the idea was abandoned. Moreover, the termination of the broadcasts has never been seriously considered since.

Initially, WWV was located on the Bureau grounds in Washington. In January, 1931, the station was moved to College Park, Maryland just outside of Washington, D. C. In Dec., 1932, the station was moved to Beltsville, Maryland where it remained until 1966 when it was relocated to Fort Collins, Colorado.

In 1932 the broadcasts were on just one carrier frequency, $5 \mathrm{MHz}$. By 1937, the station operated on carrier frequencies of $5,10,15$, and $20 \mathrm{MHz}$. The carriers were modulated so that they delivered standard audio frequencies of 440 and $1000 \mathrm{~Hz}$ and time "ticks" spaced one second apart. The carrier frequency accuracy was now about $2 \times 10^{-7}$.

In June, 1944, a cooperative program was begun with the USNO when the time signals of WWV were synchronized with theirs and standard time was broadcast at five minute intervals in telegraphic code. By 1947, calibration with mean solar time via the USNO showed that WWV was broadcasting with a carrier accuracy of $2 \times 10^{-8}$. In 1950, voice announcements of time of day were begun.

By 1952, the National Standard included six crystal oscillators plus eight quartz crystals used passively as resonators. Frequency comparisons were made daily between all the units to a precision of about $1 \times 10^{-10}$. The stability of the National Standard was now at a level which made the daily fluctuations and longer term fluctuations in the rotation rate of the earth easily discernible.

The quest for accuracy is a search for environmental independence. In a general sense, it is a seeking for primary standards that are based on fundamental constants of nature and not upon artifacts of humanity. Since accuracy can never be any better than precision, part of the search for accuracy has also been one for stability. Thus, quartz oscillators replaced the LC wavemeter partly because they permitted a higher precision of comparison. The pendulum clock, because it could act as a stable flywheel, allowed the translation of the definition of time interval, given in terms of the earth's motion, into a working standard. Quartz oscillators served the same function as the pendulum clock. As the technology of quartz oscillators grew, their stability improved sufficiently (better than $1 \times 10^{-8}$ for one day's averaging time) to detect nonuniformity of the earth's rotation rate. Thus, al though the earth's rotation has the desirable property of not being a human artifact, it lacks the invariance with time that is so devoutly sought in a primary standard. Even though the ability to keep stable time was improving rapidly because of the use of quartz oscillators, the situation was undesirable from the point of view of a primary standard. The stability of quartz oscillators averaged over a few days' time, was better than that of the earth's rotation rate. On the other hand, the earth had the naturalness the lack of human intervention - which quartz lacked. This brings me to the last facet of the story: the development of atomic frequency standards.

\subsubsection{Atomic Standards and Further Improve- ments in the Broadcast Services}

Fundamentally associated with the development of atomic frequency standards was the development of the technology of microwaves. ${ }^{1}$ Microwave technology developed rapidly during World War II and was closely associated with radar. As part of this effort, NBS, in 1944 , undertook the development of a microwave frequency standard. The project resulted in a standard which was accurate to $1 \times 10^{-7}$. Work of this type gradually built up the technology - including frequency multipliers and mixers - that was essential to the development of atomic frequency standards.

In 1879, Lord Kelvin, using a suggestion by James Clerk Maxwe11, proposed the use of a toms of hydrogen and sodium as natural standards of frequency and length. The first "atomic" frequency standard, however, was based not upon an atom, but upon the ammonia molecule. Important in this development were the microwave spectroscopic observations that were performed at the University of Michigan around 1934. The ammonia standard, based upon the absorption cell principle [36], was used for the first time as a clock on

The microwave frequency range 1 ies, roughly, between $1 \mathrm{GHz}\left(10^{9} \mathrm{~Hz}\right)$ and $40 \mathrm{GHz}$. 
August 12, 1948. This clock demonstrated a stability that was greater than that of the rotation of the earth on its axis but not quite as good as the earth in its orbit around the sun.

The absorption cell technique was the first to be used in an operational a tomic clock. Many people felt, however, that an atomic beam technique [36] would produce a device of greater stability and accuracy. As early as 1945, Professor Isador Rabi of Columbia University suggested the beam technique for use as a frequency standard. In the summer of 1949, a project to exploit the beam technique for a frequency standard was begun at NBS. The atom selected was cesium and Professor Polycarp Kusch of Columbia University was employed as a consultant. A year earlier, Professor Charles H. Townes (also of Columbia University) was employed as a consultant in a project to study the microwave spectra of gases and solids. ${ }^{2}$

The physics and engineering considerations that resulted in the present state of the art in atomic frequency standards are beyond the scope of this work. The reader who is interested in this fascinating subject can profit from reading chapters $3,4,5,6$, and 7 of reference 4 and, also, reference 13 .

Station WWVH is one of the three NBS standard time and frequency stations. Located in the Hawaiian Islands, it began broadcasting in 1948. Its broadcast format is essentially that of WWV and the station is designed to provide T\&F service over much of the Pacific Ocean and surrounding lands. In 1954, most of the radio activities of NBS were moved to Boulder, Colorado: among those were the National Standard for Radio Frequency (the ensemble of quartz oscillators), the ammonia clock, and the first cesium beam frequency

standard. Even though the quartz ensemble was now located in Boulder, it was still used to monitor the broadcasts of WWV near Washington. This monitoring-at-a-distance was not new to NBS. A related task had been performed earlier for the Federal Radio

\footnotetext{
2It is interesting that three of the people who have worked on the NBS frequency standards and spectroscopy activities later won Nobel prizes in physics. Walter $H$. Brattain, who worked on the temperature stabilization of quartz oscillators in the late 1920's, won the 1956 prize for the discovery of the transistor effect. Polycarp Kusch won the 1955 prize for the determination of the magnetic moment of the electron. Charles $\mathrm{K}$. Townes won the 1964 prize for work demonstrating the principles of the maser.
}

Commission and since 1948, we have been monitoring the carrier frequencies of WWVH. One result of this monitoring-at-a-distance was the establishment of the third NBS broadcast station, WWVB. Measurements of the WWV broadcasts showed that the received signal could be in error in frequency by as much as $4 \times 10^{-8}$. This error resulted because of the Doppler shift from the moving ionosphere [8]. Station WWVB, operating at the much lower carrier frequency of $60 \mathrm{kHz}$, was set up to reduce this effect. The initial broadcasts originated from the Boulder Laboratories of NBS and began in 1956. Both WWVB and WWV were later moved to Fort Collins, Colorado, 50 miles northeast of Boulder.

The first NBS cesium beam frequency standard was in operation by 1958 as the NBS working standard of frequency and became known as NBS-1. It was used to study the frequency stability of the WWV broadcasts. By spring, 1959, a second NBS cesium beam standard was in experimental operation, known as NBS-II. NBS-I and NBS-II were intercompared and found to agree in frequency to about $1.5 \times 10^{-11}$, meaning that devices now existed which provided the physical basis for a new definition of frequency. From 1956 to 1967 , the official definition of frequency was based on the rotation of the earth about the sun (the ephemeris second). The precision with which this motion can be determined - and therefore, its accuracy - is about $1 \times 10^{-9}$. Thus there was evidence that a definition of the second based on the cesium atom could be at least 100 times better than that based on the earth's orbit about the sun. The way was open for basing frequency on the microscopic world of the atom instead of the macroscopic world of the earth.

On January 1, 1960, NBS-II was officially adopted as the U. S. Frequency Standard. The broadcast stations WWV, WWVH, and WWVB were now being controlled as well as monitored by NBS-II. (Commercial cesium beam standards were used at the stations themselves and NBS-II was used to correct long-term errors. Construction of a third cesium beam standard NBS-III, with a demonstrated accuracy of a few parts in $10^{12}$ - was begun in 1959 , becoming the new U. S. Frequency Standard in September, 1963. By now, a time scale was in operation at the Boulder Laboratories, based on an ensemble of commercial quartz oscillators. The rate (frequency) of this ensemble was regularly calibrated by the NBS primary standard. In Apri1, 1963, the time scale broadcast by WWV, by setting a quartz clock in Boulder and transporting it to the WWV transmitter in Maryland, was brought into synchronizm with the Boulder time scale to within $5 \mu \mathrm{s}$. The WWVB transmitter was moved to Fort Collins, Colorado 
in July, 1963. Its carrier frequency was controlled by NBS-III to approximately $2 \times 10^{-11}$. On November 30,1966 , station WWV was shut down at its Maryland site and transmission was begun at Fort Collins, Colorado.

In October, 1967, the 13th General Conference of Weights and Measures (CGPM) officially defined the second in terms of a transition frequency of cesium. On June 30, 1972, the NBS radio stations (as well as many other standard T\&F stations around the world) made the first "leap second" correction to its time broadcasts, an action recommended by the International Radio Consultative Committee (CCIR) to compensate for the fact that a time scale based on the atomic definition of the second runs at a rate some $3 \times 10^{-8}$ faster than that based on the rotation of the earth on its axis as of $1972 .^{3}$

The T\&F Division of NBS continues to work at both oscillator development and the means of dissemination by which the signals generated by those oscillators can be transmitted. NBS-II I has been replaced by NBS-4 and NBS-5, both based on the cesium beam technique and demonstrating an accuracy of about $5 \times 10^{-13}$ and $1 \times 10^{-13}$ respectively. They are both used in calibrations of the NBS time scale.

The ensemble of eight commercial cesium beams that currently makes up the NBS time scale is also used to control the broadcasts of the NBS radio stations. The NBS time scale is presently synchronized to that of the BIH to within one microserond.

Since the frequency standards activity has been moved to Boulder, studies of the thallium and hydrogen atoms and the ammonia molecule--as applied to frequency standards-have also been conducted. Work with the thallium atom and the ammonia molecule was terminated several years ago; but work with hydrogen continues, showing promise for a very useful secondary, if not a primary, standard. In recent years, work in the T\&F and other divisions of NBS on the molecular stabilization of lasers has shown promise for frequency standard applications. Investigations of short-term stability are important in several applications of time and frequency standards, including the primary standard. To this end, development of quartz oscillators still continues; and a new project, the superconducting cavity oscillator, is underway.

\footnotetext{
उI mentioned that some applications, such as celestial navigation, must have apparent solar time, but there are some applications that depend upon the stability of atomic time. See Section 2.5.2.5.
}

Research and development in dissemination techniques is also being emphasized. Over the years, division personnel have studied the characteristics of the Loran- $C$ and Omega systems, as well as dissemination via satellite and line-of-sight microwave (TV) systems. The satellite and TV projects are active at the present time. Results from the satellite project indicate the possibility of at least a partial replacement of the NBS broadcast stations by 1980 . L'npublished information available today indicates that a standard T\&F broadcast via satellite could be operated at a significant cost reduction over the present broadcast services. The quality, too, shows promise of being significantly improved.

The TV technique (which makes use of the rubidium frequency standards used by the major television networks) will probably prove to be an important substitute for some of the frequency services of the NBS broadcast stations. The technique can be particularly useful to those who need 9 frequency -11 accuracy in the range of $1 \times 10^{-9}$ to $1 \times 10^{-11}$ One very important application of the technique is in the slaving of stations WWV and WWVB to the NBS time scale. With this method, the signal as broadcast from Fort Collins, is in synchronism with the time scale to within 30 nanoseconds $\left(30 \times 10^{-9} \mathrm{~s}\right)$. It also allows a very accurate frequency comparison - in long-term - with the NBS primary frequency standard, Comparisons to the order of $1 \times 10^{-12}$ have been achieved.for averaging times of about one week.

\subsection{The Present: Scope of NBS Services}

\subsubsection{Description of NBS Services}

The Time and Frequency effort of NBS, as it is presently constituted, is mainly located in two sections. The section responsible for broadcast services and dissemination research is called the Time and Frequency services Section. The other section, Frequency-Time Standards, is responsible for the primary frequency standards, the time scale, and research towards new standards and measurement methods.

In Fiscal Year 1975 there were 15 major projects active within these Sections. It is useful to classify these projects in terms of the first six of the "outputs" discussed in section 2.5.1.1. Using this description to categorize the outputs, the FY 75 projects are distributed as follows: 
A. Source

B. Signa 1

C. Receiver

D. Dissemination Means

E. Publish

F. Consult

Seven of the fifteen projects are significantly described by two and not just one output. In those cases I have estimated which one of the two outputs best describes the project and used that description.

Describing the Sections in terms of outputs versus dollars spent (in FY 75 ) results in:

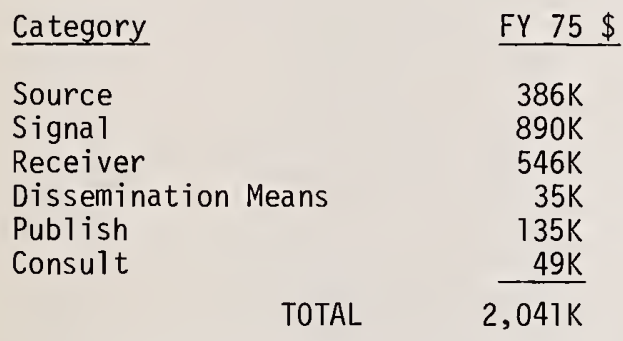

A significant part of the effort that goes into the categories of Source, Receiver and Dissemination Means, is motivated by a desire to maintain or improve the quality of the signal at the user's site. Moreover, when calibration is performed at the site of the primary standard (or time scale) the Source and the Signal become indistinguishable.

Time and Frequency Division personnel currently participate in the following T\&F standardization organizations:

- Department of Defense Coordination Committee for General Specifications of Crystal 0scillators

- IEEE Administrative Committee

- IEEE Technical Committee on Frequency and Time, Subcommittee on Frequency Stability

- IEEE Technical Committee on Frequency and Time, Subcommittee on Time

- CCIR Study Group IV

- T\&F Subcommittee of Federal Telecommunications Standards Committee

- CCIR Study Group VII

- IAU Com. 31

- URSI Com I

- CCIR, International Delegate to Plenary Session of Study Group VII

- Consultative Committee for the Definition of the Second

At any given time, some Division personnel are likely to be involved in trying to help
Solve a time or frequency problem for some other organization or group. This may be only consultation or it may be an experimental or theoretical project. At the present time there are two such activities: 1.) consultation and experimental effort for industry and the military on atomic oscillators to be used with the Global Positioning System (see also sec. 2.5.1.2.3.1); and 2.) consultation with U. S. Navy Standards Laboratories about the use of the TV frequency-equalization technique. [38]

In describing the realized measurement capabilities of the Division, I will restrict the discussion to that of the performance of our several sources. The reason is that the quality obtainable from our broadcasts strongly depends on the user's circumstances. The quality finally obtained will depend on at least four factors: 1.) the user's location with respect to the transmitter; 2.) the quality of his receiving equipment; 3.) his ski11; and 4.) the amount of time he is willing to spend averaging the signal.

The experimental and theoretical ability to characterize frequency standards has grown tremendously over the years as has the quality of these standards. The NBS has played a significant part in this development. Advancements in the state of this science have been particularly great since the introduction of atomic oscillators. Referring to figure 3 , the reader will notice that no one type of oscillator can be said to have the highest quality. Quality depends upon the averaging time, $\tau$, in which the user is interested. For example, in the range $1<\tau<10^{3}$ seconds, the superconducting cavity osciltator is superior to any other known type of device. On the other hand, for averaging times of months and years, this type of oscillator would probably not be as good as the cesium device. I say probably, because such experiments have not yet been tried.

In figure 6 , the $\sigma_{j}(\tau)$ versus $\tau$ curves of four types of devices ${ }^{y}$ in operation at NBS are shown. ${ }^{1}$ The dotted curve shows the proven capability of our measurement system,

specifying the quality of the best oscillator which we could now measure if an oscillator of such quality existed.

To our knowledge, no other measurement system exists which is the equal of this over the range indicated. The four curves shown are good approximations of the stateof-the-art for each of these types of devices.

${ }^{\mathrm{I} A c t u a} 11 y$, the superconducting cavity oscillator is not yet in operation and the curve shows only our expectation of its performance. The device should be operating within six months to a year. 
Over the ranges in which each type of device is superior, we know of no other type of device which is better. It is important to reiterate that the present definition of time interval (frequency) is in terms of a certain transition of the cesium atom, which is therefore the basis for frequency accuracy. (The reader may wish to reread the discussion of accuracy in sec. 2.3.)

The primary standard, NBS -5 , with estimated accuracy between 1 and 2 parts in $10^{13}$, is our physical realization of the definition of frequency. It is essentially equal in accuracy to the best two other primary standards in the world. (See sec. 2.2.2.)

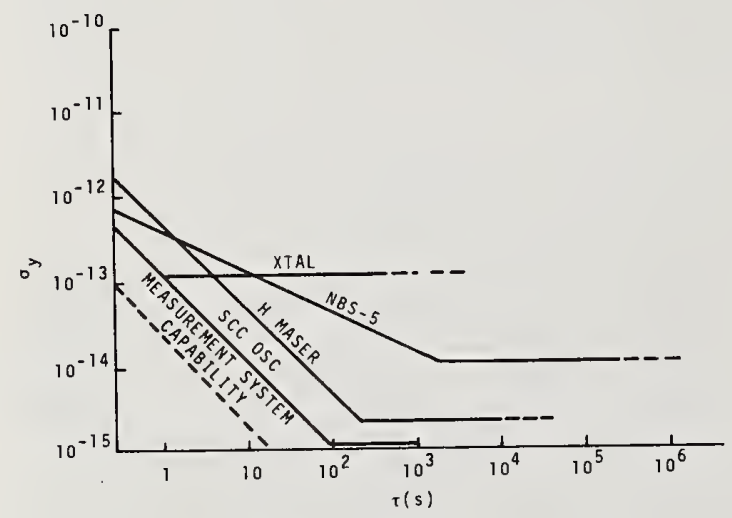

Fig. 6: Time-domain behavior of NBS sources and measurement system

Consider now the frequency-domain stability measure, $S_{y}(f)$. For Fourier frequencies, $f$, beyond about $100 \mathrm{~Hz}$, our capability is not as good as it needs to be. The upper two curves of figure 7 show the range of quartz oscillator stabilities that we are often asked to measure. Beyond about $100 \mathrm{~Hz}$, for the best oscillators, our measurement system is a Timitation. The oscillators were at least as good as our measurement capability and perhaps better. $[43,44]$

Although we know of no other measurement system superior to our own, our capability is, in part, inadequate, and we are attempting to improve it.

In reporting the capability of the Nationa) Measurement System, I have not dwelt on the actual performance in terms of $S_{y}(f)$. A description in terms of $\sigma_{y}(\tau)$ is usually adequate. There are cases, however, when a $S_{y}(f)$ description is at least helpful and perhaps indispensible. One such case is for primary standard research and development. The measurement of $S_{y}(f)$ both increases the understanding of the device and helps in its optimization [5]. A second occasion is for frequency multiplication of very high order, such as that between the microwave and infrared ranges, already proven to be of great importance to metrology $[16,17]$. When the multiplication is of high order, measurements of $S_{y}(f)$ of the lower-frequency oscillator are most useful $[39,40,41]$.

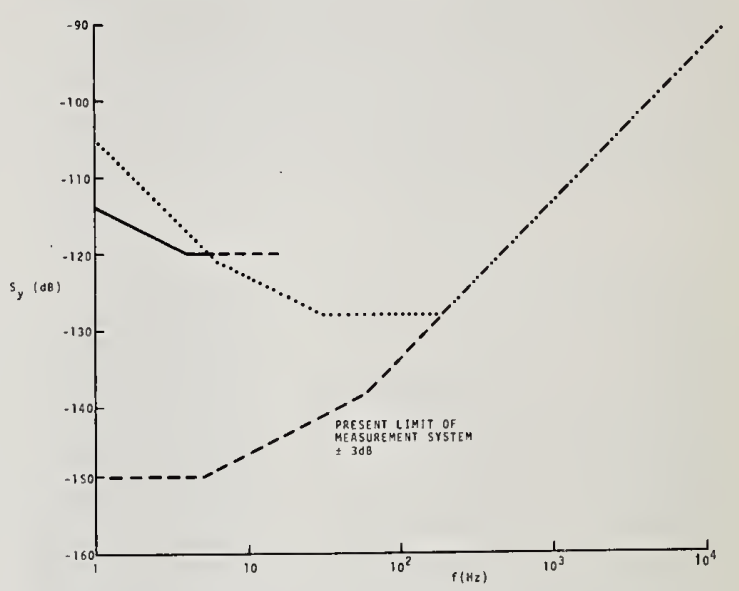

Fig. 7 Frequency-domain behavior of NBS sources and measurement system

The Division's activities should also be examined from the viewpoint of the Supplier/ Users matrix of section 2.5. In row 6 , with NBS as the supplier, the reader will observe some letters. They are the output categories listed in this section and in Section 2.5.1.1). In those cases where more than one letter appears, the first represents the output upon which the two descriptors were evaluated. (See sec. 2.5.1.2.1.) When two or more are given, the additional letter(s) represent outputs which are too significant not to mention.

I have, for convenience, again listed some of the areas in which the Division is involved. The sections in which the discussions appear are given parenthetically.

- Custody of national standards (2.2.2 $2.3,4.1$ )

- The international measurement system (2.4.1)

- Relationship to other central standards authorities (2.4.1)

- State and local offices of weights and measures (2.4.2)

- Regulatory agencies $(2.4 .2,2.4 .4$ )

- Relationship to lower echelon calibration laboratories and services (2.4.3, 2.5.2.1) 
- Role in the dissemination and enforcement network $(2.4,2.5,4.1)$

- Support of science, education, and the dissemination of knowledge (2.2.5, $3.1 .1)$

\subsubsection{Users of NBS Services}

The users of the NBS standard T\&F broadcasts are numerically our most important clientele. Moreover, as shown in sections $4.1,4.2 .1$, and 4.2 .3 , the broadcasts are strongly tied to the primary standards and the time scale. Thus, the services of the primary standard and the time scale are made widely available. This section will be confined to the users of stations WWV, WWVH, and to the NBS telephone time-of-day service. ${ }^{1}$

of the three NBS broadcast stations--WWV, WWVH, and WWVB--station WWV. has, by far, the most users with such widely varied applications that it is nearly impossible to obtain a comprehensive understanding of them. Nevertheless, the Division has completed an attempt to do just this, with a side benefit of an increase of the overall perspective of the National Measurement System for T\&F. In this section I attempt to summarize the results of the questionnaire sent to survey the users of the radio station services. The questionnaire is reproduced as appendix A.3., and complete results and discussion given in reference 42.)

Beginning on January 20,1975 , a questionnaire was sent out to obtain information about the users of WWV and WWVH. It attempts to determine who uses these stations, which of the severa] services they use, and for what applications they use them. Twelve thousand questionnaires were completed and returned.

At the present time both WWV and WWVH transmit eight categories of information:

- Time of Day: Voice
- Time of Day: BCD Code
- One second ticks

\footnotetext{
${ }^{1}$ The stations WWV and WWVH perform another service which is not directly related to T\&F but which is, nonetheless, quite important. The signals broadcast at each frequency leave the transmitters at' a fixed power level. Thus, a monitoring of the broadcasts versus time gives a person a good measure of the propagation conditions over this path and for these frequencies. It is the great reliability of our broadcast operations that allows this function to be served.
}

- Standard Frequency ${ }^{2}$

- DUT 1 values (DUT 1 is the difference between a mean solar time known as UT1 and an atomic time containing "leap" second adjustments which is known as UTC)

- Weather

- Geoalerts

- Propagation Forecasts

The questionnaire asks about degree of use and degree of importance for each of these categories. (For the category of standard frequency, it asks the same for each of the carrier frequencies.) The user is asked to identify both his organizational affiliation and his principle application for the T\&F service. Among the other questions asked is the degree of adequacy of the accuracy of the service.

Degree of use, importance, and accuracy were each to be judged in one of four possible qualitative categories. For degree of use the categories are frequently, sometimes, rarely, never. For degree of importance the categories are: very important, somewhat important, relatively unimportant, very unimportant. For accuracy they are: more than adequate, adequate, marginal, useless. The results are displayed in tables 5,6 , and 7 .

Table 5 quantifies the relationship between the eight broadcast services and the 14 organizational affiliations with respect to the degree of use of the service. The procedure for quantification is to assign the value, 0 , to each "never" response, the value, 1, to each "rarely", 2 to "sometimes", and 3 to "frequently." 3 These values are then summed for each of the eight services and for each of the 14 affiliations - 112 possibilities in all. The sums for each affiliation are then divided by the total number of respondents having that affiliation. The result, necessarily, is a number lying between 0 and 3 . These values appear in the individual elements of the matrix.

It is also desirable to have an overall view of the use of each service. This was obtained for each service by adding all the values for that service and dividing by the

"In "Standard Frequency" I include the carrier frequencies themselves and the audio frequencies of $440,500,600$, and $1000 \mathrm{~Hz}$ (1200 Hz at WWVH). The carrier frequencies are $2.5,5,10,15,20$, and $25 \mathrm{mHz}$.

${ }^{3}$ The reader should very carefully note the non-linearity of this scale. A linear scale would be more desirable but who knows how to quantify qualitative judgment? 


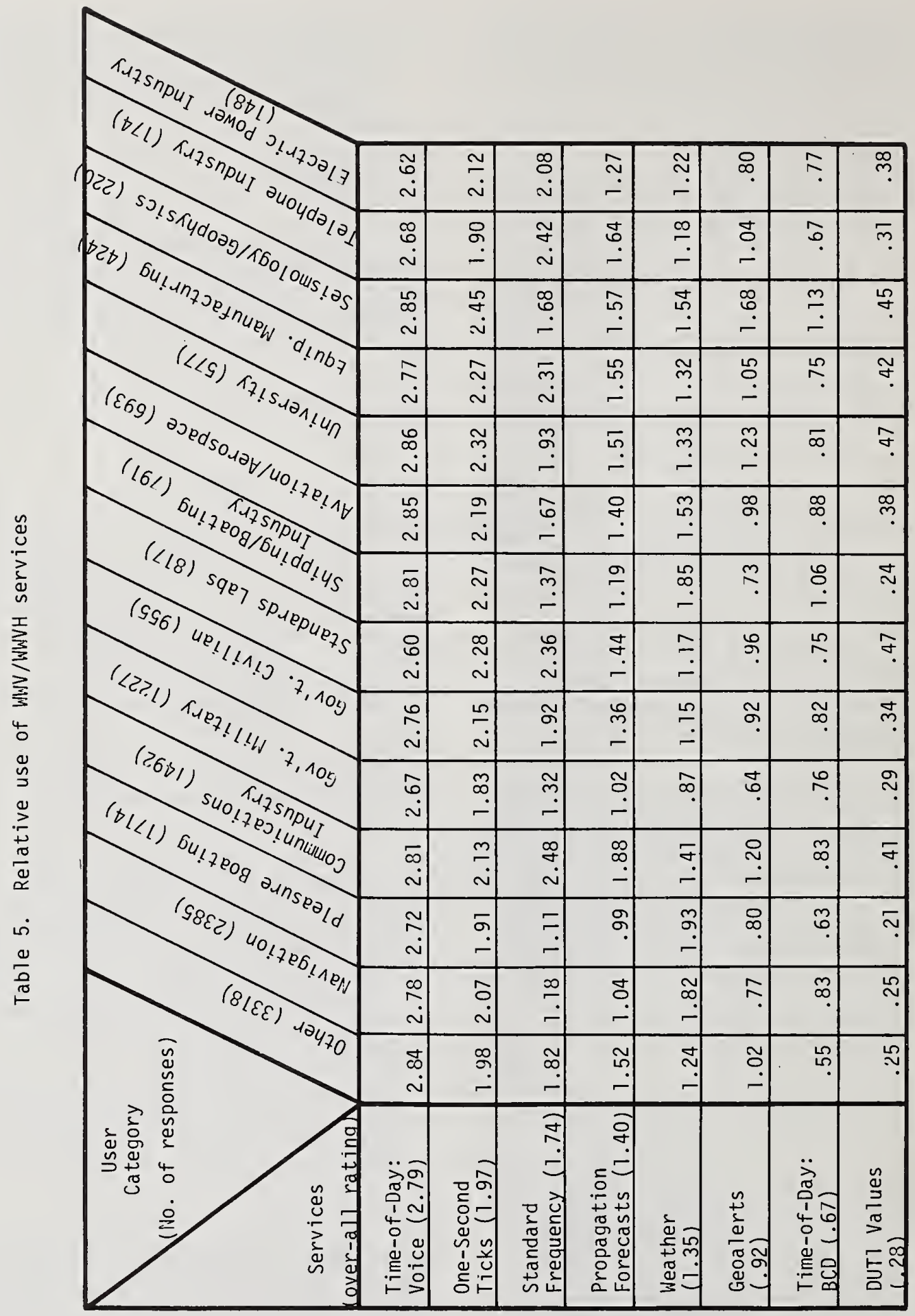


total number of respondents. These results are listed in parentheses following the service in the left column. Also appearing in the matrix, beside the column labels, are the total number of respondents for each affiliation.

Summarizing the "relative use" data: as a whole, the three most-used services are voice announcements of time-of-day, one second "ticks", and standard frequencies. Of those, voice TOD is by far the most used. Those affiliations whose use deviates significantly from the average are also apparent. Looking at the distribution of respondents as a function of affiliation, the result seems consistent with other things we know about the National Measurement System for Time and Frequency. The category of "other" is very large, probably because it contains a great many amateur radio operators. Other information has indicated that there are hundreds of thousands of amateurs.

This same procedure was followed in terms of relative importance. The results were so close to those of relative use (table 5) that I have not displayed them.

Using this same quantification scale $(\overline{0}$ to 3 ), the question of adequacy of accuracy was studied. (See table 6.) Probably the most important single conclusion is that, for the majority of users, the accuracy is at least adequate. It would be nice to know about the adequacy of accuracy of each of the eight services, but, to reduce the complexity of the questionnaire, it was decided to simplify by generalizing about all the services.

The response to the use of the six carrier frequencies shows that 5,10 , and $15 \mathrm{MHz}$ are by far the most used, with $10 \mathrm{MHz}$ being the most used of all.

The applications to which T\&F are put are shown in table 7 . The respondents generally checked more than one "principal use" so that the total is over 29,000 .

The NBS telephone time-of-day service was also investigated in the questionnaire. This revealed that a significant number of phone calls come from out of state, mostly from the East Coast, but some even come from out of the country.

In the last quarter of 1970 , certain T\&F information was made available from the Fort Collins stations via telephone. By dialing 303-499-7111, the user can hear the WWV broadcasts.

In the last quārter of 1970 , certain T\&F information was made available from the Fort Collins stations via telephone. By dialing 303-499-7111 the user can hear the WWV broadcasts. Counters were installed to tally the calls and records were kept of the number received per week. The results
Table 6: Adequacy of WWV-VH services to various users

\begin{tabular}{ll} 
Other & 2.54 \\
Communications & 2.49 \\
University & 2.47 \\
\hline Shipping/Boating & 2.43 \\
Gov't Mil. & 2.43 \\
Aviation & 2.42 \\
\hline Seismology/Geophysics & 2.41 \\
Telephone & 2.40 \\
Navigation & 2.40 \\
\hline Equip. Mfg. 2.41 \\
Gov.'t. Civ. & 2.40 \\
Pleasure Boating & 2.39 \\
\hline Stds. Labs & 2.39 \\
Electric Power & 2.31 \\
\hline \hline
\end{tabular}

Table 7: Distribution of respondents by principal use

\begin{tabular}{lr} 
Principal & $\begin{array}{l}\text { No. of people respor } \\
\text { that a given use }\end{array}$ \\
Use & \multicolumn{1}{c}{$\begin{array}{l}7149 \\
\text { terizes their use }\end{array}$} \\
\cline { 2 - 2 } Calibration of Watches/ & 3995 \\
Clocks & 3358 \\
Amateur Radio & 2793 \\
Instrument Calibration & \\
Propagation Forecasts & 2513 \\
Navigation/Position & 2468 \\
Location & 1813 \\
Storm Warnings & 1810 \\
Hobby (other than ama- & 1170 \\
teur radio) & 842 \\
Communications Systems & 641 \\
Geoalerts & 287 \\
Astronomy & \\
Scientific Data Monitoring & \\
Rocket/Satellite Tracking & \\
Other &
\end{tabular}

are shown in figure 8 . Two things should be noted about the figure: first, the growth in use has been rapid and, apparently, is still continuing; and second, the absolute number of calls is quite impressive, presently running about 17,000 per week. We estimate that the total number of calls for the whole of 1975 will be about one million.

All in all, I think it can be said that the NBS broadcasts and the telephone services have a large audience and many of these users appear to use the services as part of other important technologies. 


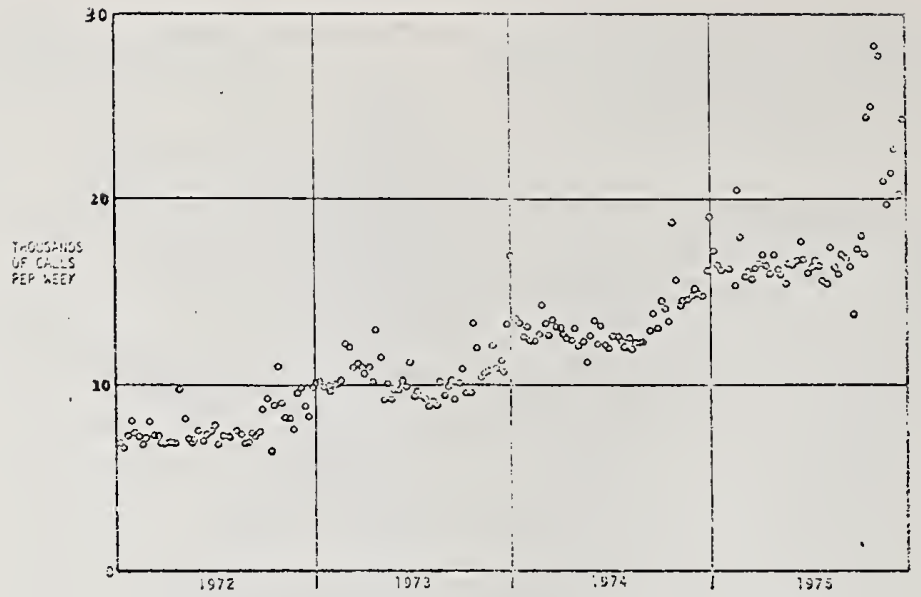

Figure 8: Calling rate for NBS

Time- of Day service (303-499-7111)

(A subsidiary but important function of the stations WWV - IIWVH is their relationship to measurement and prediction of radio propagation conditions [ 45$]$ ).

\subsubsection{Al ternate Sources}

The NBS time and frequency services have been extensively discussed in section 4.2.1. For the present purposes, it is useful to generalize a bit on what was said there. In considering alternatives I describe the Division's activities in three major categories: first, broadcast of standard T\&F, essentially the same as "Signal" in section 4.2.1; second, stable and accurate sources of T\&F, roughly equal to "Source" of 4.2.1; and third, research and development of dissemination-reception means for T\&F, combining "Receiver" and "Dissemination Means" of that section. The terms "Publish" and "Consult" are included in varying degrees in each of the three.

The "listeners" to our broadcast services clearly predominate numerically. For the large majority, the quality of the sources upon which our broadcasts are ultimately based is not a major consideration. (See sec. 4.2.2.) I will explain and then consider the need for a central agency which develops and operates very accurate (as well as stable) standards of T\&F. The discussion of these first two services will show the need for research and development in dissem- ination-reception. The point is that there is a need for a central agency which attempts to oversee the entire spectrum of T\&F technology. This point of view is the one from which the subject of alternatives to NBS services is best considered.

\subsubsection{Broadcasts}

We should separately consider the standard frequency and time interval services from those of date. The broad utility of the frequency services provided by the NBS broadcasts have been adequately covered in sections $4.2 .2,2.4$ and 2.5 . We should consider however, whether some other organization might not provide the same service on a more economical basis. It would be possible to simplify the operation for the vast majority of users of the frequency and time interval parts of our broadcasts, and the simplification would make a small reduction in the cost of operation. For these users the broadcasts could be based on three commercial cesium standards such as is being done in the new AT\&T system (see sec. 2.5.2.3). There would be no need for reference to a primary standard, and the accuracy of such a system would be about $1 \times 10^{-11}$. For almost al1 users, the received accuracy and stability would be as good as it is now. However, for those who need frequency accuracy greater than $1 \times 10^{-11}$ the control of the broadcasts 
by a primary frequency standard is indispensible.

Standard time intervals of, for example, a few seconds to a few years could also be generated to an accuracy of about $1 \times 10^{-}$ without a primary standard. Thus, over a whole year's time, the probable accumulated time error would be a few hundred microseconds. On the other hand, a time scale formed from a very sophisticated ensemble of commercial cesium standards, and calibrated by a primary standard, can keep time to a few microseconds over a year.

There are other countries with standard T\&F broadcast stations similar to WWV. Of these, Canada and Great Britain radiate signals which are of usable strength in restricted portions of the U.S. The U.S. Navy operates several standard T\&F broadcast stations, one or more of which is nearly always accessible anywhere in the U.S. However, the format of the Navy's broadcasts and the nature of their broadcasting schedule make them of significantly less general use than those of WWV, WWVH, and WWVB.

Date is based on the angular position of the earth with respect to other celestial bodies. It is atomic-time keepers who best know how large the second is but it is astronomers who best know what the date is. By collaborating with some group that makes the proper astronomical observations, an adequately stable electronically-based time scale can be calibrated to yield date. The BIH coordinates the astronomical measurements of several laboratories to provide the best estimate of date.

Because of the existence of commercial cesium standards it would be possible to operate such a station without access to a primary standard. This means that a non-NBS operated service would satisfy most users. The control of the broadcasts by a primary standard is, however, worth its cost, which I hope to make clear in the next section. Assume for the moment that this true and also, that NBS is the organization best suited for developing and operating a primary standard. The point to be considered then is not whether somebody else should run the broadcast services, but rather, can NBS run them at lower cost for the same or better service? Division personnel bel ieve that the answer to this is yes, and I discuss this further in sections $4.4-4.5$.

\subsubsection{Accurate Standards}

The importance of accuracy centers on the need for coordination. Sometimes it is coordination internal to an organization; sometimes it is coordination between organizations or between functions. An example of an internal need for coordination is the frequency division multiplexing system of AT\&T. One major thing that their new atomic reference (see sec. 2.5.2.3) provides is a signal whose frequency is highly invariant with time. The reason is that accuracy establishes a limit upon how far the frequency is likely to drift in long-term.

An example of coordination between functions is the recent improwement in the knowledge of the speed of light [16]. This measurement rests on an enduring relationship between the unit of frequency and the unit of length, so that accuracy is again needed.

Definitions of physical units in terms of natural invariants such as the "ciock transition" in cesium potentially allows closer coordination between originally independent systems. As a hypothetical example, consider the possible cooperation between AT\&T and the position location industry. The AT\&T frequency equalization system is based on cesium standards as is some of the position location industry. Because both systems depend upon standards whose absolute frequency is highly invariant, there is a potential for an efficient calibration service. The telephone system could serve to check frequency equality between isolated standards within the position location network.

In practice, the greater the accuracy of individual oscillators, the less the amount of communication needed to achieve and maintain a given level of frequency and time coordination between them. The existence of a primary standard - a standard whose absolute frequency is known much better than that of commercial standards - serves as a check upon the accuracy claims of commercial standards. A primary standard should have an accuracy which is at least an order of magnitude better than the accuracy of the devices which it is checking. This not only increases the believability of the results, but, because its stability is also at least this good, the difficulty of making the measurements is also decreased.

This allows me to return to the subject of controlling the broadcasts of a TaF station with a primary standard. For those who are attempting to hold frequency equalization to the limits of the accuracy of commercial cesium standards, reference to such a station is an important cross check.

The level of accuracy and stability possessed by some users is high enough that access to a primary standard is very important. For some, access via radio broadcast is sufficient. For others, a calibration at the site of the primary standard itself may be necessary. Is there any other organization which could more economically develop, maintain, and - if necessary - improve the pri- 
mary standard? I contend that no private organization attempting to make a profit would take on the task of the primary standard: the costs are too high and the potential market is too small because the value of the primary standard tends to be in its long-term effects upon T\&F technology. Thus, it is difficult to price the service high enough to make a profit in short term. The primary standard of frequency is a classic example of what economists call a "collective good". I have not excluded, of course, the possibility that some other governmental or private, non-profit, organization might more economically do the job. In the absence of evidence to the contrary, however, I contend that the whole concept of primary standards is most "at home" at NBS. It is difficult to believe that some other organization could do as good a job at a lower cost.

\subsubsection{Dissemination-Reception Research and Development}

There are a multitude of applications for T\&F. The carrier frequencies and broadcast format of the NBS stations tend to be optimum for serving these applications, but some users are not adequately served. It is an important part of the mission of this Division to improve the means by which we can serve the user or, by which he can serve himself. Sometimes this effort takes the direction of trying to improve access (remote access) to the primary standard and the time scale. At other times it is directed to reducing the cost - in money and labor the user must incur to get the same quality of T\&F. This service, therefore, becomes inseparable from the two previously discussed services. In fact, my point is that all three services comprise an entity that is best described as a "collective good".

I don't think that there is an alternative supplier of the NBS services, although there are some changes in our resource allocations that could make us more cost effective. I will discuss this subject in sections 4.4 and 4.5 .

\subsubsection{Funding Sources for NBS Services}

We receive most of our funding from Congressional appropriations. A minor amount of funding comes by transfer from other government agencies or by reimbursements for calibrations and similar services.

\subsubsection{Mechanism for Supplying Services}

This subject is discussed in great detail in sections $2.4,2.5,4.1,4.2 .1,4.2 .2$, and 4.2.3.

\subsection{Impact of NBS Services}

\subsubsection{Economic Impact of Major User Classes and}

\subsubsection{Technological Impact of Services}

These two subjects are discussed in section 3.1 .

\subsubsection{Pay-off From Changes in NBS Services}

This subject is most believably considered by studying past activities rather than speculating about the future. Fortunately, we are in a good position to look back. The best two examples I can give of benefit from changes in service are with respect to our broadcasts. In section 4.2 .2 I discuss the results of a current study of users of our broadcasts. The study shows that voice announcements of time-of-day and one second "ticks" are the two most highly used services of our broadcast stations. The latter service was added in 1937 and the former was added in 1950. Other additions to our broadcasts have also been favorably received.

\subsection{Evaluation of NBS Programs and}

4.5 The Future

The history of NBS time and frequency programs is replete with many successes and some attempts in the "other-than-successful" category. The development and documentation of NBS-4 and NBS-6 places these two devices among the four best national standards in the world. The expansion of frequency measurement technology from the microwave to the visible and the measurement of the velocity of light have received continued high praise from scientific groups and our advisory panel. The development of widespread radio dissemination and of the expansion of the types of services has received high ratings from user groups and made time and frequency the most accessible of the fundamental standards.

Because time and frequency are used in so many places by so many people, and for so many purposes, it is not possible to concisely describe their importance to society. The study of the National Measurement System for Time and Frequency has attempted to encompass the broad spectrum of this technology by examining the system from three vantage points:

1.) i.he instrumentation which is the source of T\&F

2.) the interrelationship between suppliers and users of T\&F

3.) several of the calibration hierarchies which provide compatibility between the many sources 
Time and again, in each of these views, the economic aspects of the system emerge, along with the fact that the time and frequency services of the NBS are absolutely essential to our technological society.

In order to provide these services at all, there is a logical chain of activities extending from the operation and development of the base standard to the operation of an effective delivery system for T\&F information to the user community. Not only has the National Measurement System for Time and Frequency Study identified the present needs for T\&F, it has identified growing needs for the future. Thus, the NBS programs must (and do) include significant elements designed to meet the needs of the future as well.

In section 2.5.1.2.3, I considered the likelihood of three major changes in the National Measurement System for Time and Frequency:

1.) A widespread network of clocks, synchronized to about 1 to $10 \mu$ seconds.

2.) A low-cost, easy-to-use, means of obtaining frequency equalization in the range $1 \times 10^{-8}$ to $1 \times 10^{-11}$.

3.) A low-cost, very widely available means of obtaining time-of-day to an accuracy of about 0.1 seconds.

The third area of probable change could well force some modifications in the delivery of time-of-day within the telephone system. It might also require some additional resources on the part of NBS. The solution to this problem is, however, well within the present technology and will (if it arises) be primarily an economic problem.

The current dissemination-reception work in the Division is quite consistent with the first two trends in the system. It appears that the current program to provide standard T\&F broadcasts via satellite would go a long way toward accommodating the first area of probable change. In addition to this, it would provide a general replacement for the present broadcast services at a much lower average yearly cost. The present estimate is that the average yearly cost could be reduced, in the period around 1980, from about $\$ 1.5 \times 10^{6}$ to about $\$ 4 \times 10^{5}$. This savings of about $\$ 1.1 \times 10^{6}$ would be of great importance in supporting other worthy

programs within the Division.

The second area of probable change is being addressed by one current program and another which will soon begin. The very important results already obtained with the TV "color burst" technique should be of great utility here. [38] This work - like that on the satellite broadcasts - is another good ex- ample of being aware of and making use of a dissemination system, some of whose properties are superior to those of our broadcast stations. In addition to this continuing project, the Division is about to commence work on a feasibility study for a low-cost, medium-accuracy oscillator.

We have a coherent Division program which both addresses current needs and is directed towards the probable future:

1.) The maintenance and operation of the primary frequency standard and the time scale.

2.) The maintenance and operation of the three broadcast stations.

3.) Research and development on a possible standard T\&F broadcast service via satellite.

4.) Primary standard research and development.

5.) Further development upon and encouragement of the use of the TV "color burst" technique.

6.) Feasibility studies for a low-cost, medium-accuracy oscillator: the "utility" standard.

7.) Further testing, and possible encouragement of the use of, a technique for evaluating two major systematic errors in beam-type atomic frequency standards.

8.) Automation of the broadcast stations.

9.) A search for new methods for improving T\&F dissemination.

Areas 1 and 2 are our responsibility both by law and by historical involvement. Possibly the latter is an even more powerful force for our continued efforts. In the case of a reduction in funds, these two areas should be the last to go.

The satellite broadcast service, if implemented, would be doubly important; it would significantly reduce the cost burden for an essential service, and also provide a time synchronization service highly compatible with the first area of probable change mentioned previously. This work should have highest priority after our legal obligations.

Research into better primary standards is an essential investment in the future. Here, the word "better" should include ease of use as well as higher stability and accuracy. We strongly feel, however, that no construction

plans should be made for a replacement for the present standards (NBS-4 and NBS-6) for at least two years. And, only then if actual needs within the National Measurement System show that the present standards are becoming inadequate.

The TV technique and the utility standard have two strong similarities. The market for both will probably be important by 1980. Both 
could probably be done by private industry. We think, however, because of skills already available within the Division and because of economic considerations in private industry, that these activities can be most effectively implemented by NBS and should remain a part of our program.

As a part of the evaluation of the present primary standards, a new technique for evaluating certain systematic errors in beamtype frequency standards was developed. It appears that, using this technique, commercial cesium standards can - in effect - be made accurate to better than $1 \times 10^{-12}$. This technique should be further evaluated. If, in fact, the method is proven to be generalily useful, then it should be made available to those who can use it. The position location industry is a likely candidate. Areas 5, 6, and 7 in the above list are all excellent examples of the "collective good" nature of our work.

Automation of the stations can, potentially, save a lot of money in the next two to eight year period. Nevertheless, we give this (possible) activity lower priority than the satellite work, because we believe that satellite broadcasts will prove considerably superior to land-based broadcas ts both in overall cost and in quality.

At the present time, there do not appear to be other dissemination methods showing more promise than those now under study either by NBS or by other groups. We would, therefore, assign lowest priority to additional work of this type.

The essential points being addressed above are (1) that the process of providing effective time and frequency information must be approached in a systematic and logically coherent manner, and (2) the NBS programs are carefully designed with this in mind.

\section{SUMMARY AND CONCLUSIONS}

The National Measurement System Study should have two types of effects: first, it should indicate proper programmatic directions; and, second, it should provide confidence that these programmatic directions are proper ones. This is quite analogous to a statistician's interest not only in the average value of a quantity but also its spread or uncertainty.

of course, it is logically possible that the programmatic directions uncovered by the study are already the directions being taken. In point of fact, this is essentially the case for much of what is concluded and this should be considered a healthy state of affairs. This is true because the National Measurement System Study formalizes and expands a continuous and less formalized effort implicit in much of what has been done for years. Indeed, it would be quite surprising (and even devastating!) if it were not so.

Even though essential concurrence in programmatic directions was found, some new thrusts were identified and (hopefully) significantly greater credibility for the entire program has been achieved.

Noteworthy in the new directions already taken have been the increased broadcast schedule for radio station WWVB, and our efforts to reduce the operating expenses at WWV/WWVH/WWVB. In the first instance, it was found that many users (especially electric power companies and seismologists) need the WWVB signals in a reliable and uninterrupted fashion, and as a result, equipment at WWVB was provided to avoid the former routine, off-the-air-maintenance period. In the second instance, plans to reduce costs at the stations are being undertaken which involve a survey of the users, initiated as a part of the National Measurement System Study. One aspect of this survey is expected to reveal features of our services which can be discontinued with a net cost saving. The survey is scheduled for completion by July 1 , 1975, and preliminary results are already available.

Our efforts in satellite time dissemination and on a TV frequency transfer system seem quite appropriate in light of the study. In general, the study gives strong evidence that it would be totally inconceivable for the U.S. not to have an internationally coordinated, accurate, and readily available time and frequency service like that provided by the NBS.

A great many people in the Time and Frequency Division of the NBS have contributed information to this report. Earlier studies, similar in nature to this one, have been particularly helpful.

Several people have contributed directly to this study: Mr. John T. Stanley did an extensive study of the T\&F needs of the aviation industry. Mrs. Sandra L. Howe was the major contributor to the study of the NCSL standards laboratories. Mr. Lawrence $E$. Gatterer made important contributions to understanding the uses and users of time. Dr. Yardley Beers made valuable editorial suggestions.

Drs. Raymond C. Sangster and James R. Seed, as coordinators of the entire study of the National Measurement System have increased the scope of this particular report.

Dr. Sangster made helpful editorial suggestions.

Mrs. Karen Merrell typed the report and made valuable contributions to editing. 


\section{APPENDIX A.1 GENERAL METHODOLOGY}

Based on the experience of personnel in the Time and Frequency Division, and an earlier study performed by the Division entitled "Study of Time and Frequency Dissemination", eight areas were selected for further investigation. The eight areas examined were:

- Standards Laboratories

- Users of NBS Radio Broadcasts

- Telephone Industry and Specialized Carriers

- Military

- Position Location

- Aviation Industry

- Electric Power Industry

- Shipping and Boating Industries

In the present work, the literature available depended upon the particular area under study. For the Common Carrier work, the four volume report entitled "World Telecommunications" by Arthur D. Little, Inc. was exceptionally useful. The trade magazine "Telephony", and the Bell System publication, "Bell Laboratories Record", were also quite helpful. Each of these sources was also of some help in the study of the Military, primarily because military communications leans so heavily upon the telephone industry.

In the Shipping and Boating and the Electric Power Industry investigations, there were two books that provided important information: The American Practical Navigator by Nathaniel Bowditch, and Power System Operation by Robert $\mathrm{H}$. Miller.

In each of the above four areas, additional information was obtained by personal contact. Most of these contacts were by telephone. In these areas, of the order of 100 people were contacted - some of them several times.

In the other areas, other than the Standards Laboratories, telephone and face-toface contact was the primary means of information gathering. Initial contacts were identified by Division personnel, with these sources leading to additional people. Approximately another 100 people were contacted here.
The other major source of information was via questionnaire. Appendices A.3 and A.4 were used in the studies of the users of NBS Broadcasts and the Standards Laboratories, respectively.

A third major use of the questionnaire method was for technology forecasting. Appendix A.2 reproduces the questionnaire and other information sent to the participants. The various aspects of this questionnaire and its results are summarized in section 3.2 .

\section{APPENDIX A.2}

This appendix contains a copy of the questionnaire and explanatory material which was sent to each of 107 potential participants, figure 5 represents the responses to the first set of questions. Ideally, these 107 people represented the entire set of all those people who are knowledgeable about the matters discussed. If this were true, and if, all those 107 people had responded, then there would be no question about the statistical validity of figure 5. Although a strong attempt was made to poll the entire qualified - and none of the unqualified - population I have no acceptable measure of the degree to which I succeeded. Moreover, only about 50 people of those polled responded, and even then, only about half of the respondees responded to any given question. Thus, even for the most definitive items (such as the period 1985 in item 7) a serious question of statistical validity can be raised.

Despite this drawback I believe it is a mistake to ignore this data. In the text I explicitly discuss only items 1,5 , and 7 - those items which (for the period 1985) give the most definitive results. In these discussions I give other information, all of which is consistent with the results of figure 5 . With these qualifications then, nothing more can be usefully said and each reader will reach his own conclusions about the interpretation of figure 5 . 


\section{TECHNOLOGY FORECAST \& ASSESSMENT PROJECT}

September y, 1974

vear Sir:

The Tecinnology Forecast and Assessment Committee of the IEEE Communications Society is engaged in attempting to develop forecasts of future communication needs. In fact, many IEEE Groups and Societies are engaged in technology forecasting and assessment under the overall direction of the IEEE Technology Forecast and Assessment Project. The ivational Bureau of Standards is engaged in a similar venture through its systematic study of the National lieasurement Systern. The IEEE Communications Society has, therefore, agreed to participate with the NES in the Time and Frequency (T\&F) portion of this study.

We would like to encourage your participation in a Delphi study of the future needs for time and frequency technology. Delphi is a technology forecasting technique based on the polling of a panel of experts and is explained in more detail in the Foreword which accompanies the questionnaire. The IEEE Communications Society's TF\&A Subcommittee is participating in this study because of its general relationship to technology forecasting and because of its very direct bearing upon communications.

If you decide to participate in this study, please return the completed questionnaire to Ur. Allan S. Risley in the preaddressed, prepaid envelope. Furtiner details are given in the Foreword.

Thank you very much for your cooperation.

Very truly yours,<smiles>CCC#CCCCCCCCCCC</smiles>

William llorsch

Manager, TF\&A Project

WM/ar

Enclosures 
Dear

This is an invitation to participate in a study that attempts to forecast the future of Time and Frequency Technology. If you agree to participate, it will require answering a questionnaire now and again in about two months. On the second occasion, you will be supplied with a summary of the results of the first polling. In light of this summary, you might (or might not) choose to modify some of your original answers. This general procedure has become known as the Delphi technique of technology forecasting.

WHY SHOULD YOU WANT TO PARTICIPATE? Answering the questionnaire will take a fair amount of effort, but these questions bear on a technology that will importantly influence your career. A good response from all participants will give you a chance to observe the opinions of a wide spectrum of your colleagues.

The Time and Frequency (T\&F) Division of the National Bureau of standards (NBS) is one of many divisions engaged in technology forecasting and assessment. The major goal of our study is to develop a socioeconomic basis for determining the research, development, and services in T\&F that the NBS should perform.

A Delphi study is needed because there are so many sectors of society experiencing such a wide variety of pressures that no one person or small group can do this forecasting. By doing this study, we hope to sum up the effects of those many sectors and all those many forces that ultimately result in a changed T\&F technology.

There are three questions. The first asks about the probability of use of eight different T\&F Resources. Any one of these Resources is a technological possibility; that is, it may be feasible to build and therefore, it could be a potential resource to society. The eight Resources fall into two groups: The first four refer to individual oscillators. The second four refer to disseminated quantities. These "Resources" are good approximations of what is likely to be the desired T\&F technology of the future.

The first question uses the phrase "will be in significant use." This is defined on the page entitled "DEFINITIONS AND RESOURCES." In the list of Resources, the terms "frequency repeatability" and "frequency equalization" are used. These, also, are defined.

Notice that I stress use. It is one thing to prove technical feasibility for a change in technology and quite another to secure its implementation such that it becomes a part of the working economy. The first question is based on the assumption that each of the Resources will be feasible (in all senses-quality, cost, and field utility) sometime between now and the year 2000. Your task is to decide the likelihood that a given 
Resource will be "in significant use" on any of the given dates. of course, you may decide that a given Resource will not be avialable (that it is not feasible) on any of the given dates, in which case you should mark "Virtually Impossible" for that Resource on that date. All prices are based on 1974 dollars.

We have gone to some pains to try to pick qualified participants. In a real sense, there is no one qualified to predict the future. On the other hand, you may have some measurable effect in creating that future with regard to your own sector. I therefore ask you to be prudent but imaginative; cautious but not timid. If you truly feel inadequate to answer a given question, then the "Not Qualified" blank should be checked.

The second question asks about the pressures that each of the seven sectors (see question 2 for the sectors) will exert to try to insure that a given Resource is available by 1980. The pressures could take many forms. For example, the Navigation Industry might encourage the Oscillator Manufacturers to engage in a research and development project with regard to one or more of the Resources. You should attempt to answer this question for your sector only. If, of course, you feel competent to answer for one or more of the other sectors, please do.

The third and final question deals with those technologies which have had great importance to one or more of the seven sectors. This question attempts to determine what the future importance of these technologies will be in each of the sectors. Answer for other sectors only if you feel qualified.

The responses will be processed both as a whole and by sectors. The data will be given in such a way that tendencies toward consensus or diversity will be apparent. I have about 15 participants for each of the seven sectors. Although they will be identified by sector, they will not be identifiable as individuals. I feel that sector identification is important in order to detect a possible difference of views between sectors.

If you decide to participate, please return the completed questionnaire in the preaddressed, prepaid envelope. If you can complete the questionnaire within two weeks, it will be greatly appreciated. If you decide not to participate, please check the box for that purpose on the front of the questionnaire and immediately return the questionnaire via the prepaid envelope.

I thank you in advance for your cooperation.

Sincerely yours,

Allin s'. Resley

Allan S. Risley, Physicist

Time \& Frequency Division

National Bureau of Standards

Enclosure 


\section{QUESTIONNAIRE ON TIME AND FREQUENCY TECHNOLOGY: FORWARD}

If, after having read this Forward and having examined the questions, you decide not to participate, please check this box and return this material via the prepaid envelope.

\section{[ ] Thank you for the opportunity to participate in this study, but I have decided not to accept.}

If you know someone else qualified to participate, check the box below and return only this page to us in the prepaid envelope.

[ ] I cannot participate in this study. However, I have forwarded the questionnaire to

who is highly qualified to answer these questions. 


\section{DEEINITIONS AND RESOURCES}

\section{DEEINLTLONS}

1. "... will be in significant use." :

This means that the Resource has been applied to such an extent that it has become an important part of normal operations. It would be disruptive to do without it.

2. "Frequency repeatability....":

In discussing frequency repeatability, I refer to any two devices of the same model from the same manufacturer that may be initially calibrated against a reference or each other. Under these conditions, and for frequency measurement averaging time of 1 second or more for Resource \#1; $10^{3}$ seconds or more for Resource \#2; and 1 day or more for Resource \#3; the frequency difference between the two devices shall not exceed the values stated for at least one year of service. This is a "one sigma" statement.

3. "Erequency equalization...." :

Refers to the ability to set the frequency of an oscillator located at a field site equal to the disseminated frequency to within the specified tolerance. This is also a "one sigma" specification and applies to the specified averaging time.

4. "Time synchronization....":

The ability to make a specific pulse of a local time scale occur simultaneously with a specific pulse of the disseminated time scale. That is, to cause the local scale to be "on time" with respect to the disseminated scale. It is to be understood in this definition that propagation delays are accurately compensated.

5. "Field utility....":

Refers to the sensitivity of the device to such things as temperature change, vibration and shock.

\section{RESOURCES (ALL PRICES ARE BASED ON 1974 DOLLARS, )}

1. Frequency repeatability of $1 \times 10^{-10}$ with improved field utility for $\$ 1 \mathrm{k}$ per unit.

2. Frequency repeatability of $1 \times 10^{-12}$ with improved field utility for $\$ 5 \mathrm{~K}$ per unit.

3. Frequency repeatability of $1 \times 10^{-14}$ with limited field utility for $\$ 15 \mathrm{~K}$ per unit.

4. Frequency drift per day of $1 \times 10^{-9}$ with high field utility for $\$ 100$ per unit.

5. Frequency equalization to $1 \times 10^{-11}$, for 15 minutes of averaging, for $\$ 200$ per station.

6. Frequency equalization to $3 \times 10^{-14}$, for 10 days of averaging, for $\$ 10 \mathrm{k}$ per station.

7. Time synchronization to 2 microseconds (one sigma) for one minute of signal recovery time, for $\$ 200$ per station, anywhere in the U.S.

8. Time synchronization to 30 nanoseconds (one sigma), for 10 minutes of signal recovery time, for $\$ 10 \mathrm{~K}$ per station, anywhere in the U.S. 
1. GIVE THE PROBABILITY FOR THE YEARS 1980, 1985, AND 2000, THAT EACH OF THE FOLLOWING T\&F RESOURCES WILL BE IN SIGNIFICANT USE. ALL PRICES ARE BA.SED ON 1974 DOLLARS.

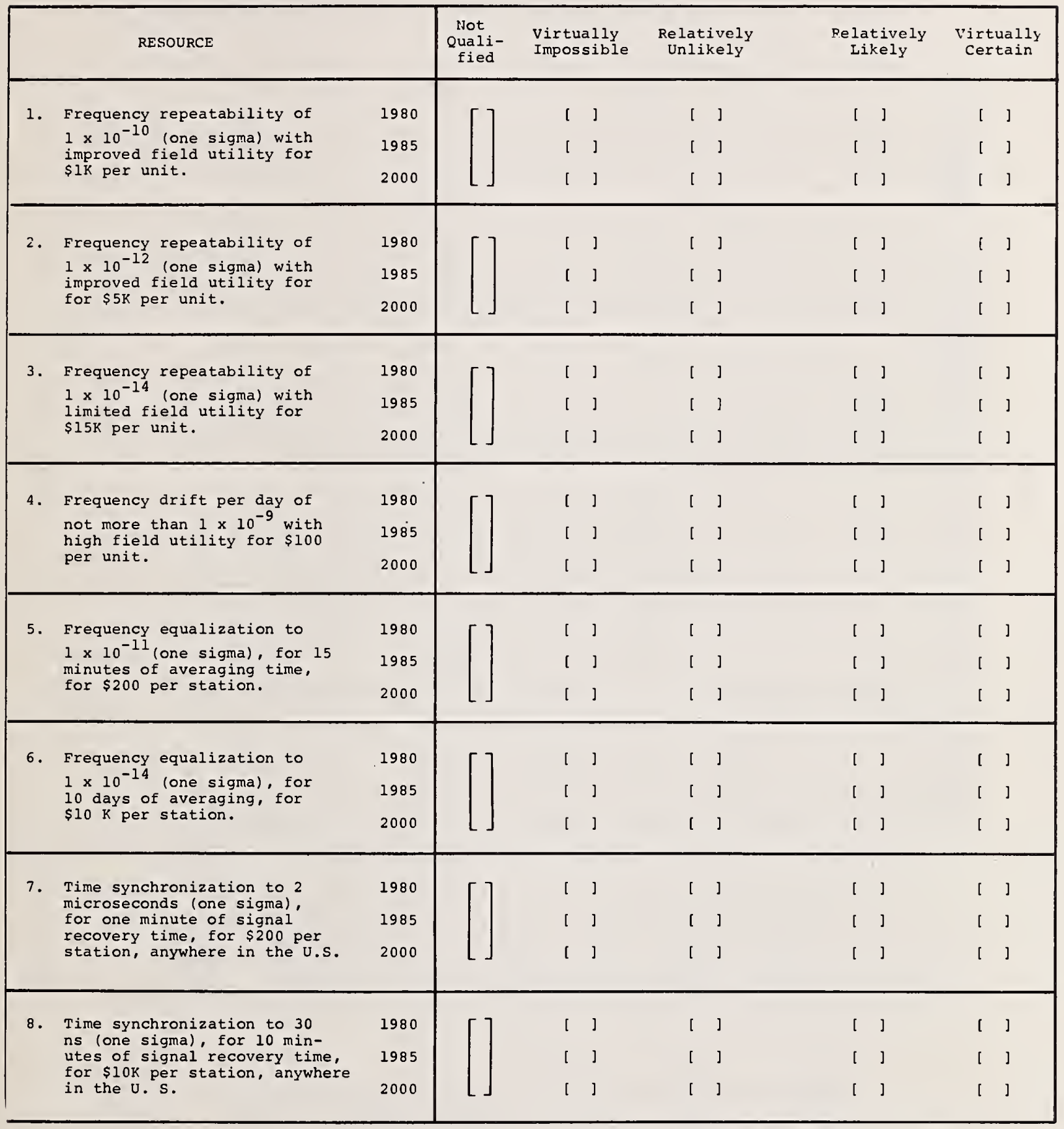




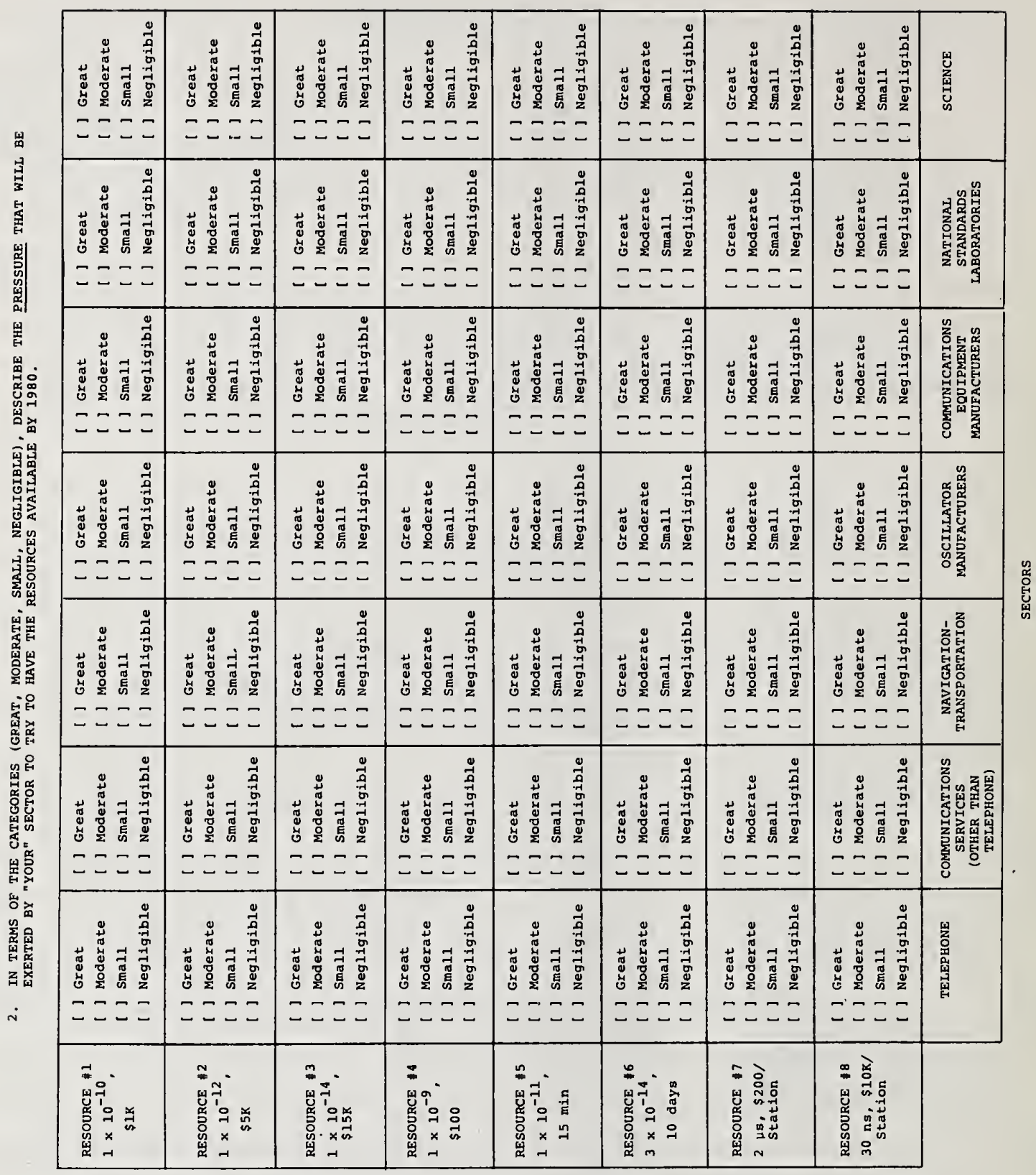




\begin{tabular}{|c|c|c|c|c|c|c|c|}
\hline 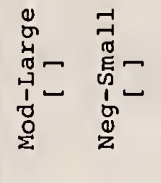 & 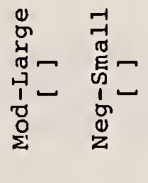 & $\begin{array}{ll}0 & =1 \\
0 & 7 \\
\pi & 0 \\
0 & 5 \\
0 & 0 \\
1 & 1 \\
0 & 0 \\
0 & 0 \\
2 & z\end{array}$ & 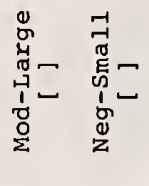 & 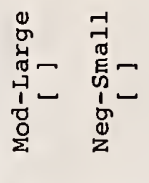 & 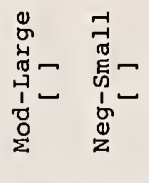 & 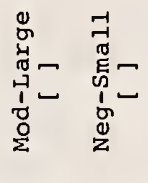 & 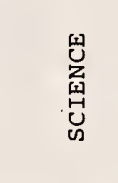 \\
\hline 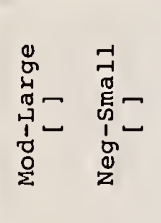 & 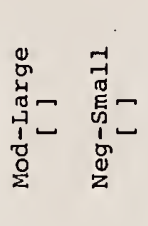 & 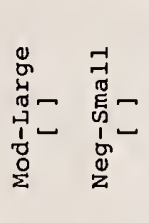 & 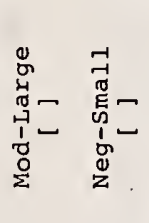 & 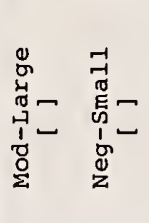 & 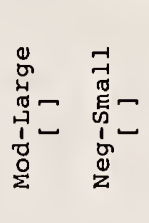 & 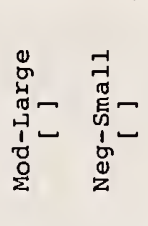 & 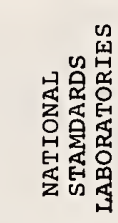 \\
\hline 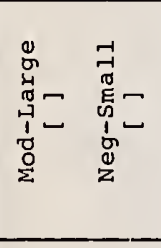 & $\begin{array}{ll}0 & =1 \\
0 & 7 \\
\pi & \pi \\
\pi & 5 \\
0 & 0 \\
1 & 1 \\
0 & 0 \\
0 & 0 \\
2 & z\end{array}$ & 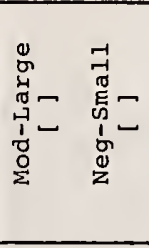 & $\begin{array}{ll}0 & = \\
5 & 7 \\
\pi & \pi \\
0 & 5 \\
0 & 1 \\
1 & 1 \\
0 & 0 \\
0 & 0 \\
2 & 2\end{array}$ & 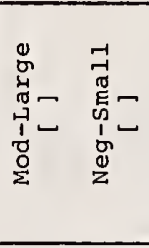 & 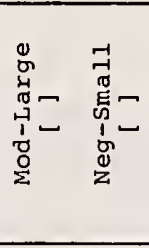 & $\begin{array}{ll}0 & =1 \\
0 & 7 \\
\pi & \pi \\
0 & 5 \\
0 & 0 \\
1 & 1 \\
0 & 0 \\
0 & 0 \\
\Sigma & z\end{array}$ & 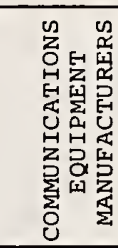 \\
\hline 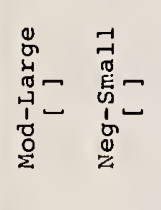 & 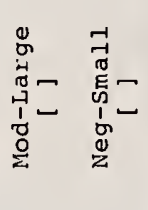 & 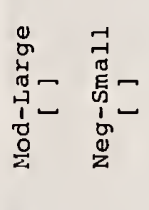 & 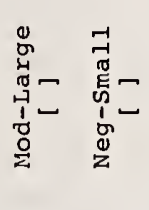 & 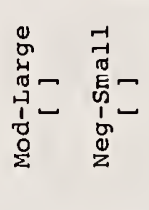 & 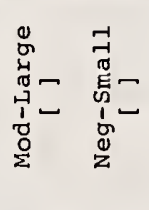 & 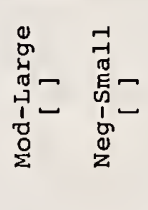 & 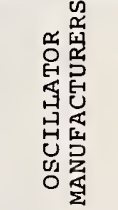 \\
\hline 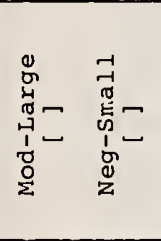 & 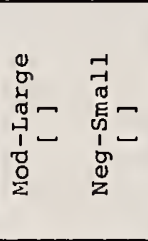 & 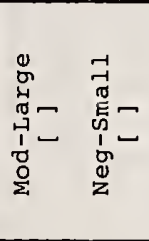 & 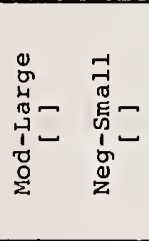 & 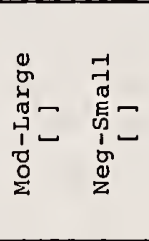 & 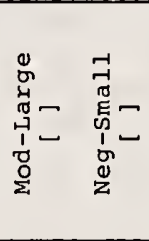 & 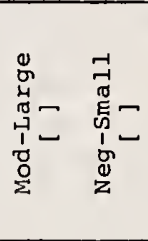 & 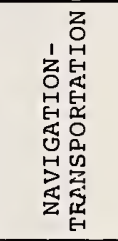 \\
\hline 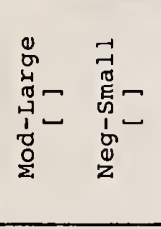 & $\begin{array}{ll}0 & =1 \\
0 & \pi \\
\pi & \pi \\
\pi & E \\
4 & 0 \\
1 & 1 \\
0 & 0 \\
0 & 0 \\
0 & z\end{array}$ & 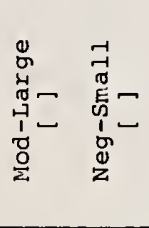 & 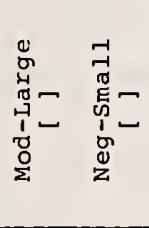 & 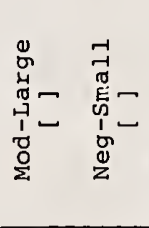 & 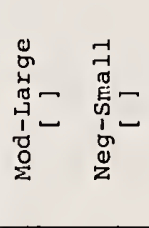 & 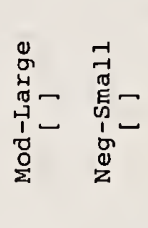 & 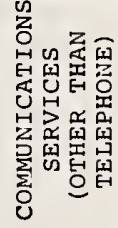 \\
\hline 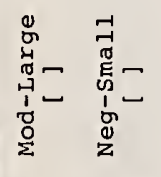 & $\begin{array}{ll}0 & = \\
5 & 7 \\
\pi & \pi \\
\pi & 5 \\
0 & 0 \\
1 & 1 \\
0 & 0 \\
0 & 0 \\
\frac{0}{2} & z\end{array}$ & 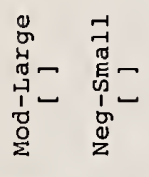 & 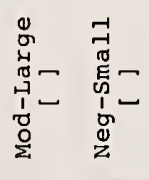 & 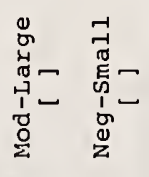 & 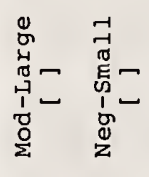 & 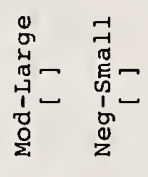 & 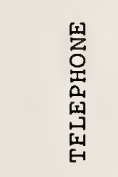 \\
\hline 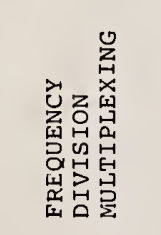 & 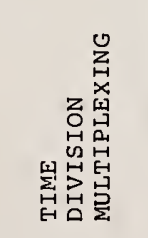 & 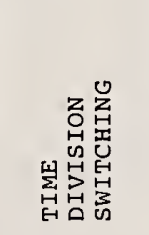 & 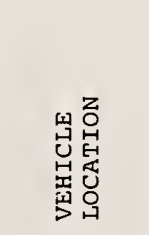 & 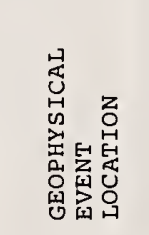 & 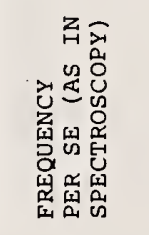 & 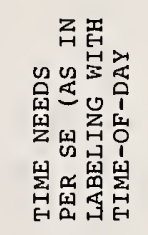 & \\
\hline
\end{tabular}


January 8, 1975

\section{Dear Participant:}

In response to government-wide efforts to reduce operating costs and conserve energy, we are considering various alternatives for operating radio stations WWV and WWVH. Interested listeners to these stations are being asked to provide information, via the enclosed questionnaire, which will help us set priorities and guide our decision-making processes with respect to these services. Examples of possible changes include the elimination of some broadcast frequencies from WWV and/or WWVH or reductions in transmitted power on some frequencies.

As a result of greatly increased energy costs at our Hawailan radio station, WWVH, we have already solicited comments from users regarding a proposed 50 percent reduction of power at 5,10 , and $15 \mathrm{MHz}$ from WWVH only. We have received so many objections to this proposal that we have decided to explore other possible means of cost and energy reductions. It is hoped that the responses to this questionnaire will allow us to provide the services needed most within our financial constraints and at an efficient level of energy use. Thus, it is very desirable that you provide us with thoughtful responses to the enclosed questions. Please fold the questionnaire in thirds with the return address on the outside and staple or tape it closed and mail. No postage is necessary if mailed within the U. S. However, a postage stamp is necessary if a reproduced copy of this questionnaire is malled.

Your help is greatly appreciated.

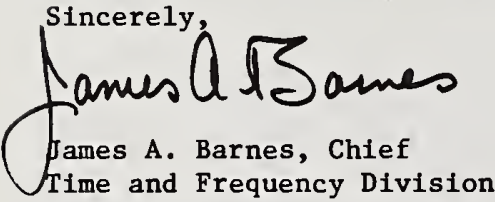

Enclosure 


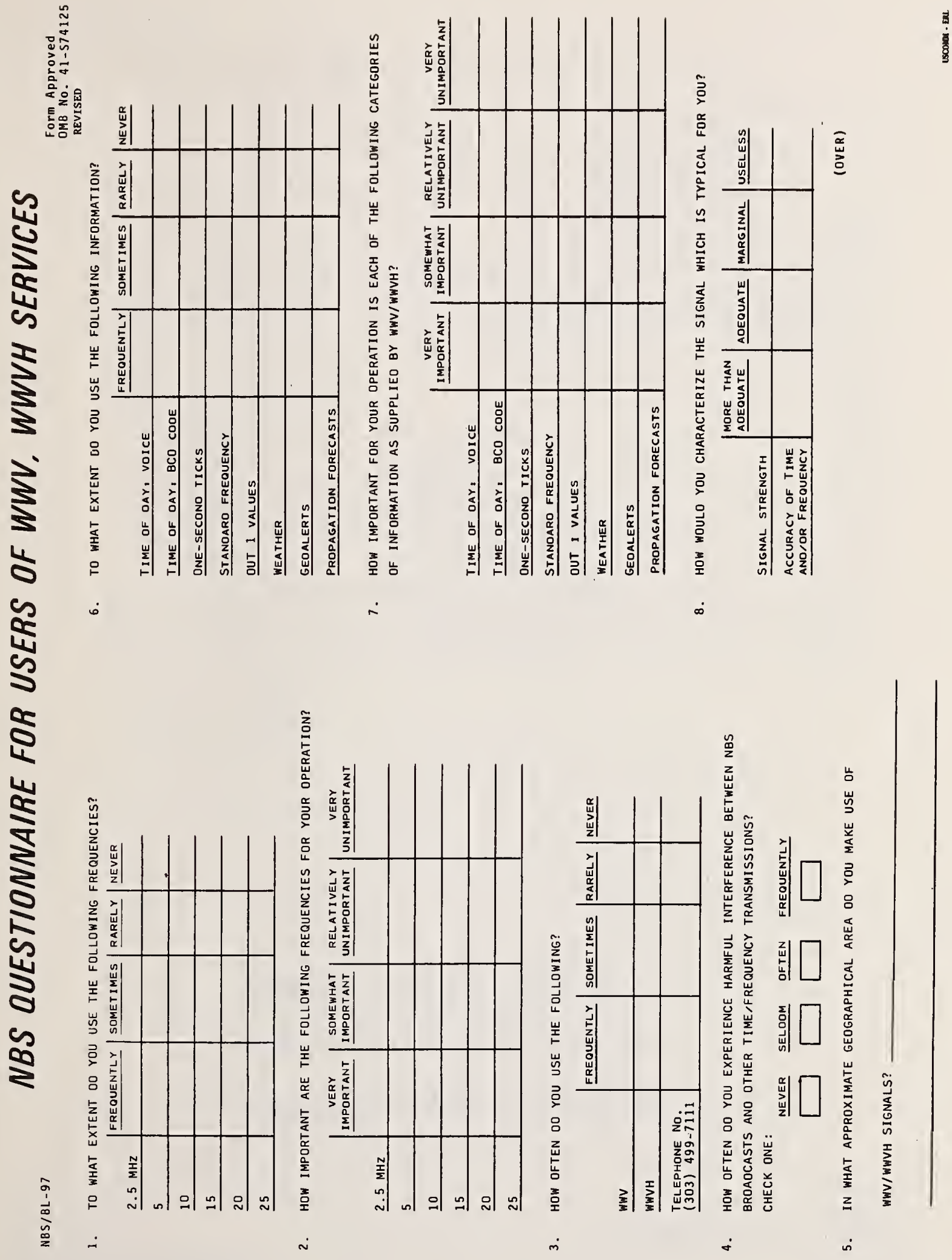




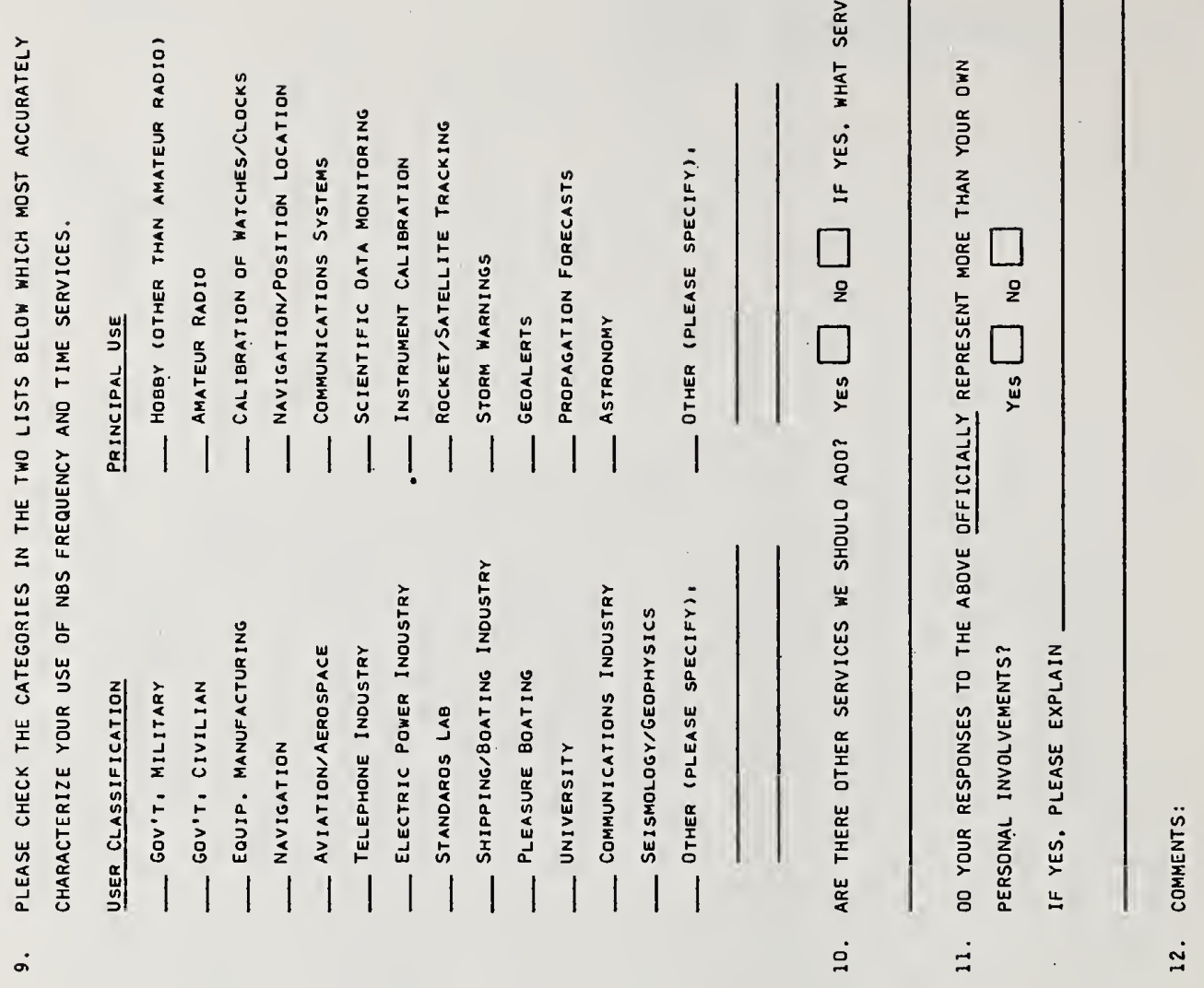

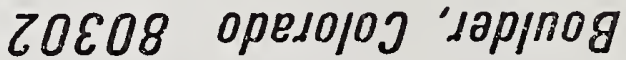 uo!s!n! К Кuanbaly pue au!! spsepuets to neo.Ing jeuo!neN}

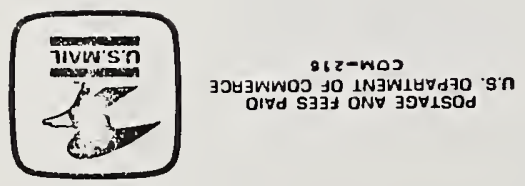

DOES 'OSn asea!ld Jo3 A3jeved S93NISกล าษIวเมงก

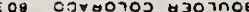
opjepuess to neojng leuolzon prepureas 
1. Do you provide frequency calibrations for your own organization?

2. Do you provide frequency calibrations for groups outside your organization?

3. Do you provide time interval calibrations for your own organization?

4. Do you provide time interval calibrations for groups outside your organization?

5. Approximately how many time and/or frequency calibrations do you provide in-house customers over a years period?

6. Approximately how many time and/or frequency calibrations do you provide "outside" customers?

7. What are your customers' uses and projected area of needs for frequency and time calibrations?

(1) communications and related equipment?

(2) navigation?

(3) power line control and regulation?

(4) geophysical time and frequency needs?

(5) precision test equipment for other application?

(6) other

-- Can you give details?

8. What is a good estimate of your yearly operational cost of the frequency and/or time portion of your service?

(1) $\$ 100-\$ 1000$

(2) $\$ 1000-\$ 10,000$

(3) over $\$ 10,000$

(4) over $\$ 50,000$

9. What is a good estimate of the capital investment in your frequency and time calibration equipment?

10. What frequency and time standards do you maintain in your lab?

11. Do you use NBS frequency and time services? (Booklets [SP-236 Time Scale] relative to these services are enclosed.)

12. Of the frequency calibrations you perform, in which accuracy class do most fall?

(1) more accurate than a part per million

(2) less accurate than a part per million

(3) other (specify)

13. Do you foresee time and frequency calibration services increasing in your organization?

14. Can you discuss future applications for time and frequency calibrations in your organization?

USCOMM-NBS-DC 


\section{References}

[1] Jespersen, J. and Fitz-Randolph, J., NBS Time and Frequency Handbook. Title and publication details not yet available.

[2] Hellwig, H. W., Atomic frequency standards: a survey, Proc. IEEE, Vol. 63, No. 2, 212-229 (February 1975).

[3] Kamas, G., editor, NBS Time and Frequency Handbook. Title and publication details not yet available.

[4] Blair, B. E., editor, Time and frequency: theory and fundamentals, Nat. Bur. Stand. (U.S.) Monogr. 140 (June 1974).

[5] ibid., Chapter 5

[6] ibid, Chapter 8

[7] Barnes, J.A., et. al., Characterization of frequency stability, IEEE Trans. on Inst. and Meas., IB-20, No. 2, 105-120 (May 1974).

[8] Blair, B. E., editor, Time and frequency: theory and fundamentals, Nat. Bur. Stand. (U.S.) Monogr. 140, Chapter 10 (June 1974).

[9] ibid, Chapter 6

[10] ibid, Chapter 11

[11] Howe, S. L., and Risley, A. S., Ihe NBS study of the time and frequency needs of U.S. standards laboratories, NCSL Newsletter, Vol. 15, No. 1 (Apri1 1975).

[12] Risley, A. S., The time and frequency needs of the U. S. telephone industry: A portion of the study of the National Measurement System, An Internal NBS report dated May, 1974.

L13」 Hellwig, H. W., A review of precision oscillators, NBS Tech. Note 662 (January 1975).

[14] Risley, A. S., A study of the shipping and boating industries as a part of the study of the National Measurement System, An Internal NBS report dated July 26, 1973.

[15] Blair, B. E. editor, Time and frequency: theory and fundamentals, Nat. Bur. Stand. (U.S.) Monogr. 140, Chapter 7 (June 1974).

[16] Evenson, K. M., Wells, J. S., Petersen, F. R., Danielson; B. L., and Hall, J. L., Speed of light from direct frequency and wavelength measurments of the methane-stabi1ized laser, Phys. Rev. Letters, Vo1. 29, No. 19 (6 November 1972).

[17] Jennings, D. A., Petersen, F. K., and Evenson, K. M., Extension of absolute frequency measurements to $148 \mathrm{THz}$; frequencies of the 2.0 and $3.5 \mu \mathrm{m} \mathrm{Xe} \mathrm{laser,} \mathrm{to} \mathrm{be} \mathrm{published.}$ 
[18] Field, B. F., Finnegan, T. F., and Toots, J., Volt maintenance at NBS via 2 e/h: A new definition of the NBS volt, Metrologia 9, 155-166 (1973).

[19] Kamper, K. A, and Zimmerman, J. E., Noise thermometry with the Josephson effect, J. App1. Phys. 42, No. 1, 132-136 (January 1971).

[20」 Delattes, R. D., et. a1., Determination of the Avogadro Constant, Phys. Rev. Lett. Vo1. 33, 463.(1974).

[21] Thomas, J. B., and Fliegel, H. F., I ime and frequency requirements for radio interferometric earth physics, Proc. 5th PTTI Conference, 15-31, Washington, D.C. (1973).

[22] Hafele, J. C., Keating, R. E., Around-the-world atomic clocks: predicted relativistic time gains, Science 177, 166-167 (July 14, 1972).

[23] Pound, R. V., and Rebka, G. A., Jr., Apparent weight of photons, Phys. Rev. Lett., 4, 337-341 (Apri1 2, 1960).

[24」 Kleppner, D., Vessot, R. F. C., Ramsey, N. F., An orbiting clock experiment to determine the gravitational red shift, Astrophys. and Space Sci. 6, 13-32 (1970).

[25] U. S. Industrial Outlook 1973, a U. S. Department of Commerce Publication.

[26] World Telecommunications, Vol. 3, 75 (copyright by Arthur D. Little, Inc. 1971).

[27」 Stanley, John T., Time and frequency applications in the aviation industry, to be published as an NBS internal report.

[28] Statistical Abstract of the United States, 1972.

[29」 A personal communication with an official of the U. S. Maritime Administration.

L30」 Poutson, B. W., and Kranick, R., Some aspects of the economics of the U. S. communications industry, an internal NBS report.

[31」 Risley, A. S., A historical view of the relationship between technology and other features of society, to be published as an NBS Technical Note.

[32] Risley, A. S., Ihe creation of a Delphi study for forecasting time and frequency technology, Proc. of the 1974 National Telecommunications Conf. San Diego, Calif. (December 2-4, 1974).

[33] Perkinson, R. E., and Watson, F. D., Airborne collision avoidance and other applications of time/frequency, Proc. IEEE, 572-579 (May 1972).

L34」 American Telephone and Telegraph Company Digital Data System. Compatibility and interface specification at the inter-digital serving area DS-1 leve1, (July 1973). 
[35] Snyder, W. F., Achievement in radio: seventy years of radio science and measurement at the National Bureau of Standards, to be published as an NBS Special Publication in 1977.

โ36」Blair, B. E., editor, Time and frequency: theory and fundamentals, Nat. Bur. Stand. (U.S.) Monogr. 143, Chapters 4 and 5 (June 1974).

[37] ibid, Chapter 3.

[38] Davis, D. D., Calibrating crystal oscillators with tv color-reference signals, Electronics, 107-112 (March 20, 1975).

[39」 Risley, A. S., Shoaf, J. H., and Ashley, J. R., Frequency stabilization of x-band sources for use in frequency synthesis into the infrared, IEEE trans. on I \& $M$, Vo1. IM-23, No. 3 (September 1974).

[40] McDonald, D. G., et a1., Four-hundredth-order harmonic mixing of microwave and infrared laser radiation using a Josephson junction and a maser", Appl: Phys. Lett. Vo1. 20, 296-299 (Apri1 1972).

[41] Walls, F. L., and DeMarchi, A., RF Spectrum of a signal after frequency multiplication; measurement and comparison with a simple calculation, Submitted to IEEE Trans. on Instr. and Meas.

[42] Barnes, J. A., and Beehler, R. E., Report on the 1975 survey of the services of radio station WWV and WWVH, NBS Technical Note 674 (October 1975).

[43] Allan, David W., "The Measurement of Frequency and Frequency Stability of Precision Oscillators," iBS Technical Note \#669 (May 1975).

[44] Howe, David A., "Frequency Domain Stability Measurements, a tutorial introduction," NBS Technical Note $\# 679$.

[45] Tilton, Edward P., "The DXer's Crystal Ba11," QST, June 1975, Vol LIX No. 6, August 1975, Vol. LIX No. 8, and September 1975, Vol. LIX No. 9. 
NBS-114A (REV, 7-73)

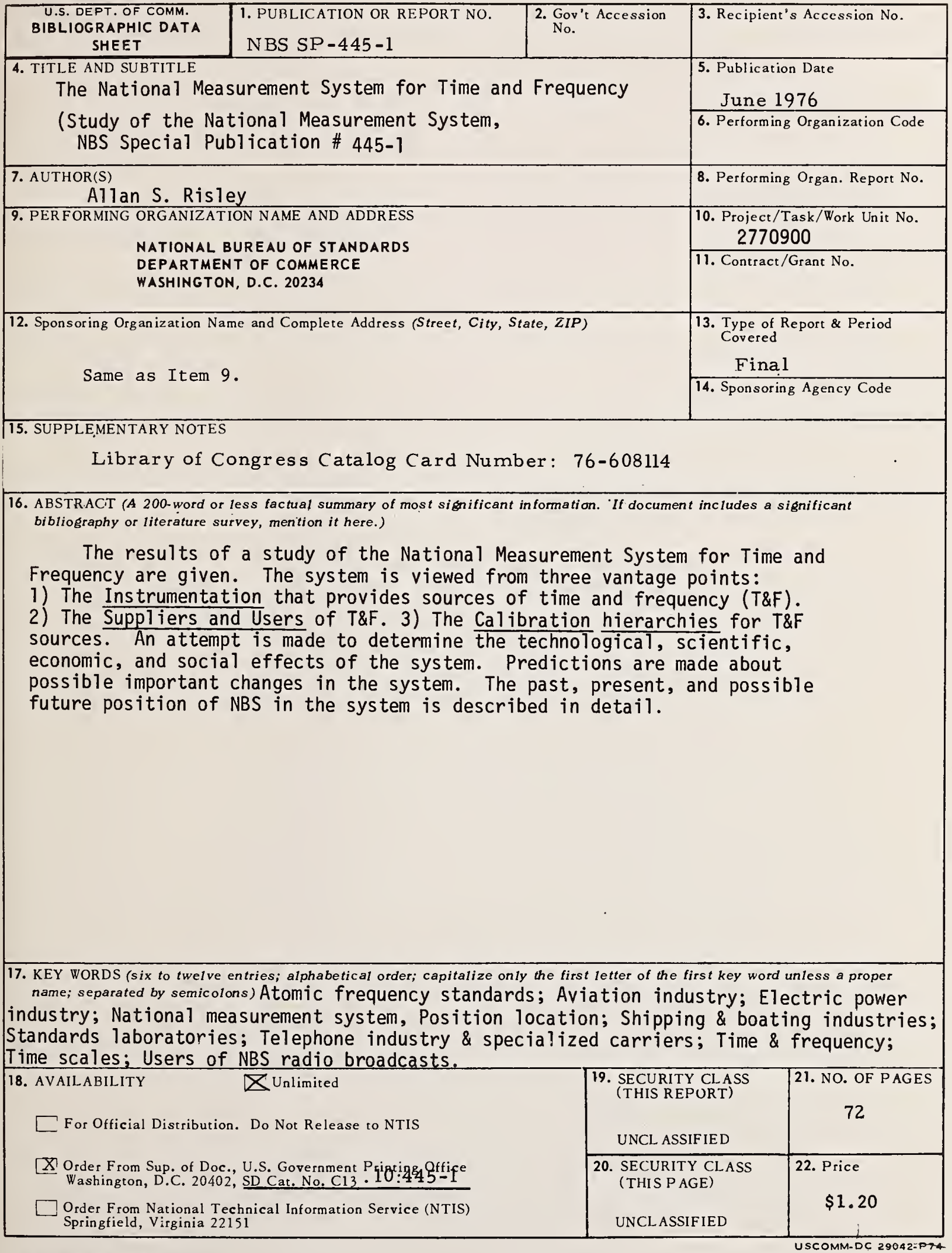











\section{PERIODICALS}

JOURNAL OF RESEAR'CH reports National Bureau of Standards research and development in physics, mathematics, and chemistry. It is published in two sections, available separately:

- Physics and Chemistry (Section A)

Papers of interest primarily to scientists working in these fields. This section covers a broad range of physical and chemical research, with major emphasis on standards of physical measurement, fundamental constants, and properties of matter. Issued six times a year. Annual subscription: Domestic, \$17.00; Foreign, $\$ 21.25$.

\section{- Mathematical Sciences (Section B)}

Studies and compilations designed mainly for the mathematician and theoretical physicist. Topics in mathematical statistics, theory of experiment design, numerical analysis, theoretical physics and chemistry, logical design and programming of computers and computer systems. Short numerical tables. Issued quarterly. Annual subscription: Domestic, \$9.00; Foreign, \$11.25.

DIMENSIONS/NBS (formerly Technical News Bulletin)-This monthly magazine is published to inform scientists, engineers, businessmen, industry, teachers, students, and consumers of the latest advances in science and technology, with primary emphasis on the work at NBS. The magazine highlights and reviews such issues as energy research, fire protection, building technology, metric conversion, pollution abatement, health and safety, and consumer product performance. In addition, it reports the results of Bureau programs in measurement standards and techniques, properties of matter and materials, engineering standards and services, instrumentation, and automatic data processing.

Annual subscription: Domestic, $\$ 9.45$; Foreign, $\$ 11.85$.

\section{NONPERIODICALS}

Monographs-Major contributions to the technical literature on various subjects related to the Bureau's scientific and technical activities.

Handbooks-Recommended codes of engineering and industrial practice (including safety codes) developed in cooperation with interested industries, professional organizations, and regulatory bodies.

Special Publications-Include proceedings of conferences sponsored by NBS, NBS annual reports, and other special publications appropriate to this grouping such as wall charts, pocket cards, and bibliographies.

Applied Mathematics Series-Mathematical tables, manuals, and studies of special interest to physicists, engineers, chemists, biologists, mathematieians, computer programmers, and others engaged in scientific and technical work.

National Standard Reference Data Series-Provides quantitative data on the physical and chemical properties of materials, compiled from the world's literature and critically evaluated. Developed under a world-wide program coordinated by NBS. Program under authority of National Standard Data Act (Public Law 90-396).

NOTE: At present the principal publication outlet for these data is the Journal of Physical and Chemical Reference Data (JPCRD) published quarterly for NBS by the American Chemical Society (ACS) and the American Institute of Physics (AIP). Subscriptions, reprints, and supplements available from ACS, 1155 Sixteenth St. N. W., Wash. D. C. 20056.

Building Science Series-Disseminates technical information developed at the Bureau on building materials, components, systems, and whole structures. The series presents research results, test methods, and performance criteria related to the structural and environmental functions and the durability and safety characteristics of building elements and systems.

Technical Notes-Studies or reports which are complete in themselves but restrictive in their treatment of a subject. Analogous to monographs but not so comprehensive in scope or definitive in treatment of the subject area. Often serve as a vehicle for final reports of work performed at NBS under the sponsorship of other government agencies.

Voluntary Product Standards-Developed under procedures published by the Department of Commerce in Part 10, Title 15, of the Code of Federal Regulations. The purpose of the standards is to establish nationally recognized requirements for products, and to provide all concerned interests with a basis for common understanding of the characteristics of the products. NBS administers this program as a supplement to the activities of the private sector standardizing organizations.

Federal Information Processing Standards Publications (FIPS PUBS)-Publications in this series collectively constitute the Federal Information Processing Standards Register. Register serves as the official source of information in the Federal Government regarding standards issued by NBS pursuant to the Federal Property and Administrative Services Act of 1949 as amended, Public Law 89-306 (79 Stat. 1127), and as implemented by Executive Order 11717 (38 FR 12315, dated May 11, 1973) and Part 6 of Title 15 CFR (Code of Federal Regulations).

Consumer Information Series-Practical information, based on NBS research and experience, covering areas of interest to the consumer. Easily understandable language and illustrations provide useful background knowledge for shopping in today's technological marketplace.

NBS Interagency Reports (NBSIR)-A special series of interim or final reports on work performed by NBS for outside sponsors (both government and non-government). In general, initial distribution is handled by the sponsor; public distribution is by the National Technical Information Service (Springfield, Va. 22161) in paper copy or microfiche form.

Order NBS publications (except NBSIR's and Bibliographic Subscription Services) from: Superintendent of Documents, Government Printing Office, Washington, D.C. 20402 .

\section{BIBLIOGRAPHIC SUBSCRIPTION SERVICES}

The following current-awareness and literature-survey bibliographies are issued periodically by the Bureau: Cryogenic Data Center Current Awareneas Service

A literature survey issued biweekly. Annual subscription: Domestic, $\$ 20.00$; foreign, $\$ 25.00$.

Liquefied Natural Gas. A literature survey issued quarterly. Annual subscription: $\$ 20.00$.

Superconducting Devices and Materials. A literature survey issued quarterly. Annual subscription: $\$ 20.00$. Send subscription orders and remittances for the preceding bibliographic services to National $\mathrm{Bu}$ reau of Standards, Cryogenic Data Center (275.02) Boulder, Colorado 80302.

Electromagnetic Metrology Current Awareness Service Issued monthly. Annual subscription: \$24.00. Send subscription order and remittance to Electromagnetics Division, National Bureau of Standards, Boulder, Colo. 80302 . 
U.S. DEPARTMENT OF COMMERCE

National Bureau of Standards

Washington, D.C. 20234

OFFICIAL BUSINESS

Penalty for Privete Use. $\$ 300$
POSTAGE AND FEES PAID

U.S. DEPARTMENT DF CDMMEACE $C O M-215$

SPECIAL FOURTH-CLASS RATE

BOOK

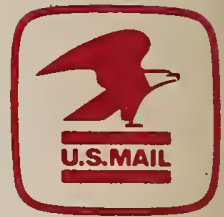

